
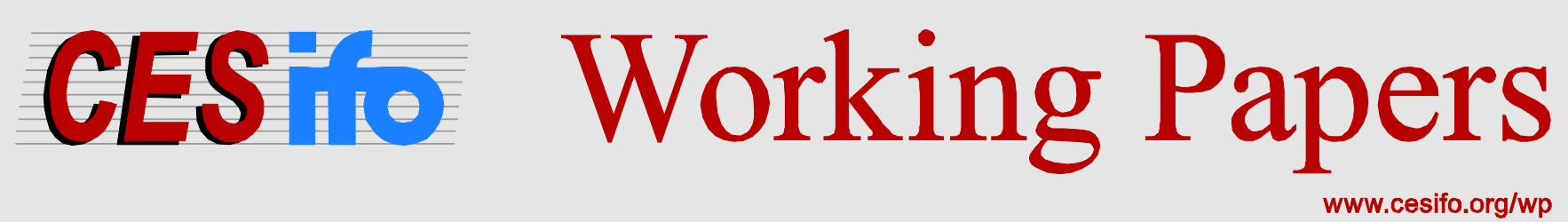

\title{
The Unemployment Accelerator
}

\author{
Julio Blanco \\ Gaston Navarro
}

CESIFO WORKING PAPER NO. 6248

CATEGORY 4: LABOUR MARKETS

DECEMBER 2016

An electronic version of the paper may be downloaded

- from the SSRN website: Www.SSRN.com

- from the RePEc website: Www.RePEc.org

- from the CESifo website: www.CESifo-group.org/wp 


\title{
The Unemployment Accelerator
}

\begin{abstract}
This paper studies the unemployment accelerator, a mechanism where workers directly affect the firms' financial conditions, and, in turn, firms' financial conditions feedback again to the real economy. The unemployment accelerator builds on two key assumptions: search frictions in the labor market and firms' default risk. The former assumption implies a positive relation between the firm's value and its number of workers; the latter assumption entails a tight connection between the value of the workers and the firm's incentives to default. We develop and estimate a model with these two frictions together with firm-level heterogeneity; and show the model matches firm-level statistics as well as business cycle fluctuations in labor and financial markets. We provide compelling micro-evidence of the unemployment accelerator: a $10 \%$ increase in a firm's number of workers is associated with a $4 \%$ increase in its market value and a $6 \%$ decline in its probability of default. We show that our model can account for these facts, and that the two key assumptions we make are essential for this.
\end{abstract}

JEL-Codes: E240, E320, E440.

Keywords: unemployment, default risk, credit market frictions, search frictions, wage bargaining.

\author{
Julio Blanco \\ Department of Economics \\ University of Michigan \\ 611 Tappan Ave, 365B Lorch Hall \\ USA - Ann Arbor, MI 48109-1220 \\ jablanco@umich.edu
}

\author{
Gaston Navarro \\ International Finance Division \\ Federal Reserve Board \\ 20th and Constitution Ave K1-02 \\ USA - Washington, DC 2055 \\ gaston.m.navarro@frb.gov
}

October 11, 2016

We would like to thank Saki Bigio, Mark Gertler, Ricardo Lagos, John Leahy, Jianjun Miao, Virgiliu Midrigan, Juan Pablo Nicolini, Andrea Raffo, Thomas Sargent, Robert Shimer, Toni Whited and Eric Young for very insightful discussions. The views expressed are those of the authors and not necessarily those of the Federal Reserve Board or the Federal Reserve System. Preliminary and incomplete; comments are very welcome.

Click http://www.gastonnavarro.net/index.htm for updates. 


\section{Introduction}

What is the value that a firm attach to its workers, and how does this affect the firm's total value? We argue that a firm's workers is an essential asset for the firm - same as capital - that can significantly contribute to fluctuations in a firm's total value. We develop a micro-foundation to rationalize this relation, and argue that it has important macroeconomic consequences: employment fluctuations over the business cycle propagate to movements in firms' total value, which amplifies the effect of aggregate shocks in the presence of imperfect financial markets.

To formally study these ideas, we develop the unemployment accelerator, a new mechanism where workers directly affect firms' value and financial conditions, and, in turn, firms' financial conditions feedback into to the real economy, further affecting investment and hiring decision. We develop three elements of the unemployment accelerator: a micro-foundation embedded in a dynamic stochastic general equilibrium model with heterogeneous firms and business cycle fluctuations; direct micro-evidence of the unemployment accelerator; and its impact in the propagation of business cycle dynamics. The unemployment accelerator thus complements the standard financial accelerator, where firms' financial conditions are mainly accounted by the value of physical assets.

The micro-foundation of the unemployment accelerator derives from the interplay of two frictions: 1) a search frictions in the labor market; 2) firms' default risk. Because of the search friction, firms attach a positive value to having a worker since it is costly otherwise to hire a new one. Therefore, a firms' market value positively depends on the value of their workers, which directly affects the firm's incentives to default. This implies that workers are qualitatively identical to capital as an asset affecting the firms' value and its probability to default.

We embed these two frictions in a DSGE model with heterogeneous firms and an endogenous capital structure decision for the firm. Heterogeneity results from decreasing returns to scale technology together with idiosyncratic productivity shocks; and thus generates a rich firm-level dynamics. Additionally, the economy is subject to aggregate shocks, and therefore to business cycle dynamics. Firm-level heterogeneity allows our model to replicate the micro-evidence we find of the unemployment accelerator. The business cycle dynamics allow us to study the aggregate propagation implications of the unemployment accelerator. Despite of its complexity, the model is highly tractable which enables us to estimate it.

We provide persuasive evidence of a significant and persistent positive relation between a firm's number of workers and its market value: a $10 \%$ increase in a firm's workers is associated with a $4 \%$ increase in the firm's market value. Similarly, more workers induce a lower probability to default: a $10 \%$ increase in a firm's workers 
is associated with a $6 \%$ decline in her probability to default. These results are robust to controls typically used in the literature, such as firms leverage and profitability or even future firm's performance. Therefore, firm-level data supports the key element of the unemployment accelerator, with workers adding value to the firm beyond its capital and profitability. Importantly, we obtain the same implications we running the same estimations in our model, which allows to provide a structural interpretation of our empirical results.

The unemployment accelerator mechanism we develop has important consequences for unemployment, default risk, investment and output; which makes our mechanism important for macroeconomists. At the same time, the unemployment accelerator has key implications for job finding and separation rates, which makes the model relevant for labor economists. Finally, because we show that labor is an asset, our mechanism has implication for firm's valuation (asset pricing) as well as its capital structure decision. This make our new mechanism important for financial economics and corporate finance.

We continue with an overview of the contributions in this paper and how they relate to other.

\section{A Model of the Unemployment Accelerator:}

The key component in the model is the search friction in the labor market. Because it is costly to hire a new worker, a firm is only willing to do it if it expects a profit out of the marginal worker. Thus, search friction models imply a positive value to the firm of having a worker in equilibrium (Pissarides, 1985). Consequently, the value of a firm depends on the number of workers it has, as well as of how profitable/productive these workers are expected to be. The value of a worker, both the number and profitability of workers, fluctuate over time and thus propagate to the value of the firm.

Additionally, our model includes the firm's default and capital structure decisions, in a fashion similar to Hennessy and Whited (2007). As standard in trade-off theory of firm's capital structure, firms borrow because there is a tax advantage to financing with debt. ${ }^{1}$ Then, a firm can find itself in a state with low enough value so that it decides to exit and default on its liabilities. Consequently, because the value of the firm depends on its workers, fluctuations on the value of a worker affects the firms incentives to default. This is a direct effect that workers have on the firms' financial conditions.

We develop a model with a rich firm-level heterogeneity, which allows us to meaningfully compare model and data. This implies having a distribution of firms, each one with multiple workers, which can be problematic when using bargaining protocols typically used in the search literature. At the same time, the distribution of firms moves in response to aggregate shocks, which adds computational challenges. In order to overcome these issues, we follow some recent advances in the labor literature. In particular, in order to handle multiple workers firms, we use a contractual arrangement between firms and workers similar to the

\footnotetext{
${ }^{1}$ See Abel (2015) and Graham and Leary (2011) for recent discussions on trade-off theory
} 
one in Schaal (2015) and Kaas and Kircher (2015). In these environments, as in ours, labor contracts deliver efficient allocations that can be obtained by simpler (surplus maximizing) problems. In a similar manner, we follow Lise and Robin (2016) and assume that unemployed workers have no bargaining power, which makes the value of unemployment independent of the distributions of firms, and thus does not affect the surplus between a firm and its workers.

\section{Methodological Contributions:}

The assumptions we make allows us to accurately and efficiently solve our heterogeneous firms model using higher-order perturbation techniques. In particular, we compute a second-order approximation of the model policies and use a pruning technique of the state-space system as recently developed by Andreasen, Fernandez-Villaverde and Rubio-Ramirez (2016). This simplifies obtaining stability of the model solution and simultaneously captures non-linear terms which are key in a model with default risk, specially in the presence of very volatile idiosyncratic shocks of the firm.

We develop a solution technique that os suitable for handling long-term debt. We assume that firms issue long-term debt because it generates persistent dynamics for firms' debt as observed in the data. ${ }^{2}$ However, as recently pointed out by Gomes et al. (2013), long-term debt present a challenge for perturbation techniques: the slopes of the firm's policies is needed to compute the non-stochastic steady-state, but firms' policies cannot be computed using perturbation techniques without knowledge of the steady-state. In Section 4.1 we show how to overcome this problem by employing an iterative computation of second-order approximations: we guess the needed slopes in order to solve for the steady-state, compute the model approximation, and iterate until the implied slopes of the solution are close to the ones initially guessed. Thus, an advantage of our solution technique is that it incorporates information about the persistence of the stochastic processes, which significantly alters the firm's policies, in the computation of the steady-state. A disadvantage, is that we have to compute the model solution repeatedly. However, this accounts mostly for very inexpensive computations and still allows to solve the model and simulate a panel of firms in a few seconds.

We take advantage of the tractability of the model and its solution in order to estimate most of the parameters. We use a simulated method of moments with an estimation procedure as introduced by Chernozhukov and Hong (2003), which uses Markov Chain Monte Carlo Methods to make inference about the estimates. This estimation procedure has recently been used to estimate models with significant heterogeneity. ${ }^{3}$ In particular, we target several firm-level moments in order to discipline the cross-sectional implications of our model. We also target aggregate moments to make the model empirically consistent with business

\footnotetext{
${ }^{2}$ See Gomes, Jermann and Schmid (2013) or Miao and Wang (2010) for recent DSGE models analyzing the effect of long-term debt.

${ }^{3}$ For instance, Lise (2012), Jarosch (2015), Lamadon (2014) and Lise, Meghir and Robin (2016).
} 
cycle fluctuations. The model is successful in both macro and micro-moments, which is important when computing a model quantification of the unemployment accelerator. Importantly, estimating the model using simultaneously aggregate and firm-level data allows us to provide tight estimates of parameters that are common to several models of firm dynamics. also calibrate some parameters that have common values in the literature.

\section{Evidence on the Unemployment Accelerator:}

We provide evidence that the market value of a firm significantly increases with its number of workers, and that its probability to default significantly declines. ${ }^{4}$ These are results after controlling for several firm's variable such as capital, debt, profits, and investment. Thus, we find that the number of workers affects the firm's value after controlling for standard variables used in the literature, in line with the predictions of the unemployment accelerator.

These empirical findings are naturally subject to a misspecification problem, since an omitted variable could result in biased estimations. In this sense, our empirical exercises have the advantage of being guided by theory: the regression we run, and the controls we include, are the outcomes or a structural model. Not only this allows us to attach economic interpretation to the findings, but also to compare them with the quantitative predictions of the model. Still, it could always be the case that some alternative mechanism -not included in our model- is simultaneously affecting a firm's market value and its hiring decision, thus generating our findings for different reasons. For instance, public information about a firm's future profitable projects will likely induce an increase in its market value and hiring decisions simultaneously. To account for these alternatives, we perform several robustness exercises including more firm's controls. These included liquidity measures of the firm as well as its future and lagged performance (profits, investment and sales). Although point estimates vary, in all of these robustness exercises we systematically find that the firm number workers has a significant effect on the firm's market value. because

The recent works by Bazdresch, Belo and Lin (2014) and Favilukis, Lin and Zhao (2015) share our emphasis in using firm-level data jointly with a structural model to understand the effects of a firm's workers on its market value. The work by Bazdresch et al. (2014) provide evidence of a link between employment growth and stock returns predictability, and develop a structural model with employment adjustment costs to account for this fact. We see our work as complementary: Although both of our models and empirical exercises are substantially different, we share the idea that workers affects a firm's value.

Closer to our work is the one by Favilukis et al. (2015), who analyzes the effect of labor obligations

\footnotetext{
${ }^{4}$ Our empirical measure of firms' probability to default is the so called "distance to default", base on the seminal work by Merton (1974). Section 5.2.1 contains more details.
} 
on the firm's probability to default. Our paper differs from them in several aspect. At the empirical level, they find some mixed results: an increase in payroll tends to increase the firm's probability to default, while higher labor share does the opposite. These are somewhat different results to ours, and probably due to different samples: while we focus on the US, they look at international evidence. At the model level, the key to their mechanism is wage rigidity, which makes labor compensation less cyclical, and firms more likely to default after periods of wage growth. In our model, wages are set efficiently to maximize a joint surplus, which makes workers unequivocally increase a firm's value. Ultimately, which type of labor market frictions are more relevant for each economy/country could shed light on these differences.

The recent papers by Giroud and Mueller (2014) and Chodorow-Reich (2014) provide evidence of a link between employment and the firm's financial conditions. Theoretical models in the same line have recently been develop by Monacelli, Quadrini and Trigari (2011), Buera, Fattal-Jaef and Shin (2013), Arellano, Bai and Kehoe (2011), Petrosky-Nadeau (2011) and Garin (2011) among others. We add to these papers by providing new evidence on the relation between workers and financial conditions, as well as a structural model to interpret findings. Importantly, we argue that a workers directly affect a firm's financial conditions, a relation not analyzed by these papers.

Section 2 presents the model, and Section 3 provides an analytical characterization of the model. Section 4 discusses the model solution and its estimation. Section 5 presents the evidence of the unemployment accelerator. Section 6 concludes.

\section{Model}

In order to study the effects of a firm's worker on its financial conditions, we build a dynamic general equilibrium model with firm heterogeneity and aggregate shocks. We assume decreasing returns to scale technology and persistent idiosyncratic shocks to obtain a realistic firm distribution, which allows us to compare the model with data. We include a default problem at the firm level, which is key to the interaction between the firm's financial decision and the value of its workers. Furthermore, we analyze the effects that this interaction has on labor market dynamics and aggregate outcomes more generally. In order to keep the model tractable, we borrow some modeling assumptions from Lise and Robin (2016), Kaas and Kircher (2015) and Schaal (2015). 


\subsection{Environment, Preferences and Technology}

Time is discrete and indexed by $t \in\{0,1,2, \ldots\}$. The economy is populated by a continuum of infinitely-lived workers, a continuum of of investors, and a continuum of firms. The measure of firms is normalized to one, and $\tilde{N}$ is the measure of workers. ${ }^{5}$ Firms have access to a decreasing returns to scale technology given as

$$
Y=\eta z K^{\alpha \nu} N^{(1-\alpha) \nu}, \quad 0<\nu<1
$$

where $\eta$ and $z$ are the aggregate and idiosyncratic productivity shocks respectively, $K$ is the firm's capital and $N$ is its number of workers. Production entails a cost $F_{K}$ per unit of capital, and a random fixed cost $F$. We assume that $F$ is i.i.d. across firms and time, and distributed as $F \sim G$; and $z$ follows a Markov process with transition matrix $P_{z}\left(z, z^{\prime}\right)$.

In order to hire new workers, firms must post vacancies in a labor market with search frictions (Mortensen and Pissarides, 1994). A firm can also layoff workers at a cost, and a fraction $\delta_{N}$ of the firm workers are exogenously separated every period. In the same manner, firms invest to accumulate physical capital, and a fraction $\delta_{K}$ depreciates every period.

To finance its expenditures, firms can issue debt which takes the form of long maturity bonds. In particular, a bond promises to pay a coupon $c$ per unit of outstanding debt every period, and to retire (mature) a fraction $\lambda$ of the remaining principal. ${ }^{6}$ However, since firms may decide to default, debt is risky. Upon default, lenders recover a fraction $\theta \in[0,1]$ of the firms capital, and a new firm is set to replace the exiting one. ${ }^{7}$ Thus, there is an endogenous (default induced) exit/separation every period.

Investors and workers are risk-neutral, with preferences over consumption given as $\mathbb{E}_{0}\left[\sum_{t=0}^{\infty} \beta^{t} C_{t}\right]$. Investors are the only agents that buys the firms' debt and they are the ultimately owners all of the firms in the economy.Thus, firms discount at the same rate $\beta$.

Let $s=(K, N, B, z)$ denote the states of the firm, where $B$ stands for the outstanding debt of firm at the beginning of the period, and $\mu$ be the distribution of firms over states $s$. Let $X$ collect the exogenous aggregate states, including aggregate productivity $\eta$, and let $\Lambda=(X, \mu)$ be the aggregate state of the economy. We assume that $X$ follows a Markov process with transition probability $P_{X}\left(X, X^{\prime}\right)$. Notice that, because the cost shock $F$ is i.i.d., $\mu$ is enough to know the distribution of firms over $(s, F)$. While in principle

\footnotetext{
${ }^{5}$ We allow for exogenous firms' entry, which is selected to keep a measure one of firms. See Section 2.5.

${ }^{6}$ This structure is convenient because of its recursive nature. It have been extensively used recently in the sovereign default literature; see Hatchondo and Martinez (2009) and Arellano and Ramanarayanan (2012) among others. It has also been recently used in macro-finance environments; see Gomes et al. (2013) and citations therein. As in all of these papers, we think of $1 / \lambda$ as the average maturity of the debt.

${ }^{7}$ Section 2.5 below discusses firms' entry.
} 
the variable $\Lambda$ contains all the information in the economy, we show below how to construct an equilibrium where individual decisions for firms and workers depend only on idiosyncratic states and aggregate shocks $(X, s, F)$.

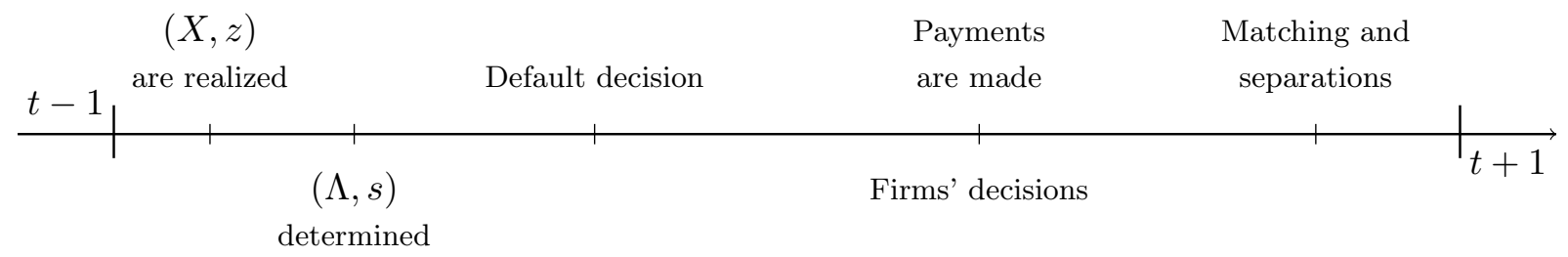

Figure 1: Timing in the model in period $t$

Figure 1 describes the timing within the period. At the beginning of the period, the idiosyncratic and aggregate shocks $(X, z)$ are realized, and the state $(\Lambda, s)$ for each firm is determined. At this point firms decide whether to default or not. Conditional on not defaulting, firms make their investment, hiring and portfolio (debt and equity) decisions. Simultaneous to these decisions, all payments in the economy are made: firms pay dividends, wages and maturing debt, and benefits are distributed to unemployed workers. Finally, the labor market opens at the end of the period, and with the separations and new matches are realized. The recursive problems of all agents are written just after the firms' default decision.

\subsection{Labor Market and the Value of Unemployment}

Firms must post vacancies $H$ in order to find new workers, and we assume that each vacancy posted yields one worker with certainty. Let $U$ be the number of unemployed workers searching for a job and $f(\Lambda)$ be the probability that they a find a job this period. Our timing assumption implies that a worker hired this period starts working next period, unless the firm that hired him defaults in which case the worker returns to the unemployment pool. Let $\chi(\Lambda, s, F)=1$ be an indicator function when the firm defaults. Similarly, Let $\boldsymbol{H}(\Lambda, s, F)$ be the firm's policy function for vacancies, and let $\overline{\boldsymbol{H}}(\Lambda)=\int \boldsymbol{H}(\Lambda, s, F) d \mu(s) d G(F)$ be the total number of vacancies posted.

While unemployed, a worker receives a benefit $\bar{u}(X)$ per period, which can in principle depend on the aggregate exogenous state $X{ }^{8}$ Let $\mathcal{U}(\Lambda)$ be the value of being unemployed when the aggregate state of the economy is $\Lambda$, and $\mathcal{W}_{0}(\Lambda, s, F)$ be the value to an unemployed worker of being hired by a firm with states $(s, F)$.

\footnotetext{
${ }^{8}$ Allowing the unemployment benefit to depend on the exogenous shocks of the economy would be in line with the evidence in Chodorow-Reich and Karabarbounis (2013). Additionally, it would help us to quantify the macroeconomic effect of increasing the unemployment benefit during a recession.
} 
Let $P_{s^{\prime}, F^{\prime}}^{U U}\left(\Lambda, \Lambda^{\prime}\right)$ be the probability of an unemployed worker to continue being unemployed next period given by

$$
P_{s^{\prime}, F^{\prime}}^{U U}\left(\Lambda, \Lambda^{\prime}\right)=1-f(\Lambda)+f(\Lambda) \chi\left(\Lambda^{\prime}, s^{\prime}, F^{\prime}\right)
$$

Equation 2 shows that a worker is unemployed next period either because he didn't find a job today, or because was hired by a firm that defaulted at the beginning of the next period - the event of default depends on the firms state variables next period. In the remaining case, the worker is matched to a firm. Following Lise and Robin (2016), we assume that unemployed workers have zero bargaining power, and thus receive their reservation value upon hiring: $\mathcal{W}_{0}(\Lambda, s, F)=\mathcal{U}(\Lambda)$. Then, the value of being unemployed satisfies

$$
\begin{aligned}
\mathcal{U}(\Lambda) & =\bar{u}(X)+\beta \mathbb{E}_{\Lambda^{\prime}, F^{\prime}}\left[\int_{s, s^{\prime}}\left\{P_{s^{\prime}, F^{\prime}}^{U U}\left(\Lambda, \Lambda^{\prime}\right) \mathcal{U}\left(\Lambda^{\prime}\right)+\left(1-P_{s^{\prime}, F^{\prime}}^{U U}\left(\Lambda, \Lambda^{\prime}\right)\right) \frac{\boldsymbol{H}(\Lambda, s, F)}{\overline{\boldsymbol{H}}(\Lambda)} \mathcal{W}_{0}\left(\Lambda^{\prime}, s^{\prime}, F^{\prime}\right)\right\} d \mu^{\prime}\left(s^{\prime} \mid s\right) d \mu(s) \mid \Lambda\right] \\
& =\bar{u}(X)+\beta \mathbb{E}_{\Lambda^{\prime}, F^{\prime}}\left[\int_{s, s^{\prime}}\left\{\left(P_{s^{\prime}, F^{\prime}}^{U U}\left(\Lambda, \Lambda^{\prime}\right)+\left(1-P_{s^{\prime}, F^{\prime}}^{U U}\left(\Lambda, \Lambda^{\prime}\right)\right) \frac{\boldsymbol{H}(\Lambda, s, F)}{\overline{\boldsymbol{H}}(\Lambda)}\right) \mathcal{U}\left(\Lambda^{\prime}\right)\right\} d \mu^{\prime}\left(s^{\prime} \mid s\right) d \mu(s) \mid \Lambda\right] \\
\mathcal{U}(\Lambda) & =\bar{u}(X)+\beta \mathbb{E}_{\Lambda^{\prime}, F^{\prime}}\left[\mathcal{U}\left(\Lambda^{\prime}\right) \mid \Lambda\right]
\end{aligned}
$$

where $s^{\prime}=\left\{K^{\prime}, N^{\prime}, B^{\prime}, z^{\prime}\right\}$ and $d \mu^{\prime}\left(s^{\prime} \mid s\right)$ is next period distribution over $s^{\prime}$ conditional on $s$.

Notice that the value of unemployment, recursively defined by (3), depends only on the exogenous aggregate state $X$ and it is independent of the distribution of firms' state. Thus,

$$
\mathcal{U}(X)=\bar{u}(X)+\beta \mathbb{E}_{X^{\prime}}\left[\mathcal{U}\left(X^{\prime}\right) \mid X\right]
$$

\subsection{Labor Contracts and the Value of Employment}

We assume that firms can commit to a state-contingent contract with the workers. In particular, a firm offers a contract that specifies four elements: this period wage $w$, a layoff probability at the end of this period $\varphi$, a firm's exit/default decision next period $\chi$, and a continuation value for the worker in case of no default $W$. Contracts are state-contingent, and the default decision as well as the continuation values are a function of next period states $\left(\Lambda^{\prime}, s^{\prime}, F^{\prime}\right)$. Let

$$
\omega=\left\{w, \varphi, \chi\left(\Lambda^{\prime}, s^{\prime}, F^{\prime}\right), W\left(\Lambda^{\prime}, s^{\prime}, F^{\prime}\right)\right\}
$$

denote a contract.

Let $\mathcal{W}(\Lambda, s, \omega)$ be the value to a worker of being matched with a firm with state $s$ under a contract $\omega$, 
when the aggregate exogenous state is $\Lambda$. Then

$$
\begin{aligned}
\mathcal{W}(\Lambda, s, \omega) & =w+\beta \mathbb{E}_{\Lambda^{\prime}, z^{\prime}}\left[\left\{\varphi+(1-\varphi) \chi\left(\Lambda^{\prime}, s^{\prime}, F^{\prime}\right)\right\} \mathcal{U}\left(X^{\prime}\right)\right. \\
& \left.+(1-\varphi)\left(1-\chi\left(\Lambda^{\prime}, s^{\prime}, F^{\prime}\right)\right) W\left(\Lambda^{\prime}, s^{\prime}, F^{\prime}\right) \mid \Lambda, z\right]
\end{aligned}
$$

where $\chi=1$ means the firm decides to exit. Thus, an employed worker may become unemployed next period either because he was let off this period (with probability $\varphi$ ), or because the firm decided to default at the beginning of next period. In the remaining case, the worker remains employed and receives life-time utility $W\left(\Lambda^{\prime}, s^{\prime}, F^{\prime}\right)$.

\subsection{Firm's Problem}

Consider next the firm's problem. If the firm does not default, it decides how much to invest in capital, how many vacancies to post, as well as the new debt and equity issuance. Simultaneously, the firm offers contracts $\left\{\omega_{j}\right\}_{j \in[0, N]}$ to its workers $j \in[0, N]$. These contracts are constrained to deliver at least the life-time utility promised to each worker last period. We describe next each component of the firm's problem.

Let us start with the resources the firm has. Denote $\mathcal{P}$ the cash-flow the firm generates from production after paying all its costs. Then

$$
\mathcal{P}=\eta z K^{\alpha \nu} N^{(1-\alpha) \nu}-\int_{0}^{N} w_{j} d j-F_{K} K-F-[(1-\tau) c+\lambda] B
$$

The cash-flow of the firm is given by its production, minus three costs: wages $\left\{w_{j}\right\}$ paid to workers, the proportional cost of production $F_{K}$, and the cost shock $F$. Because the firm only produces if it does not default, it also has to pay its debt: the coupon $c$ and the fraction $\lambda$ of its outstanding debt $B$. Notice that there is a tax subsidy $\tau$ on coupon payments, which incentivizes the firm to issue debt. ${ }^{9}$

Next, let $\pi$ denote the net flow the firm obtains from investment, hiring and debt issuance decision. Then

$$
\pi=-I+Q\left(K^{\prime}, N^{\prime}, B^{\prime}, \Lambda, z\right) b^{\prime}-\mathcal{C}^{K}(I, K)-\mathcal{C}^{N}(H, N)-\mathcal{C}^{B}\left(b^{\prime}, B\right)
$$

where $I$ is capital investment, $H$ is vacancy posting and $b^{\prime}$ is the new debt the firm issues. The function $\mathcal{C}^{N}(H, N)$ reflects the cost posting vacancies and hiring a new workers in a search frictionless market. We also

\footnotetext{
${ }^{9}$ This assumption is typically referred as the trade-off theory of firm's capital structure. See Abel (2015) and Graham and Leary (2011) for recent discussions.
} 
allow for adjustment $\operatorname{costs} \mathcal{C}^{K}$ and $\mathcal{C}^{B}$ for capital and debt respectively. Notice that, while $\mathcal{P}$ is determined by firm's past decisions, and the flow $\pi$ is under the firm's control. The net resources the firm has is $\mathcal{P}+\pi$.

Consider now the contracts the firm is offering. When selecting contracts $\left\{\omega_{j}\right\}$, the firm faces a promise keeping constraint: if the firm promised in the past a life-time utility $\left\{W_{j}\right\}_{j \in[0, N]}$ to its workers, contracts must satisfy

$$
\mathcal{W}\left(\Lambda, s, \omega_{j}\right) \geq W_{j} \quad \forall j \in[0, N]
$$

Thus, last period promised utilities $\left\{W_{j}\right\}_{j \in[0, N]}$ is a state to the firm.

Another constraint on the firm's contracts is that the layoff probability $\varphi$ must be consistent with its vacancy posting and the exogenous separation rate $\delta_{N}$. In particular

$$
\int_{0}^{N} \varphi_{j} d j=\delta_{N} N-\{H\}^{-}
$$

where $\{H\}^{-}=\min \{H, 0\}$. Thus, if the firm desires to reduce workers by more than the exogenous rate $\delta_{N}$, it must post negative vacancies.

Finally we make a last assumption over the contracts the firms can offer to the workers. This assumption states that the covariance between the probability of firing and the continuation value for the firm's worker has to be equal to zero.

$$
\int_{0}^{N} \varphi_{j} W_{j}^{\prime} d j=\int_{0}^{N} \varphi_{j} d j \int_{0}^{N} W_{j}^{\prime} d j
$$

The main intuition of this assumption is that the firm has incentives to generate a positive relationship between probability of firing a worker and the continuation value, since for the worker these two objects are constant, but for the firms they are a random variable - since the firm has several workers.

The objective of the firm is to maximize the present discount value of its dividend payments $d$. Let $\mathcal{J}\left(\Lambda, s, F,\left\{W_{j}\right\}_{j \in[0, N]}\right)$ be the value of a firm with state $(s, F)$ that promised life-time utility $\left\{W_{j}\right\}_{j \in[0, N]}$ 
to its workers, when the exogenous aggregate state of the economy is $\Lambda$. Then

$$
\begin{aligned}
& \mathcal{J}\left(\Lambda, s, F,\left\{W_{j}\right\}_{j \in[0, N]}\right)=\max _{d, I, H, b^{\prime},\left\{\omega_{j}\right\}}\left\{d+\beta \mathbb{E}_{\Lambda^{\prime}, z^{\prime}}\left[\left\{\mathcal{J}\left(\Lambda^{\prime}, s^{\prime}, F^{\prime},\left\{W_{j^{\prime}}^{\prime}\right\}_{j^{\prime} \in\left[0, N^{\prime}\right]}\right)\right\}^{+}\right]\right\} \\
& \text {subject to } \quad d \leq \mathcal{P}+\pi \\
& N^{\prime}=\int_{0}^{N}\left(1-\varphi_{j}\right) d j+\{H\}^{+} \\
& B^{\prime}=(1-\lambda) B+b^{\prime}, \quad K^{\prime}=I+\left(1-\delta_{K}\right) K \\
& W_{j^{\prime}}^{\prime}=\left\{\begin{array}{cc}
\mathcal{U}\left(X^{\prime}\right) & \text { if } j^{\prime} \text { new worker } \\
W_{j}\left(\Lambda^{\prime}, s^{\prime}, F^{\prime}\right) & \text { if } j^{\prime} \text { incumbent worker }
\end{array}\right. \\
& \text { and } \quad(6), \quad(7), \quad(8), \quad(9), \quad(10)
\end{aligned}
$$

where $\{H\}^{+}=\max \{0, H\}$. Firm's dividend payments $d$ must be paid with its resources $\mathcal{P}+\pi$. However, a firm can set $d<0$ which we understand as equity issuance. Notice that the default decision next period $\chi$, included in the contract choice, is incorporated in the term $\{\mathcal{J}\}^{+}$next period.

The remaining constraints of the problem on (11) are the law of motions for the firm's sates. Total workers next period $N^{\prime}$ is the sum of incumbent ones that were not laid off plus the new hires $\{H\}^{+}$. Total debt next period $B^{\prime}$ is the fraction $(1-\lambda)$ of debt this period $B$ that did not mature plus the new debt issuance $b^{\prime}$. A standard law of motion also applies for capital. The constraint on next period promised utilities $\left\{W_{j^{\prime}}^{\prime}\right\}$ states that new workers should get the unemployment value $\mathcal{U}\left(X^{\prime}\right)$, and that incumbents receive the contract choice $W_{j}\left(\Lambda^{\prime}, s^{\prime}, F^{\prime}\right)$. By combining the law of motion for $N^{\prime}$ in $(11)$ and the constraint on $\int_{0}^{N} \varphi_{j} d j$ in (9), we can express next period workers as

$$
N^{\prime}=\left(1-\delta_{N}\right) N+H
$$

which is the standard law of motion in search models, and also equivalent to the law of motion for capital.

Firms find it optimal to issue debt solely because of the tax advantage $\tau$, and would only use dividends/equity absent this advantage. ${ }^{10}$ Naturally, once the firm issues debt, it exposes itself to default risk. In turn, the bond price depends on the firm's decisions because these determine the firm's value and thus likelihood to default next period. The firm understands this and internalizes it when making decisions.

The key of our mechanism is that, as a result of the search friction in the labor market, the number of workers increases the firm's value and thus relaxes financial conditions. In this sense, labor works the same way as physical capital in our model.

\footnotetext{
${ }^{10}$ See Abel (2015) and Graham and Leary (2011) for empirical evidence on the trade-off theory.
} 


\subsection{Bond Pricing and Firms Entry}

All of the firms' bonds are purchased by the investors, members of the representative household, who have risk-neutral preferences. However, we assume that investors have a stochastic marginal utility of wealth given by $\psi$. This is a simplified manner in which we introduce a financial shock that directly affects bond prices. $^{11}$

Accordingly, the bond price is simply the discounted expected value of repayment next period adjusted by the marginal value of wealth today. In particular, for any choice of the firm's debt, capital and workers, the price of the firm bond is

$$
\begin{aligned}
Q\left(K^{\prime}, N^{\prime}, B^{\prime}, \Lambda, z\right) & =\psi \beta \mathbb{E}_{\Lambda^{\prime}, z^{\prime}, F^{\prime}}\left[\left[1-\chi\left(\Lambda^{\prime}, s^{\prime}, F^{\prime}\right)\right]\left[(c+\lambda)+(1-\lambda) Q\left(\boldsymbol{h}^{\prime}\left(\Lambda^{\prime}, s^{\prime}, F^{\prime}\right), X^{\prime}, z^{\prime}\right)\right] \mid \Lambda, z\right] \\
& +\psi \beta \mathbb{E}_{\Lambda^{\prime}, z^{\prime}, F^{\prime}}\left[\chi\left(\Lambda^{\prime}, s^{\prime}, F^{\prime}\right) \theta \frac{K^{\prime}}{B^{\prime}} \mid \Lambda, z\right]
\end{aligned}
$$

where $s^{\prime}=\left(K^{\prime}, N^{\prime}, B^{\prime}, z^{\prime}\right)$ and $\boldsymbol{h}^{\prime}(\Lambda, s, F)=\left\{\boldsymbol{K}^{\prime}(\Lambda, s, F), \boldsymbol{N}^{\prime}(\Lambda, s, F), \boldsymbol{B}^{\prime}(\Lambda, s, F)\right\}$ collects the firm's optimal policies. ${ }^{12}$

A firm's bond price then has two components. If the firm defaults $\left(\chi\left(X^{\prime}, s^{\prime}, F^{\prime}\right)=1\right)$, lenders recover a fraction $\theta$ of the firm's capital pro-rated by the its outstanding debt. If the firm does not default next period, the lender obtains the coupon payment $c$, the fraction of debt that matures $\lambda$, and the market value of the remaining fraction $1-\lambda$. In turn, the market value of debt- $Q\left(\boldsymbol{h}^{\prime}\left(X^{\prime}, s^{\prime}, F^{\prime}\right), X^{\prime}, z^{\prime}\right)$-depends not only on the realization of shocks tomorrow, but also on the policies the firm will follow next period. Thus, lenders correctly forecast firms' policies next period in order to price the debt today.

The presence of future firm's policies in equation (12) makes solving and estimating the model a nontrivial task. In Section 4.1 we discuss an efficient and accurate algorithm to overcome this issue.

We assume an exogenous entry process in order to keep the measure of active firms constant. In particular, after a firm defaults/exits, we assume that the capital $\theta K$ recovered by lenders is used to set a new firm. This new firm also starts with a number of workers and debt equal to $\min \left\{\varsigma_{N} \theta K, N\right\}$ and $\min \left\{\varsigma_{B} \theta K, B\right\}$, respectively. Thus, no new firm has more debt or workers than the exiting one. The productivity of the new firm is randomly set as $\varsigma_{z}+\varepsilon$, where $\varepsilon$ has the same ergodic distribution as the $z$. We estimate the parameters $\left\{\varsigma_{N}, \varsigma_{B}, \varsigma_{z}\right\}$, and use a prior that all of them are strictly lower than one. We discuss the estimation results

\footnotetext{
${ }^{11}$ A stochastic marginal value of wealth can be micro-founded as the results of income shocks in an investors who faces a leverage constraint. See Navarro (2015), who shows this in an environment like Gertler and Kiyotaki (2009).

${ }^{12}$ Assuming that household's preferences are risk-neutral is important to maintain the model's tractability. Alternatively, agents would need to forecast consumption each state next period which depends on the firms' distribution $\mu$. To compensate for the lack of a consumption-bases asset pricing model, we include the shock $\xi$. Details on the household and investor problem can be found in Appendix A.1.
} 
in Section 4.3.1.

\subsection{Equilibrium Definition}

Before defining the recursive equilibrium, we provide a description of the law of motion for the aggregate state in the economy. Let $S$ be the space where $s$ lies $(s \in S)$ and $\mathcal{B}$ be the Borel $\sigma$-algebra induced by $S$. For any set in $\mathcal{A} \in \mathcal{B}$

$$
\begin{aligned}
\mu^{\prime}(\mathcal{A}) & =\int_{s} \mathbb{I}\left\{\left(\boldsymbol{h}^{\prime}(\Lambda, s, F), z^{\prime}\right) \in \mathcal{A}\right\} \mathbb{I}\{\chi(\Lambda, s, F)=1\} d P_{z}\left(z, z^{\prime}\right) d \mu(s) \\
& +\int_{s} \mathbb{I}\left\{\phi^{\text {new }}(s) \in \mathcal{A}\right\} \mathbb{I}\{\chi(\Lambda, s, F)=0\} d P_{z}\left(z, z^{\prime}\right) d \mu(s)
\end{aligned}
$$

where $\mathbb{I}\{\cdot\}$ is the indicator function, and $\phi^{\text {new }}(s)$ is the new state of the entrant firm as explained in Section 2.5 .

Next we provide next a formal equilibrium definition of the model.

Definition 1 A recursive equilibrium is given by a set of value functions $\mathcal{U}(X)$ and $\mathcal{J}\left(\Lambda, s, F,\left\{W_{j}\right\}_{j \in[0, N]}\right)$; firms' policy function $\boldsymbol{h}^{\prime}(\Lambda, s, F)$; a bond price function $Q\left(K^{\prime}, N^{\prime}, B^{\prime}, \Lambda, z\right)$; and a law of motion for $\mu^{\prime}=\Gamma(\mu)$ such that:

- $\mathcal{U}(X)$ satisfies (4).

- Given a bond price function $Q(\cdot)$, firm's policies $\boldsymbol{h}^{\prime}(\Lambda, s, F)$ solve (11) and achieve value $\mathcal{J}\left(\Lambda, s, F,\left\{W_{j}\right\}_{j \in[0, N]}\right)$.

- Given firm's policies $\boldsymbol{h}^{\prime}(\cdot)$, the price function $Q\left(K^{\prime}, N^{\prime}, B^{\prime}, \Lambda, z\right)$ satisfies (12).

- The law of motion $\boldsymbol{\mu}^{\prime}=\Gamma(\mu)$ is consistent with firm's policies $\boldsymbol{h}^{\prime}(\cdot)$ and given by (13).

\section{Equilibrium Characterization}

The model presented in the previous section can be solved in a simple manner. In particular, in spite of the flexibility of arrangements between firms and workers, we show that a surplus maximization problem can be used to obtain the firm's optimal policies. The advantage of doing so is that the heterogeneity of promised values to workers does not affect the surplus, and thus the dimensionsionality of the problem is drastically reduced. Normatively, this result implies that the firm's incentives are aligned with the value of the match. 


\subsection{A Surplus Maximization Problem: an Equivalence Result}

Let $\mathcal{S}(\Lambda, s, F)$ be the physical surplus obtained by a firm and its workers. In particular

$$
\begin{aligned}
\mathcal{S}(\Lambda, s, F) & =\max _{d, I, H, b^{\prime}, \chi}\left\{d+\beta \mathbb{E}_{\Lambda^{\prime}, z^{\prime}}\left[\left\{\mathcal{S}\left(\Lambda^{\prime}, s^{\prime}, F^{\prime}\right)\right\}^{+} \mid \Lambda, z\right]\right\} \\
\text { subject to } \mathcal{P} & =\eta z K^{\alpha \nu} N^{(1-\alpha) \nu}-\bar{u}(X) N-F_{K} K-F-[(1-\tau) c+\lambda] B \\
\pi & =-I+Q\left(K^{\prime}, N^{\prime}, B^{\prime}, \Lambda, z\right) b^{\prime}-\mathcal{C}^{K}(I, K)-\mathcal{C}^{N}(H, N)-\mathcal{C}^{B}\left(b^{\prime}, B\right) \\
d & \leq \mathcal{P}+\pi \\
N^{\prime} & =\left(1-\delta_{N}\right) N+H \\
K^{\prime} & =I+\left(1-\delta_{K}\right) K, \quad B^{\prime}=(1-\lambda) B+b^{\prime}
\end{aligned}
$$

The surplus maximization problem in (14) is very similar to the firm's problem in (11) except for two key differences. First of all, the distribution of promised values $\left\{W_{j}\right\}$ does not matter for the surplus, since it is a transfer between the firm and its workers. For the same reason, wages do not affect surplus, but only the unemployment benefits $\bar{u}(X)$ foregone by the workers. Accordingly, the promise keeping constraint (8) does not affect the surplus. Consequently, the controls in the surplus problem are not distributional objects any more.

The next proposition formalizes the equivalence between the firm's problem and the surplus maximization. It is very similar to the results and derivations in Kaas and Kircher (2015) and Schaal (2015).

Proposition 1 (Equivalence Result) The firm's problem in (11) and the surplus maximization problem in (14) are equivalent in the following sense

(i) The surplus and the firm's value satisfy

$$
\mathcal{S}(\Lambda, s, F)=\mathcal{J}\left(\Lambda, s, F,\left\{W_{j}\right\}_{j \in[0, N]}\right)+\int_{0}^{N}\left(W_{j}-\mathcal{U}(X)\right) d j
$$

(ii) If a policy $\left\{I, H, b^{\prime}, \chi\right\}$ maximizes the surplus, then there exist wages $\left\{w_{j}\right\}$ and continuation values $\left\{W_{j}\right\}$ such that a contract $\omega_{j}=\left\{w_{j}, \varphi_{j}, \chi, W_{j}\right\}$ is consistent with the promise keeping constraint (8), and $\left\{I, H, b^{\prime},\left\{\omega_{j}\right\}\right\}$ solves the firm's problem and achieves value $\mathcal{J}\left(\Lambda, s, F,\left\{W_{j}\right\}_{j \in[0, N]}\right)$.

(iii) Conversely, if a policy $\left\{I, H, b^{\prime},\left\{\omega_{j}\right\}\right\}$ maximizes the firm's problem; then $\left\{I, H, b^{\prime}, \chi\right\}$ solves the surplus' problem and achieve $\mathcal{S}(\Lambda, s, F)$.

Proposition 1 is rather intuitive. Because there is no contractual frictions between firms and workers, it 
is optimal to maximize the value of the match and then somehow distribute it. As long as the joint surplus is positive, there is always a sophisticated enough contract so that the match can continue, both parts benefit and past promises are kept. Thus, the incentives of the firms are aligned with those of the match, and their policies are identical. Appendix F contains the proof of this and the next propositions.

Next, we argue that there is no fundamental reason for the equilibrium to depend on the distribution of firms $\mu$. In particular, notice that the firm's problem, as well as the surplus problem, depend on the distribution $\mu$ if and only if the other problem depends on the distribution. The following proposition formalizes this.

Lemma 1 (Partial Independence) Assume the bond price is independent of $\mu$-given as $Q\left(B^{\prime}, K^{\prime}, N^{\prime}, X, z\right)$; then, the surplus problem (14) is independent of $\mu$, which yields policies as $(\chi(X, s, F), \boldsymbol{h}(X, s, F))$ independent of $\mu$ as well, and equation 12 defining $Q(\cdot)$ is independent of $\mu$. Alternatively, if firm's policies are independent of $\mu$, so is the bond price and thus the surplus problem.

This result is the outcome of several assumptions: risk-neutral preferences allow the price of debt to be independent consumption and therefore of the distribution of firms, as long as firms' policies are independent of the distribution of firms. In the same way, the assumption of zero bargaining power for unemployed workers, as well as a constant filling vacancy rate, makes the firm's problem independent of the distribution of firms.

If there has to exist an unique that depends on $X$, then there cannot be equilibriums that depend on the distribution of workers. To show this, let us define $(v, Q, h, \chi)=T_{X}(v, Q, h, \chi)$ the functional equation defined by 14 and 12 and all the functions depend only on $X$; and $T_{\Lambda}(v, Q, h, \chi)$ whenever these functions depend on $\Lambda$.

Proposition 2 (Independence) Assume that there exist an unique fixed point in $T_{X}$. Then $T_{\Lambda}$ has an unique fixed point that depends only on $X$.

Proposition 2 shows that if there exist an unique equilibrium under the unique aggregate state variable $X$, then firms policies are independent of the distribution in the original economy. Importantly, we will check numerically if there exist an unique equilibrium under $X$ locally up to a second order condition. Moreover, whenever we estimate the model, we give a minus infinity value to the quasi-likelihood function whenever there are locally more than 1 equilibrium as a function of $X$. Thus, although we cannot theoretically rule out equilibrium that depend on the distribution of firms, we restrict ourselves to cases where the bond price, the 
surplus and firm's locally unique - up to a second order - to the exogenous aggregate state: $Q(K, N, B, X, z)$, $\mathcal{S}(X, s, F)$ and $\left\{\boldsymbol{h}^{\prime}(X, s, F), \chi(X, s, F)\right\}$.

We can use the simpler surplus maximization problem to characterize some of the firm's policies. In particular, we show that most of the firm's policies are independent of the cost shock $F$, except for default that follows a threshold policy: firms with a cost shock $F$ high enough will find it optimal to default and exit the economy.

Proposition 3 (Firm's policies) A firm finds it optimal to default if and only if its cost shock is above a threshold $\underline{\boldsymbol{F}}(X, s)$ given as

$$
\underline{\boldsymbol{F}}(X, s)=\eta z K^{\alpha \nu} N^{(1-\alpha) \nu}-\bar{u}(X) N-F_{K} K-[(1-\tau) c+\lambda] B+v(X, s)
$$

where $v(X, s)=\mathcal{S}(X, s, F)-\mathcal{P}$. Then, a firm with state $(X, s)$ defaults with probability $1-G(\underline{\boldsymbol{F}}(X, s))$.

If a firm does not default, its policies for investment, vacancy posting and debt issuance are independent of the cost shock. Denote $\boldsymbol{K}^{\prime}(X, s), \boldsymbol{N}^{\prime}(X, s)$ and $\boldsymbol{B}^{\prime}(X, s)$ the resulting states for capital, workers and debt next period, respectively.

Proposition 3 tightly characterizes the firm's default decision. The more productive the firm is, or the more promising the continuation value $v(\cdot)$ is, the higher the default threshold and the less likely the firm is to default. Analogously, the larger the firm's debt the more likely it is to default. At the same time, the cost shock does not affect the firm's policies because it is i.i.d. and does not contain any information about the future.

As a corollary of Proposition 3, we can use the default decision derived in equation (15) to provide a tighter expression for the bond price in equation (12).

Corollary 1 (Firm's policies) For any choice of next period debt, capital and workers, the price of the firm bond is given as

$$
\begin{aligned}
Q\left(B^{\prime}, K^{\prime}, N^{\prime}, X, z\right) & =\psi \beta \mathbb{E}_{X^{\prime}, z^{\prime}}\left[G\left(\underline{\boldsymbol{F}}\left(X^{\prime}, s^{\prime}\right)\right)\left[c+\lambda+(1-\lambda) Q\left(\boldsymbol{B}^{\prime}\left(X^{\prime}, s^{\prime}\right), \boldsymbol{K}^{\prime}\left(X^{\prime}, s^{\prime}\right), \boldsymbol{N}^{\prime}\left(X^{\prime}, s^{\prime}\right), X^{\prime}, z^{\prime}\right)\right]\right. \\
& \left.+\left[1-G\left(\underline{\boldsymbol{F}}\left(X^{\prime}, s^{\prime}\right)\right)\right] \theta \frac{K^{\prime}}{B^{\prime}} \mid X, z\right]
\end{aligned}
$$

where $\underline{\boldsymbol{F}}\left(X^{\prime}, s^{\prime}\right)$ is the default threshold in (15)

We derive and describe the full set of equilibrium conditions in Appendix B.1. 
Finally, we will show the model relations between: the value of the match, the probability of no default and the price of debt. For this proposition it would be useful to define some objects: $G(X, s)=G(F(X, s))$ the probability of no default in current period; $g(X, s)=g(F(X, s))$ the marginal probability of no default in current period; and $g r^{Y}(X, s)=\frac{Y_{t, t+1}}{Y_{t-1, t}}-1$ the growth rate for capital and labor $-Y \in\{K, N\}$.

Proposition 4 (The marginal value of a worker and capital) The marginal value of a worker and capital is given by

$$
\frac{\partial \mathcal{S}(X, s)}{\partial N}=\frac{1}{g(X, s)} \frac{\partial G(X, s)}{\partial N} \quad ; \quad \frac{\partial \mathcal{S}(X, s)}{\partial K}=\frac{1}{g(X, s)} \frac{\partial G(X, s)}{\partial K}
$$

Assume that $\mathcal{C}^{N}(H, N)=\tilde{\mathcal{C}}^{H}(H, N)+\frac{\phi_{N}}{2}\left(\frac{\left(1-\delta_{n}\right) N+H}{N}-1\right)^{2}$ and $\mathcal{C}^{K}(I, K)=\frac{\phi_{K}}{2}\left(\frac{\left(1-\delta_{k}\right) K+I}{K}-1\right)^{2}$, where $\tilde{\mathcal{C}}^{H}(H, N)$ is increasing in $H$. Then

$$
\begin{aligned}
\tilde{\mathcal{C}}_{1}^{H}(X, s)+\phi_{N} g r^{N}(X, s) & =Q_{N}(X, s) B\left[g r^{B}(X, s)+\lambda\right]+\beta \mathbb{E}_{X^{\prime}, s^{\prime}}\left[\frac{G\left(X^{\prime}, s^{\prime}\right)}{g\left(X^{\prime}, s^{\prime}\right)} \frac{\partial G\left(X^{\prime}, s^{\prime}\right)}{\partial N^{\prime}} \mid X, s\right] \\
1+\phi_{K} g r^{K}(X, s) & =Q_{K}(X, s) B\left[g r^{B}(X, s)+\lambda\right]+\beta \mathbb{E}_{X^{\prime}, s^{\prime}}\left[\frac{G\left(X^{\prime}, s^{\prime}\right)}{g\left(X^{\prime}, s^{\prime}\right)} \frac{\partial G\left(X^{\prime}, s^{\prime}\right)}{\partial K^{\prime}} \mid X, s\right]
\end{aligned}
$$

If additionally $\lambda=1$ and $c=1$

$$
\begin{aligned}
\tilde{\mathcal{C}}_{1}^{H}(X, s)+\phi_{N} g r^{N}(X, s) & =\beta \mathbb{E}_{X^{\prime}, s^{\prime}}\left[\left(\frac{1+g r^{B}(X, s)}{\psi}+\frac{G\left(X^{\prime}, s^{\prime}\right)}{g\left(X^{\prime}, s^{\prime}\right)}\right) \frac{\partial G\left(X^{\prime}, s^{\prime}\right)}{\partial N^{\prime}} \mid X, s\right] \\
1+\phi_{K} g r^{K}(X, s) & =\beta \mathbb{E}_{X^{\prime}, s^{\prime}}\left[\left(\frac{1+g r^{B}(X, s)}{\psi}+\frac{G\left(X^{\prime}, s^{\prime}\right)}{g\left(X^{\prime}, s^{\prime}\right)}\right) \frac{\partial G\left(X^{\prime}, s^{\prime}\right)}{\partial K^{\prime}} \mid X, s\right] \\
Q_{K}(X, s) & =\beta \psi \mathbb{E}_{X^{\prime}, s^{\prime}}\left[\frac{\partial G\left(X^{\prime}, s^{\prime}\right)}{\partial K} \mid X, s\right] \quad ; \quad Q_{N}(X, s)=\beta \psi \mathbb{E}_{X^{\prime}, s^{\prime}}\left[\frac{\partial G\left(X^{\prime}, s^{\prime}\right)}{\partial N} \mid X, s\right]
\end{aligned}
$$

Proposition 4 has several components. The equations (17) gives us a relation between the Tobin's Q with respect to capital and labor with the the non-defaulting set. Basically, it is stating that the Tobins' $\mathrm{Q}$ are proportional to the increase of the non-default set. This idea is in the merton model; the relation between the market value of the firm and the default probability - see section 5.2.1. The second part of the proposition - equations (18) and (19) — gives a the relation between the marginal price of debt, marginal non-defaulting set with respect to labor, the growth rate of labor and the marginal cost hiring. Basically, if adjustment cost are zero, then at long as hiring costs are positive the price of debt increases with labor or the probability of no-defaulting increases with labor - or both. Moreover, as we can see in equations (20) and (21), if the growth rate of labor is higher, then the Tobin's Q with respect to labor is higher.

Proposition 4 shows how important is the growth rates of labor, capital and debt; together with the size 
of adjustment cost to discipline business cycle fluctuation of the Tobin's Q of capital and labor. For this reason, we use micro-date of employment, capital and debt. Moreover, we use aggregate time series of credit spread to get information about default rates. All these elements together with the cost of hiring identifies the Tobin's Q for capital, labor and debt.

\subsection{Labor Market Flows}

In this section, we compute the law of motion for several labor market variables, as well as construct measures of finding probabilities and separation rates. We the use these measures to compare model and data, as well as part of our estimation later on.

Let $\bar{N}(\Lambda)=\int N d \mu(s)$ be the total number of workers that start with a job this, and $\bar{N}^{\prime}(\Lambda)$ be the measure that start with a job next period. Then

$$
\begin{aligned}
\bar{N}^{\prime}(\Lambda) & =\int(1-\chi(X, s, F))\left(1-\delta_{N}\right) N d \mu(s) d G(F) \\
& +\int((1-\chi(X, s, F))) \boldsymbol{H}(X, s) d \mu(s) d G(F) \\
& +\int \chi(X, s, F) \min \left\{\varsigma_{N} \theta K, N\right\} d \mu(s) d G(F)
\end{aligned}
$$

Let $U(\Lambda)$ be the measure of workers not engaged in production this period. Thus, $U(\Lambda)$ is the measure of workers receiving unemployment benefits. Then

$$
U(\Lambda)=(\tilde{N}-\bar{N}(\Lambda))+\int \chi(X, s, F)\left\{\varsigma_{N} \theta K-N\right\}^{+} d \mu(s) d G(F)
$$

where $\tilde{N}$ is the total measure of workers in the economy.

Let $U E(\Lambda)$ denote the flow of workers moving from unemployment to employment when the aggregate state of the economy is $\Lambda$. Then

$$
U E(\Lambda)=\int(1-\chi(X, s, F))\{\boldsymbol{H}(X, s)\}^{+} d \mu(s) d G(F)
$$

where $\boldsymbol{H}(X, s)$ is the vacancy posting policy of the firm in (11). Then unemployment-to-employment flow equals the new positions created through positive vacancy posting.

Analogously, let $E U(\Lambda)$ denote the measure of workers moving from employment to unemployment when 
the aggregate state of the economy is $\Lambda$. Then

$$
\begin{aligned}
E U(\Lambda) & =\int(1-\chi(X, s, F))\left[\delta_{N} N-\{\boldsymbol{H}(X, s)\}^{-}\right] d \mu(s) d G(F) \\
& +\int \chi(X, s, F)\left\{N-\varsigma_{N} \theta K\right\}^{+} d \mu(s) d G(F)
\end{aligned}
$$

Then an employment-to-unemployment transition happens because of an exogenous separation, a layoff (negative vacancy posting), or a firm exit.

Notice that $\bar{N}^{\prime}(\Lambda)=\bar{N}(\Lambda)+U E(\Lambda)-E U(\Lambda)$. Finally, we define the finding and the separation rate as

$$
f(\Lambda)=\frac{U E(\Lambda)}{U(\Lambda)}, \quad \text { and } \quad s(\Lambda)=\frac{E U(\Lambda)}{\bar{N}(\Lambda)}
$$

Then we have a standard law of motion for workers given as

$$
\bar{N}^{\prime}(\Lambda)=(1-s(\Lambda)) \bar{N}(\Lambda)+f(\Lambda) U(\Lambda)
$$

\subsection{A Walrasian Labor Market Model}

In order to highlight the role of labor as an asset in our model, we compare our search friction environment with a frictionless Walrasian labor market model. In order to do this in a tractable manner, we construct a partial equilibrium model where only a continuum of firms are present.

More precisely, we assume that the firm problem the same as before (see equation (11)), with two differences. First of all, firms do not need to post vacancies and can costlessly hire new workers. This is equivalent to setting the cost of posting vacancies to zero. At the same time, labor is still hired one period in advanced but the match lasts only that period: firms hire workers on a period by period basis. This is equivalent to the exogenous separation rate to $\delta_{N}=1$. The second key difference is that the firm takes wages as given, and there is no contracting problem between firms and workers.

For practical purposes, we assume that the wage is an iso-elastic function of the aggregate productivity: $w=w_{0} \eta^{\varphi_{w}}$. We also use the bond pricing equation as in (12). We solve and estimate the Walrasian labor market model using the same techniques we use for our benchmark model. We also target the same set of moments. Appendix A.2 contains a detailed description of the Walrasian market model. 


\section{Heterogeneous Firms Model Estimation}

This section describes how we solve and estimate the model. We use an accurate algorithm to efficiently solve our heterogeneous firms model, suitable to handle some complications that arise in the presence of long-term debt. We estimate most of the model parameter using a moment matching estimation procedure as proposed by Chernozhukov and Hong (2003), which allows us to make robust inference about the predictions of the model. We target several firm-level statistics, which allows us to take the rich cross-sectional implications of our model to the data. We also calibrate some parameters that have common values in the literature.

\subsection{Solution Strategy}

The model structure makes its solution very simple: we first obtain the firm's policies from the surplus maximization problem in (14), and then compute aggregate quantities. Because the surplus maximization is a common problem, we can use standard perturbation techniques to efficiently and accurately describe its solution. However, as recently pointed out by Gomes et al. (2013), an issue arises with perturbation techniques in the presence of long-term debt. We briefly explain this problem next, as well as the solution algorithm we use to overcome this issue.

Because the firm has the monopoly of its debt, it internalizes the effect that its debt choice, as well as capital and labor choice, has on its bond price. This is captured by the derivative of the price function $\frac{\partial Q\left(B^{\prime}, K^{\prime}, N^{\prime}, X, z\right)}{\partial B^{\prime}}$. In particular, letting $\boldsymbol{h}^{\prime}(X, s)=\left\{\boldsymbol{K}^{\prime}(X, s), \boldsymbol{N}^{\prime}(X, s), \boldsymbol{B}^{\prime}(X, s)\right\}$ collect the firm's policies, we can use equation (16) to compute the price derivative as

$$
\begin{aligned}
\frac{\partial Q\left(B^{\prime}, K^{\prime}, N^{\prime}, X, z\right)}{\partial B^{\prime}} & =\beta \psi \mathbb{E}_{X^{\prime}, z^{\prime}}\left[g\left(\underline{\boldsymbol{F}}\left(X^{\prime}, s^{\prime}\right)\right) \frac{\partial \underline{\boldsymbol{F}}\left(X^{\prime}, s^{\prime}\right)}{\partial B^{\prime}}\left[(c+\lambda)+(1-\lambda) Q\left(\boldsymbol{h}^{\prime}\left(X^{\prime}, s^{\prime}\right), X^{\prime}, z^{\prime}\right)\right] \mid X(2 \phi)\right. \\
& +\beta \psi \mathbb{E}_{X^{\prime}, z^{\prime}}\left[G\left(\underline{\boldsymbol{F}}\left(X^{\prime}, s^{\prime}\right)\right) \sum_{\mathcal{Y}=\{B, K, N\}} \frac{Q \mathcal{Y}\left(\boldsymbol{h}\left(X^{\prime}, s^{\prime}\right), X^{\prime}, z^{\prime}\right)}{\partial \mathcal{Y}} \frac{\partial \mathcal{Y}^{\prime}\left(X^{\prime}, s^{\prime}\right)}{\partial B^{\prime}} \mid X, z\right] \\
& +\beta \psi \mathbb{E}_{X^{\prime}, z^{\prime}}\left[g\left(\underline{\boldsymbol{F}}\left(X^{\prime}, s^{\prime}\right)\right) \frac{\partial \underline{\boldsymbol{F}\left(X^{\prime}, s^{\prime}\right)}}{\partial B^{\prime}} \theta \frac{K^{\prime}}{B^{\prime 2}} \mid X, z\right]
\end{aligned}
$$

where $s^{\prime}=\left(B^{\prime}, K^{\prime}, N^{\prime}, z^{\prime}\right)$ and $\frac{\partial \mathcal{Y}^{\prime}\left(X^{\prime}, s^{\prime}\right)}{\partial B^{\prime}}$ is the derivative - next period - of the firm's policy function with respect to today's debt choice $B^{\prime}$.

As equation (28) shows, we need information about the firm's policies derivatives $\frac{\partial \mathcal{Y}^{\prime}\left(X^{\prime}, s^{\prime}\right)}{\partial B^{\prime}}$ in order to compute an equilibrium. ${ }^{13}$ However, equilibrium conditions do not provide any additional information

\footnotetext{
${ }^{13}$ Analogous equations for the price derivatives with respect to capital and labor, $\frac{\partial Q\left(B^{\prime}, K^{\prime}, N^{\prime}, X, z\right)}{\partial K^{\prime}}$ and $\frac{\partial Q\left(B^{\prime}, K^{\prime}, N^{\prime}, X, z\right)}{\partial N^{\prime}}$, are also part of the equilibrium conditions. See Appendix for the complete set of equilibrium equations.
} 
about these derivatives, and it can be shown that further differentiating equilibrium conditions does not help since one always ends up with one more unknown than equations. Importantly, without having the policies derivatives, we cannot solve for the non-stochastic steady-state of the model, which complicates computing the solution using standard perturbation techniques.

We overcome this problem by using an iterative procedure of local approximation to the model solution. In particular, for any policy $\mathcal{Y}$, we compute a second-order approximation around the non-stochastic steadystate of the model policies as

$$
\ln \mathcal{Y}^{\prime}(\mathcal{Z}) \approx \phi_{0}^{\mathcal{Y}}+\phi_{1}^{\mathcal{Y}} \ln \mathcal{Z}+(\ln \mathcal{Z})^{\prime} \phi_{2}^{\mathcal{Y}}(\ln \mathcal{Z}) \quad \forall \mathcal{Y}=\boldsymbol{B}^{\prime}, \boldsymbol{K}^{\prime}, \boldsymbol{N}^{\prime}
$$

where $\mathcal{Z}=[X, s]^{\prime}$ collects the aggregate exogenous and firm's idiosyncratic states. Let $\phi^{\mathcal{Y}}$ collect all the coefficients in (29), and notice that this is all the information we need to compute the policy function derivatives. The iterative procedure we use is as follows: for a given guess $\phi^{\mathcal{Y}}$, we compute the non-stochastic steady state of the model and the second order approximation of the policies around this point; this delivers an implied set of coefficients in equation (29), call it $\hat{\phi}^{\mathcal{Y}}$; we iterate until $\phi^{\mathcal{Y}} \approx \hat{\phi}^{\mathcal{Y}}$. Details on this procedure can be found in Appendix B.3 with the equilibrium conditions in B.2.

We use a second-order approximation because, as we show below, firm's idiosyncratic shocks are too volatile to be accurately described by a first-order approximation. However, higher order perturbation techniques often result in explosive paths and it is not obvious how to check for stability conditions. Thus, we follow the pruning technique for non-linear systems proposed by Andreasen et al. (2016), which includes second order terms in the solution and simultaneously allows to check for stability conditions in the model. We provide more details in Appendix B.3.

\subsection{Data Description}

We use annual firm-level balance sheet data to estimate key model parameters. We also use quarterly aggregate data from different sources. We describe next the data we use, and more details can be found in Appendix C.

Firm-level data mostly comes from Compustat-Fundamentals Annual, for the period 1983 to 2015. Table 4 describes all the variables that we used for the computation of the micro-moments in the GMM estimation. We use PPENTQ (net property plant and equipment) as the measure of the firm's physical capital in the model; we construct firm's debt as the sum of DLCQ (debt in current liabilities), DLTTQ (long-term debt total), minus CHEQ (cash and short-term investments); we use CAPXY (capital expenditures) minus SSPE 
(sales of property) as firm's investment; and SALEQ (sales) as the output produced by the firm. For the change in debt, we used DLTIS (long-term debt issuance) minus DLTR (long-term debt reduction) plus the difference between USTDNC (debt in current liabilities net change) minus CHECH (cash and term investment net change). For firms' number of workers, we use EMP (employees). ${ }^{14}$

We omit firms with SIC between 6000 and 6999 (financial firms) or between 4900 and 4999 (regulated firms), and drop firms with less than 5 years or with negative assets, capital or sales. The key firm-level variables for the estimation are the growth rate of debt, capital and employment. For capital, we compute the growth rate, for firm $i$ in period $t$, as $\Delta K_{i t}=I_{i t} / 0.5 *\left(K_{i t-1}+K_{i t}\right)$, where $I_{i t}$ is investment and $K_{i t}$ is capital. ${ }^{15}$ Similarly, we compute employment and debt growth as $\left(N_{i t}-N_{i t-1}\right) / 0.5 *\left(N_{i t-1}+N_{i t}\right)$ and $\left(B_{i t}-B_{i t-1}\right) / 0.5 *\left(B_{i t-1}+B_{i t}\right)$ respectively. For the computation of each moment, we drop $1 \%$ outliers and de-mean each growth rate with the mean across time and across each firm. Appendix C.1 describes the details of the moments computations and table 5 describes the estimated micro-moments.

We use quarterly aggregate data from different sources. We use BLS for labor market variables, and NIPA and FRED for standard macroeconomic variables like output, investment and nominal interest rates. We obtain total debt for non-financial business from Flow of Funds, partly because we found discrepancies in business cycle properties between this measure and the result of aggregating firms debt from Compustat. This discrepancy is not present for investment or employment - see tables 5 and 7 . We use the time series of credit spread constructed by Gilchrist and Zakrajsek (2012). See Table 6 for a description and sources of each variable, and Section C.4 for the computation of each variable in the data.

\subsection{Estimation: A Simulated Method of Moments Approach}

We estimate most of the model parameters using a Simulated Method of Moments (SMM): that is, we select parameters in order to minimize the distance between data moments and the same moments generated by the model. Following the recent work by Lise (2012), we use a Laplace Type estimator as introduced Chernozhukov and Hong (2003). ${ }^{16}$ This procedure constructs a pseudo-likelihood criterion function in the form of a quasi-posterior density over the model parameters. We favor this approach, instead of a standard extremum estimator, because it is computationally attractive and less likely to get stuck at local minimums. It simultaneously allows us to make inference (i.e. compute standard errors) about the parameters estimates

\footnotetext{
${ }^{14}$ The variable EMP is a "Miscellaneous Items" and not available at quarterly frequency. Although it is understood that employment is reported with measurement error in COMPUSTAT, the recent work by Davis, Haltiwanger, Jarmin and Miranda (2006) report a correlation of 0.89 with establishment level data (Longitudinal Database), although the correlations is weaker for smaller firms..

${ }^{15}$ See Section 4.2 for data description of each variable and Appendix C for more details.

${ }^{16}$ Recent papers using the same estimation approach include Jarosch (2015), Lamadon (2014) and Lise et al. (2016).
} 
together with the model implied moments observed in data. We implement the estimation by using a random walk Metropolis-Hasting algorithm and uniform priors, details can be found in Appendix D.

\subsubsection{Model Estimation: Firm-Level Statistics and Macroeconomic Aggregates}

We exploit the firms' heterogeneity generated by the model in our estimation strategy. In particular, we target several cross-sectional moments of firm-level variables, which allows us to make the model consistent with micro-statistics. We also target aggregate moments commonly used in the literature. We explain next the moments we target and the parameters we estimate.

We target the cross-sectional standard deviation and persistence of debt, capital, output and employment growth rates. In particular, for a given quarter $t$, we compute the standard deviation of $\Delta K_{i t}$ across firms $i$, and target the average over time $t$ as the standard deviation measure. Similarly, for a given quarter $t$, we compute the correlation of $\Delta K_{i t}$ and $\Delta K_{i t-1}$ across firms $i$, and target the average over time $t$ as the capital growth persistence measure. Analogous calculations are done for employment, output and debt growth. Importantly, we perform the exact same computations in the data as we do in our model-simulated panel. We provide more details in Appendix D.

We also target the cross-sectional contemporaneous correlation of capital, output and employment growth with debt growth. ${ }^{17}$ We do this because this micro-statistic contains relevant information about the magnitude of financial frictions in the economy. However, we found the volatility of debt growth to be too high to be matched by our model using plausible parameters. Thus, we added a measurement error to debt growth, to account for additional sources of debt issuance not incorporated in the model. ${ }^{18}$

The aggregate moments we target are the standard deviation, persistence and correlation with output of investment, employment, credit spreads, debt and output. We filter the data, as well as the model generated data, using a Hodrick-Prescott filter with a smooth parameter of 1600. Additionally, we target several mean values including mean investment rate, credit spread, recovery rates, default rates and unemployment rates.

We use these targets to estimate many of the model parameters. We assume quadratic adjustment costs in capital, employment and debt as $\mathcal{C}^{K}(I, K)=\frac{\phi_{K}}{2}\left(\frac{I-\delta_{K} K}{K}\right)^{2} K, \mathcal{C}^{N}(H, N)=\kappa H+\frac{\phi_{N}}{2}\left(\frac{H-\delta_{N} N}{N}\right)^{2} N$ and $\mathcal{C}^{B}(b, B)=\frac{\phi_{B}}{2}\left(\frac{b-\lambda B}{B}\right)^{2} B$ respectively, and estimate $\left\{\phi_{K}, \phi_{N}, \phi_{B}\right\}$. We assume the unemployment benefit is a constant $\bar{u}(X)=\bar{u}$ and estimate $\bar{u}$. We assume that the idiosyncratic productivity shock $z$ follows an $\operatorname{AR}(1)$ in logs and estimate its persistence and variance $\left\{\rho_{z}, \sigma_{z}\right\}$. We also estimate the tax benefit $\tau$, the recovery rate upon default $\theta$, the fixed cost of production per unit of capital $F_{K}$, and the parameters

\footnotetext{
${ }^{17}$ That is, the correlation across firms $i$ of debt growth $\Delta B_{i t}$ with capital and employment growth $\Delta K_{i t}$ and $\Delta N_{i t}$, respectively.

${ }^{18}$ See Strebulaev and Yang (2013) for a review of empirical puzzles about the way firms make leverage decisions.
} 
determining the size and productivity of new firms $\left\{\varsigma_{N}, \varsigma_{B}, \varsigma_{z}\right\}$.

Because we use a second-order approximation, just a few moments of the idiosyncratic shock distribution $G(\cdot)$ affect equilibrium conditions. In particular, only four moments, all evaluated at the default threshold in the non-stochastic steady-state, show up in the second-order approximation: these are the level (c.d.f.) of the distribution, its slope (p.d.f.), and the first and second derivatives of the p.d.f.. Denote these four values as $G, g, g_{1}$ and $g_{2}$. Because the cost shock also implies a resource cost for those firms that do not default, the average value of the cost shock for non-defaulting firms also shows up in the equilibrium conditions. Denote the steady-state value of this cost shock as as $F^{e}$. We estimate these five values related to the idiosyncratic cost shock distribution $\left\{G, g, g_{1}, g_{2}, F^{e}\right\}$, and in Appendix B we show that this is all we need about the idiosyncratic cost shock distribution $G(\cdot)$ in order to compute the second approximation of the model.

The remaining parameters of the model are calibrated using common values in the literature. We set the discount factor to $\beta=0.98$, the span of decreasing returns to $\nu=0.85$, and the exponent of capital in the production function to $\alpha=0.4$. We assume a capital depreciation rate of $\delta_{K}=0.025$, and the exogenous separation rate to $\delta_{N}=0.033$ as in Shimer (2005). Regarding debt institutional parameters, we assume an average maturity of debt of six years and set $\lambda=1 / 24$, and normalize the coupon to $c=0.0101$ so that the price of a risk-free bond is one in steady state. We normalize the size of workers $\tilde{N}$, so that average unemployment rate is $7 \%$. We assume an AR(1) process for the log of aggregate productivity $\eta$, with persistence and innovation variance of $\left\{\rho_{\eta}, \sigma_{\eta}\right\}=\{0.85,0.008\}$ in line with the Solow residual . Finally, we also assume an $\operatorname{AR}(1)$ in logs for the financial shock $\xi$, with parameters $\left\{\rho_{\psi}, \sigma_{\psi}\right\}=\{0.52,0.003\}$, which are selected to match a variance and persistence of one period real realized risk-free rate in the data. ${ }^{19}$ Table 1 shows the calibrated parameters.

Table 1 shows the 17 total parameters we estimate. As can be seen, parameters are tightly estimated despite very flat priors. In the appendix D we include the calibrated and estimated parameters for the Walrasian market, together with the kernel estimates of the marginal density of the posterior for each parameter.

\subsubsection{Model Fit: Micro Heterogeneity and Aggregate Implications}

The model has a good fit with firm-level cross-sectional moments, as Table 2 shows. It generates a standard deviation of output and employment growth in line with the data, as well as the comparatively lower volatility of capital growth. Similarly, the model generates the close to zero persistence in debt and employment growth, together with the intermediate persistence in output growth and higher persistence in capital growth.

\footnotetext{
${ }^{19}$ See appendix C.4 for the construction of each variable.
} 
Table 1: Models Parameters

\begin{tabular}{|c|c|c|}
\hline Calibrated Parameters & Value & Target/Source \\
\hline \multicolumn{3}{|l|}{ Preferences and Technology } \\
\hline Discounting $(\beta)$ & 0.98 & Standard \\
\hline Span of Control $(\nu)$ & 0.85 & Standard \\
\hline Capital Elast. $(\alpha)$ & 0.4 & Standard \\
\hline Capital depresiation $\left(\delta_{K}\right)$ & 0.025 & Standard \\
\hline Exogenous separation $\left(\delta_{N}\right)$ & 0.033 & Shimer (2005) \\
\hline \multicolumn{3}{|c|}{ Debt Contract Calibrated Parameters } \\
\hline Cost of vacancies $(\kappa)$ & 40 & Normalization \\
\hline Debt maturity $(\lambda)$ & 0.0417 & Gomez, Jermann and Schmid (2016) \\
\hline Debt coupon $(c)$ & 0.0101 & Normalization \\
\hline \multicolumn{3}{|l|}{ Exogenous Aggregate Shocks } \\
\hline Productivity $\left(\rho_{\eta}, \sigma_{\eta}\right)$ & $(0.85,0.008)$ & Solow residual process \\
\hline Financial Shocks $\left(\rho_{\psi}, \sigma_{\psi}\right)$ & $(0.52,0.003)$ & One-period risk-free process \\
\hline Estimated Parameter & Prior & Mean $[5 \%, 95 \%]$ \\
\hline Unemp. benefit $(\bar{u})$ & $\mathcal{U}[0.1,0.7]$ & $0.32[0.276,0.356]$ \\
\hline Fixed cost $\left(F_{K}\right)$ & $\mathcal{U}[-0.02,0.02]$ & $0.0051[-0.00102,-0.00102]$ \\
\hline Tax benefit $(\tau)$ & $\mathcal{U}[0.01,0.4]$ & $0.0189[0.0107,0.0301]$ \\
\hline Recovery rate $(\theta)$ & $\mathcal{U}[0.2,0.8]$ & $0.339[0.293,0.379]$ \\
\hline \multicolumn{3}{|l|}{ Adjustment Costs } \\
\hline Capital $\left(\phi_{K}\right)$ & $\mathcal{U}[0.01,6]$ & $1.77[1.67,1.86]$ \\
\hline Employment $\left(\phi_{N}\right)$ & $\mathcal{U}[0.01,6]$ & $4.39[4.39,4.52]$ \\
\hline Debt $\left(\phi_{B}\right)$ & $\mathcal{U}[0.01,6]$ & $4.81[4.68,4.95]$ \\
\hline \multicolumn{3}{|l|}{ Entrant Size } \\
\hline Employment $\left(\varsigma_{N}\right)$ & $\mathcal{U}[0.8,1]$ & $0.966[0.897,0.998]$ \\
\hline Debt $\left(\varsigma_{B}\right)$ & $\mathcal{U}[0.6,1]$ & $0.811[0.759,0.862]$ \\
\hline Productivity $\left(\varsigma_{z}\right)$ & $\mathcal{U}[0.8,1]$ & $0.936[0.884,0.986]$ \\
\hline \multicolumn{3}{|c|}{ Firm-Level TFP and Cost Shocks } \\
\hline TFP persistence $\left(\rho_{z}\right)$ & $\mathcal{U}[0.4,0.9]$ & $0.753[0.693,0.816]$ \\
\hline $\mathrm{TFP}$ variance $\left(\sigma_{z}\right)$ & $\mathcal{U}[0.05,0.14]$ & $0.0888[0.0712,0.106]$ \\
\hline c.d.f. level $(G)$ & $\mathcal{U}[0.997,0.998]$ & $0.998[0.997,0.998]$ \\
\hline p.d.f. level $(g)$ & $\mathcal{U}[0.0005,0.02]$ & $0.00211[0.000902,0.00365]$ \\
\hline$p . d . f$. first derivative $\left(g_{1}\right)$ & $\mathcal{U}[-0.02,0.005]$ & $-0.00951[-0.0163,-0.00297]$ \\
\hline p.d.f. second derivative $\left(g_{2}\right)$ & $\mathcal{U}[-0.02,0.005]$ & $-0.00946[-0.0156,-0.00207]$ \\
\hline average cost $\left(F^{e}\right)$ & $\mathcal{U}[-0.03,0.5]$ & $0.0635[0.0452,0.0794]$ \\
\hline
\end{tabular}


The model can also account for the large volatility of debt growth, although a fraction of this is due to the assumed measurement error in the estimation. In any case, a good match is also obtained with many other moments related to debt growth, which implies that the model makes a good performance in explaining moments of debt growth as well. Overall, the model has a good fit of firm-level cross-sectional moments.

Regarding aggregate moments, the model can match business cycle moments of employment, investment and output; although falls short in generating enough volatility of aggregate debt and credit spreads.

Interestingly, the unemployment accelerator model estimates a lower tax subsidy and lower recovery rates than the Walrasian market model, as Figures 10 show. These statistical difference provides stark intuition about the role of workers in both models. In the unemployment accelerator model, workers add value to the firm, which results in better debt prices and more debt issuance by the firm. The Walrasian market model misses this value of workers, and thus need higher tax subsidies and recovery rates in order to induce the same level of debt.

\subsection{Qualitative Evaluation}

In this section we compute impulse response functions to gain intuition of the workings of the model. In particular, we compute the response of a single firm, starting from state $s_{0}$, to a unique idiosyncratic productivity shock at $t=0$, and no shock thereafter. This can be understood as a partial equilibrium exercise, since only one firm is being affected by these shocks.

An increase in firm's productivity $z$ induces an immediate expansion in firm's output, as Figure 2 shows. At the same time, the firm takes advantage of the persistent higher productivity to post more vacancies and hire new workers, as well as to invest more and accumulate capital. Thus, the firm increases both of its productive assets. The higher productivity, together with the increased assets, makes the firm safer and its probability to default lower, thus increasing the price of its debt an inducing the firm to issue more debt.

We perform analogous exercises to compute impulse response functions to aggregate shocks $\eta$ and $\psi$. The effects of an innovation in $\eta$ are very similar to the response in $z$. The response to a shock in $\psi$, despite of not affecting productivity, also induces an expansion in output and employment since firms take advantage of the improved financial conditions to hire more and invest in more capital. Appendix D.1 contains a more of the effects of agregate shocks. 
Table 2: Moments Data-Model

Data Model Mean Model $I C$ [5\%, 95\%]

Firm-level moments

\begin{tabular}{lccc}
\hline \hline & & & \\
Growth rates standard deviation & & \\
\hline debt & 0.37 & 0.3 & {$[0.214,0.38]$} \\
employment & 0.15 & 0.22 & {$[0.151,0.333]$} \\
output & 0.2 & 0.17 & {$[0.129,0.231]$} \\
capital & 0.096 & 0.093 & {$[0.0609,0.148]$} \\
& & & \\
Growth rates persistence & & & \\
\hline debt & -0.044 & 0.0034 & {$[0.000186,0.00824]$} \\
employment & 0.054 & 0.02 & {$[-0.0915,0.183]$} \\
output & 0.12 & 0.072 & {$[-0.0746,0.261]$} \\
capital & 0.51 & 0.26 & {$[0.0839,0.46]$} \\
& & & \\
Growth rate correlation & with debt & & {$[1,1]$} \\
\hline debt & 1 & 1 & {$[0.131,0.185]$} \\
employment & 0.2 & 0.15 & {$[0.169,0.21]$} \\
output & 0.046 & 0.034 & \\
capital & 0.19 & 0.19 & \\
Aggregate moments & & & \\
\hline \hline
\end{tabular}

\begin{tabular}{|c|c|c|c|}
\hline \multicolumn{4}{|l|}{ Mean } \\
\hline Investment Rate & 0.14 & 0.15 & {$[0.0671,0.196]$} \\
\hline Credit Spread & 0.41 & 0.18 & {$[0.101,0.27]$} \\
\hline Default Rate & 0.0025 & 0.0057 & {$[0.00316,0.0102]$} \\
\hline Leverage & 0.66 & 0.88 & {$[0.257,1.77]$} \\
\hline \multicolumn{4}{|c|}{ Standard Deviation } \\
\hline Output & 0.016 & 0.015 & {$[0.0127,0.016]$} \\
\hline Employment & 0.011 & 0.012 & {$[0.00827,0.0156]$} \\
\hline Investment & 0.074 & 0.11 & {$[0.0289,0.295]$} \\
\hline Credit spreads & 0.0015 & $4.8 e-05$ & {$[1.94 e-05,9.1 e-05]$} \\
\hline Debt & 0.025 & 0.0023 & {$[0.00219,0.0024]$} \\
\hline \multicolumn{4}{|l|}{ Persistence } \\
\hline Output & 0.85 & 0.84 & {$[0.795,0.87]$} \\
\hline Employment & 0.85 & 0.89 & {$[0.865,0.903]$} \\
\hline Investment & 0.8 & 0.69 & {$[0.635,0.721]$} \\
\hline Credit spreads & 0.76 & 0.74 & {$[0.636,0.78]$} \\
\hline Debt & 0.92 & 0.8 & {$[0.736,0.857]$} \\
\hline \multicolumn{4}{|c|}{ Correlation with Output } \\
\hline Employment & 0.8 & 0.8 & {$[0.736,0.84]$} \\
\hline Investment & 0.84 & 0.78 & {$[0.686,0.857]$} \\
\hline Credit spreads & -0.28 & -0.82 & {$[-0.917,-0.647]$} \\
\hline Debt & 0.32 & 0.072 & {$[0.045,0.105]$} \\
\hline
\end{tabular}


Figure 2: Firm's Impulse Response to Idiosyncratic TFP shock $z$
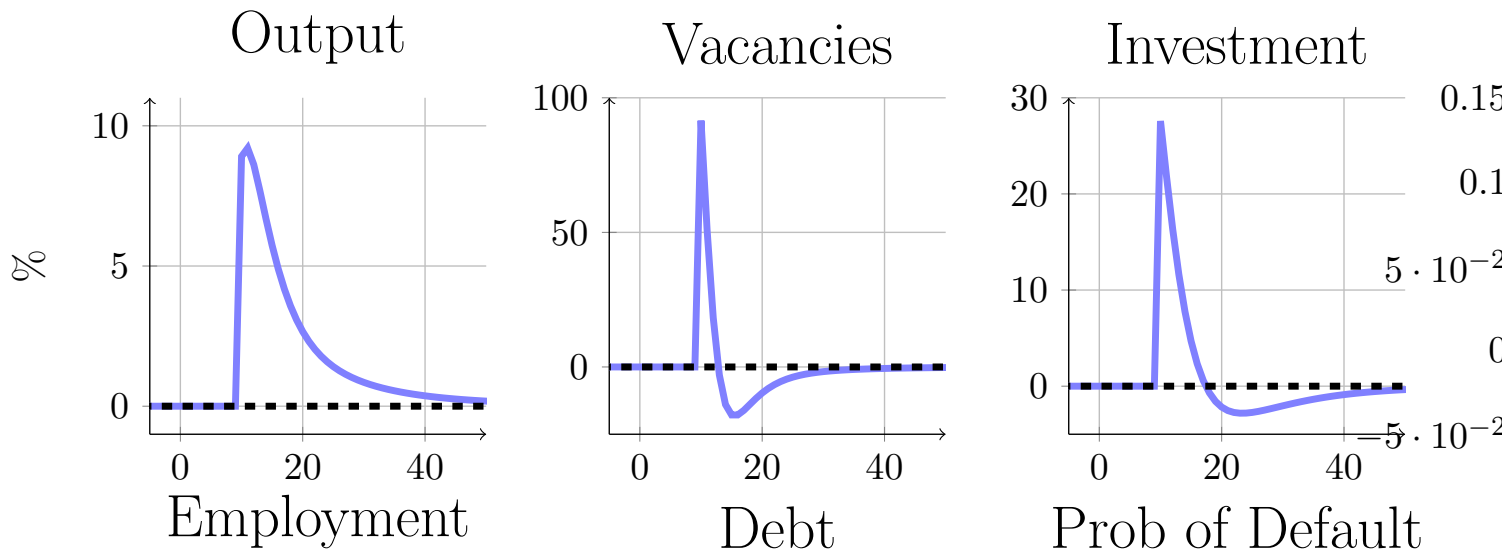

Bond Price
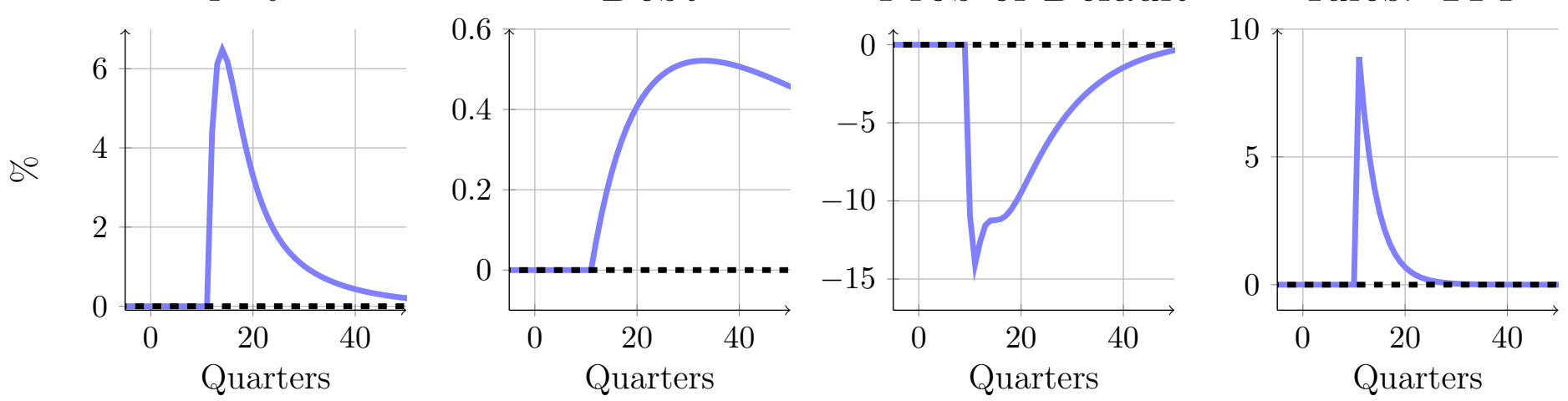


\section{The Financial Value of a Worker}

In this section, we argue that a firm's number of workers increases its market value and reduces its probability to default. We show that our model is consistent with these findings: labor is an asset to the firm, and thus increases its value and decreases its probability to default. Importantly, we show that the a Walrasian labor market cannot account for these facts, and thus conclude that the search friction is crucial.

Empirically establishing the marginal contribution that workers have on a firm's market value is not an easy task. The reason is that, arguably, a firm's number of workers correlates with several characteristics of the firm: for instance, a very productive firm is likely to be more valuable, with more assets and workers. Furthermore, there is also no obvious instrument that is highly correlated with the number of a firm's workers but not with other firm's characteristics.

In order to overcome this omitted variable issue, we proceed by adding several controls that can provide information about the firm's value. After controlling for all these variables, we interpret the remaining correlation as the marginal contribution that the number of workers have on the firm's value.

When selecting controls, we include the state variables suggested by our model, as well as many other variables that our model misses but could account firm's market value. This include news about future performance of the firm; lagged values of the firm's profits; the firm's assets composition; as well as allowing the marginal effect of workers to vary with the firm's size. Our findings are robust to all of these controls: a firm's number of workers has a positive marginal contribution on its market value, and a negative marginal contribution to the firm's probability to default.

We start by discussing the evidence on the marginal effect of workers on the firms' market value and probability to default by only taking into account the model implied state variables. We use this as a benchmark specification to compare our model with. We then move to the robustness exercises in Section 5.3 .

\subsection{Market Value of a Worker}

To understand the effect of employment on the firm's value, we first compute the effect that variables other than employment have on firms' value. We then evaluate how responsive the residual component is to the firm's number of workers. In particular, for both data and model, we estimate the following regression

$$
\ln V_{i t}=\alpha_{i}^{V}+\gamma_{t}^{V}+\beta^{V} X_{i t}+\varepsilon_{i t}^{V}
$$


where $V_{i t}$ is firm's $i$ market value in quarter $t$, and $X_{i t}$ is a set firm specific controls. We select the set of controls guided by our theoretical model described in Section 2. These controls include firm's capital, liabilities, the profits-to-assets ratio and the investment-to-assets ratio. ${ }^{20}$ While total assets and liabilities are meant to capture firms' financial conditions, the inclusion of profits and investment reflect firms' performance (a proxy for productivity). Importantly, other than employment, these variables are enough statistics in our model to describe the firm's problem. We also allow for firms' fixed effects $\left(\alpha_{i}^{V}\right)$ to represent systematic idiosyncratic differences, as well as time dummies $\left(\gamma_{t}^{V}\right)$ to capture aggregate macroeconomic conditions.

Equation (30) has the typical variables that affect firms value in most macro-finance models. Thus, we think of the residuals $\varepsilon_{i t}^{V}$ as the component of the firm's value that cannot be accounted for standard determinants in the literature. We are interested in understanding how these residuals depend on firms' employment. To this end, we estimate an analogous equation for employment. In particular, for both data and model, we estimate

$$
\ln N_{i t}=\alpha_{i}^{N}+\gamma_{t}^{N}+\beta^{N} X_{i t}+\varepsilon_{i t}^{N}
$$

As before, equation (31) regresses employment on typically used controls for the firm $X_{i t}$. Thus, we think of a positive $\varepsilon_{i t}^{E}$ as a firm with employment higher than expected in that quarter.

If employment is not a significant determinant of the firm's value, other than because of it's correlation with variables $X_{i t}$, the residuals $\varepsilon_{i t}^{V}$ and $\varepsilon_{i t}^{N}$ should be uncorrelated. ${ }^{21}$ We show next that this is not the case.

A firm with employment higher than expected, as captured by a positive $\varepsilon_{i t}^{E}$, induces a persistent increase in its market value. Figure 3 shows this by plotting, for different horizons $h$, the estimate $\delta_{h}$ of the following regression using the data panel

$$
\varepsilon_{i, t+h}^{V}=\delta_{0}+\delta_{h}^{V, N} \varepsilon_{i t}^{N}+u_{i, t+h}
$$

In order to test our model, we replicate the same set of regressions (30), (31) and (32) using a modelgenerated panel of firms, both for the unemployment accelerator model as well as with its variation with Walrasian markets. Figure 3 shows that the unemployment accelerator model predicts a positive relation between workers and the firm's market value, in line with the evidence. In this model, workers are an asset

\footnotetext{
${ }^{20}$ See Section 4.2 and Appendix $\mathrm{C}$ for data details, and Appendix E.1 for more details on the regression.

${ }^{21}$ No correlation in the residuals is equivalent to including workers in equation (30) and obtaining a coefficient of zero. This would be the case if $X_{i t}$ contains all relevant information to determine a firm's value.
} 


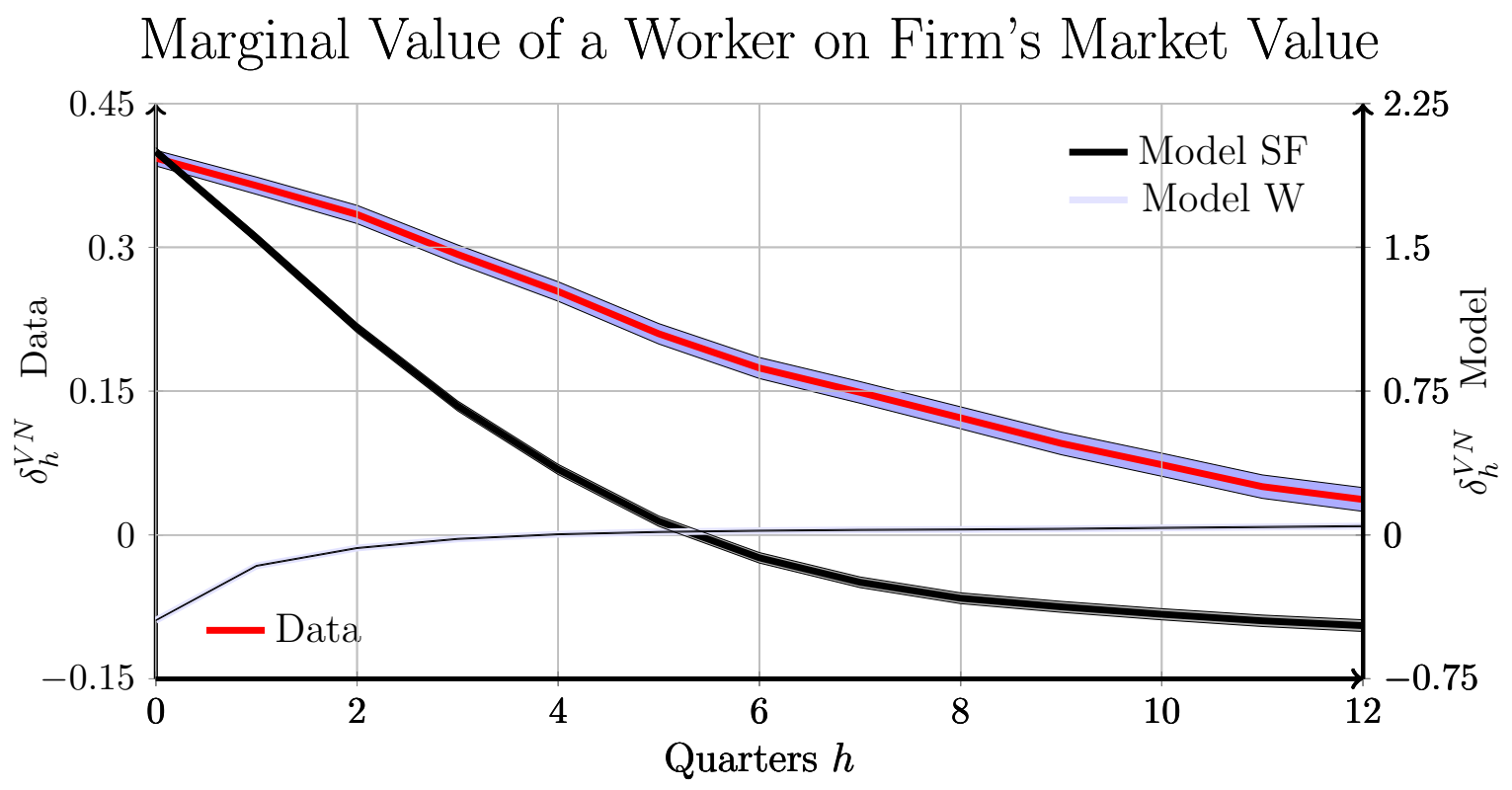

Figure 3: Marginal Value of a Worker on Firm's Market Value

which adds value to the firm. Figure 3 also shows that the Walrasian market model has counterfactual implications; with more workers decreasing the market value of firms. We conclude that the search friction is essential for accounting for our empirical findings.

Although the unemployment accelerator model has the qualitative correct implication, it overstates the marginal effect that workers have on the firm's market value. In the model, a $10 \%$ increase in the number of workers induces a $20 \%$ gain in the firm's market value, while the increase is only $4 \%$ in the data. Better understanding the source of this difference is top priority for our future work in this paper.

\subsection{Worker Effect on Probability of Default}

Next we want to measure the marginal effect that a worker has on the firm's probability to default. We proceed in a similar way as we did before: first, we compute the residual of a firm's probability of default after controlling for several variables but employment, and we then evaluate how this residual depends on the firm's number of workers. In order to do this, we first briefly describe a measure of firm's probability of default in the data, and then move to compare model and data. 


\subsubsection{A Measure of Default Risk}

While in the model we have a clear measure of default risk, this is not the case in the data. To overcome this, we follow the seminar work by Merton (1974), based on the Black-Scholes-Merton option-pricing model, to construct a distance to default measure for all the firms in our panel. The algorithm consists of two steps: first, inferring the firm's assets value given its market value; and second, use an option-price formula to compute the firm's probability of default. Because our computations closely follows the ones in Duffie (2011) and Gilchrist and Zakrajsek (2012), we keep exposition brief. ${ }^{22}$

Let $A_{i d}$ be the total assets value of the firm $i$ on day $d$, and assume that $A_{i d}$ follows a geometric Brownian motion with instantaneous drift $\mu_{i d}^{A}$ and volatility $\sigma_{i d}^{A}$. It is also assumed that firms defaults if its value $A_{i d}$ is below a accounting-liability based measure $L_{i d}$, at some point between date $t$ and $t+T$. $^{23}$ The insight of Merton (1974) is that the firm's equity value $V_{i d}$ can be viewed as an call-option on the underlying value of the firm's assets $A_{i d}$, with a strike price $L_{i d}$, and maturity date $t+T$. Then, the value of equity $V_{i t}$ is give by the Black-Scholes-Merton option-pricing formula as follows

$$
V_{i d}=A_{i d} \Phi\left(d_{i d}^{1}\right)-e^{-r_{t} T} L_{i t} \Phi\left(d_{i d}^{2}\right)
$$

where $r_{t}$ denotes the instantaneous risk-free rate, and $d_{i d}^{1}$ and $d_{i d}^{2}$ are given as

$$
d_{i d}^{1}=\frac{\log \left(A_{i d} / L_{i d}\right)+\left(r_{t}+0.5 \sigma_{i d}^{2}\right) T}{\sigma_{i d}^{2} T} \quad d_{i d}^{2}=d_{i d}^{1}-\sigma_{i d} \sqrt{T}
$$

Operationally, we proceed as follows. The equity value $V_{i d}$ is constructed using daily CRSP data on stock prices. The default threshold $L_{i d}$ is computed as the firm's short-term debt plus one-half of her long-term debt. The source of liabilities data is Compustat at quarterly frequency, and the data is linearly interpolated to obtain daily observations. The risk-free interest rate $r_{t}$ is assumed to be the 10 years US treasury yields. ${ }^{24}$ Finally, to obtain $\left\{\mu_{i d}^{A}, \sigma_{i d}^{A}\right\}$ we follow an iterative procedure: given a guess for $A_{i d}$, we compute $\left\{\mu_{i d}^{A}, \sigma_{i d}^{A}\right\}$ from a 250-days rolling window, and then use equation (33) to obtain a new guess of $A_{i d}$. We iterate until convergence.

\footnotetext{
${ }^{22}$ See Appendix C.3 for more details.

${ }^{23}$ Black-Scholes-Merton original formulation actually assumes that $L_{i d}, \mu_{i d}^{A}$ and $\sigma_{i d}^{A}$ are constants, while we allow for time variation as in Bharath and Shumway (2008).

${ }^{24}$ See Appendix C.3 for details.
} 
Finally, we compute two variables: the distance to default $D F_{i d}$, and the probability to default $\Phi_{i d}$

$$
\begin{aligned}
D F_{i d} & =\frac{\log \left(A_{i d} / L_{i d}\right)+\mu_{i d} T-0.5 \sigma_{i d}^{2} T}{\sigma_{i d} \sqrt{T}} \\
\Phi_{i d} & =\Phi\left(-D F_{i d}\right)
\end{aligned}
$$

Quarterly observation for each variable are taken as averages: $D F_{i t}=\frac{1}{D_{t}} \sum_{d} D F_{i d}$ and $\Phi_{i t}=\frac{1}{D_{t}} \sum_{d} \Phi_{i d}$ for all quarters $t$.

\subsubsection{Evaluating the Effect}

To evaluate the effect of a worker on the firm's probability to default, we proceed in analogous manner as we did in Section 5.2. First, we compute the residual of the firm probability to default after controlling for several firm's variables; Second, we evaluate how this residual depends on the firm number of workers. In particular, we estimate the following equation

$$
\ln \Phi_{i t}=\alpha_{i}^{\Phi}+\gamma_{t}^{\Phi}+\beta^{\Phi} X_{i t}+\varepsilon_{i t}^{\Phi}
$$

where $X_{i t}$ includes the same controls as before. Then, we regress the residual $\varepsilon_{i t}^{\Phi}$ on the one of employment $\varepsilon_{i t}^{N}$ as computed in (31). In particular

$$
\varepsilon_{i, t+h}^{\Phi}=\delta_{0}+\delta_{h}^{\Phi, N} \varepsilon_{i t}^{N}+u_{i, t+h}
$$

As we did with market value, we replicate the same set of regressions using model-generated data, and the variation of the model with Walrasian markets. Figure 4 shows the results for data and both models. As before, the unemployment accelerator model can replicate the negative empirical relation between number of workers and firm's probability to default. However, the Walrasian market model predicts a relation opposite to one found in data; with more workers increasing the firm's probability to default. We conclude that the search friction is essential for accounting for our empirical findings.

As was the case with market value, the unemployment accelerator model over predicts the marginal effect of workers. In the data, a $10 \%$ increase in the number of workers induces a $6 \%$ decrease in the firm's probability to default, while the decline is $20 \%$ in the model. This is the same problem we found in the previous section. 


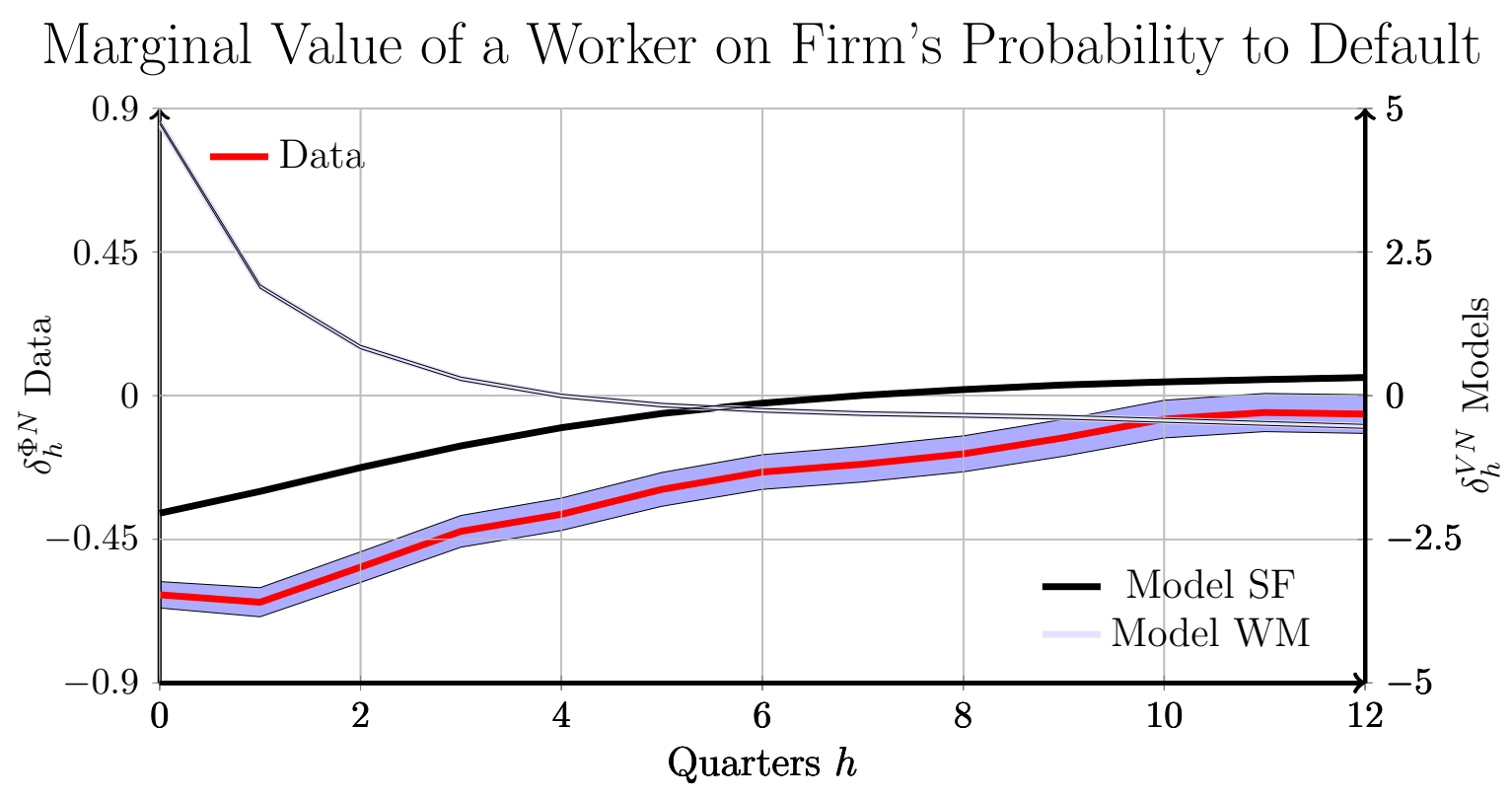

Figure 4: Marginal Value of a Worker on Firm's Probability to Default

\subsection{The Financial Value of a Worker: Model-Data Comparison and a Robust- ness}

In Sections 5.1 and 5.2 above, we estimated the marginal effect of a worker under the cross-equation restrictions implied by our model. In particular, our model guided the selection of controls $X_{i t}$ used in equations (30) and (35). Naturally, the model abstracts from several features that, if present in data, could bias our results. This section discusses potential model misspecification that could implied a bias in our estimation above, and how to control for these. We show that our results are robust to controlling for these misspecification: a firm's number of workers significantly increase as its market value and decreases its probability to default.

In particular, we estimate a regression of the following form

$$
\ln y_{i t}=\alpha_{i}^{y}+\gamma_{t}^{y}+\beta^{y} X_{i t}+\vartheta_{N}^{y} \ln N_{i t}+\zeta_{i t}^{y}
$$

where $y_{i t}$ can either be the market value of a firm, or its probability of default. We interpret the coefficient $\vartheta_{N}$ as the marginal effect that employment has on $y_{i t}$ after controlling for firms' states $X_{i t} .{ }^{25}$ The estimate for $\vartheta_{N}^{y}$ will naturally depend on what variables we decide to include as controls in $X_{i t}$. Unlike in previous

\footnotetext{
${ }^{25}$ The $\log$-log nature of equation (37) allows to interpret $\vartheta_{N}$ as an elasticity.
} 
sections, we include additional controls in $X_{i t}$ to account for alternative model misspecification. See Table 22 for the robustness exercises with probability of default and Table 25 for the robustness exercises with market value and more details in Appendix E.2. See appendix E.1 for the robustness exercises with the specifications as in section 5.1 and 5.2.

A first source of bias could arise from a misspecification of the persistence component of productivity. For instance, if firm's productivity depends on several of its lags, this period profits and investment would not contain enough information about the firm's future profitability. In this case, market value and number of workers could exhibit a positive relation because both respond to an information about productivity not included in our controls. In order to control for this source of bias, we add lags of profits to our controls. We find that the value of a worker is robust to this additional controls.

A second source of bias could arise if firms, or market participants, have some information or signals about future firms' profitability. Good news about the future, for instance, could induce a firm to hire more and simultaneously experience an increase in its market value. This would imply our found correlation, but because of a different mechanism. In order to control for this, we include future profits in our controls.

A third source of bias could arise if the firms assets composition affects the firm's value. For instance, a very illiquid firm may experience a decrease in its market value, and persistently lower hiring rates. In order to control for this source of bias, we include several measures of the firms portfolio as controls, such as; total assets, physical assets and liquid assets. ${ }^{26}$ We find that the value of a worker is robust to this additional controls.

A final source of potential bias could from the existence of customer capital. For instance, higher sales today may enlarge the firm's costumers base and increase future profitability. In this case, a firm's market value and its number workers may exhibit a positive correlation even after controlling for the firm's assets. In order to control for this source of bias, we add total sales as a control variable, which are not perfectly correlated with number of workers. Again, we find that the value of a worker is robust to this additional controls.

The computations we have done so far estimate the average effect that a marginal worker has on the firm's market value or its probability to default. However, this effect could in principle vary with the firm's size. To test robustness across firms size distribution, Appendix E.5 divides firms into quantiles depending either on the firm's assets size or employment size, and repeats the previous exercises. We find evidence of the unemployment accelerator across the spectrum of firms size distribution.

As a result of these robustness checks, we conclude that there exist a significant positive relation between

\footnotetext{
${ }^{26}$ Notice that, in regressions of Section 5.1 and Section 5.2.1, we only had included physical capital.
} 


\begin{tabular}{|c|c|c|c|c|c|c|c|}
\hline Variable & $\mathrm{UA}$ & WM & I & II & III & IV & $\mathrm{V}$ \\
\hline Workers & $1.34^{* * *}$ & $-0.45^{* * *}$ & $0.40^{* * *}$ & $0.39^{* * *}$ & $0.38^{* * *}$ & $0.10^{* * *}$ & $0.20^{* * *}$ \\
\hline Capital & $1.66^{* * *}$ & $7.59^{* * *}$ & $0.35^{* * *}$ & $0.35^{* * *}$ & $0.36^{* * *}$ & $0.22^{* * *}$ & $0.63^{* * *}$ \\
\hline Assets & - & - & - & - & - & $0.60^{* * *}$ & - \\
\hline Debt & $0.19^{* * *}$ & $-5.93^{* * *}$ & $-0.06^{* * *}$ & $-0.05^{* * *}$ & $-0.06^{* * *}$ & $-0.12^{* * *}$ & $-0.08^{* * *}$ \\
\hline Profits & $2.40^{* * *}$ & $-1.11^{* * *}$ & $0.22^{* * *}$ & $0.22^{* * *}$ & $0.33^{* * *}$ & $0.07^{* * *}$ & $0.05^{* * *}$ \\
\hline Profits $L$ & - & - & - & $0.39^{* * *}$ & - & - & - \\
\hline Profits $L^{2}$ & - & - & - & $0.68^{* * *}$ & - & - & - \\
\hline Profits $L^{3}$ & - & - & - & $1.03^{* * *}$ & - & - & - \\
\hline Profits $F$ & - & - & - & - & $0.39^{* * *}$ & - & - \\
\hline Profits $F^{2}$ & - & - & - & - & $0.17^{* * *}$ & - & - \\
\hline Profits $F^{3}$ & - & - & - & - & $0.09^{* * *}$ & - & - \\
\hline Invest. rate & $6.28^{* * *}$ & $54.80^{* * *}$ & $0.01^{* * *}$ & $0.00^{* *}$ & $0.04^{* * *}$ & $0.01^{* * *}$ & $0.06^{* * *}$ \\
\hline Liquid assets & - & - & - & - & - & $0.01^{* * *}$ & - \\
\hline Sales & - & - & - & - & - & - & $0.33^{* * *}$ \\
\hline N obs & 153302 & 152913 & 160761 & 145249 & 142585 & 157896 & 159615 \\
\hline$R^{2}$ & 0.817 & 0.977 & 0.726 & 0.724 & 0.730 & 0.811 & 0.759 \\
\hline
\end{tabular}

the value of a firm and its number of workers. Similarly, there is a significant negative relation between the expected probability of default and the number of workers. These results are robust across several features in the data that our model abstracts from. This suggests that workers act as an asset to the firm, in the same manner that capital does. This is the new fact we provide, together with a model that is capable of replicating this relation.

\subsection{The Value of Capital: Model-Data Comparison}

We repeat the exercises of Section 5.1 and 5.2 by using physical capital instead of employment. This is, we estimated the marginal contribution that physical capital adds to a firm's market value, after controlling for several variables including employment. Not surprisingly, we find that capital adds value to the firm as well as declines the firm's probability of default: a $10 \%$ increase in the firm's capital induces a $3.5 \%$ increase in the firms market value, and a $3.5 \%$ decrease in its probability of default.

In this dimension, both the unemployment accelerator model and the Walrasian market model have very similar implications. In both models, the capital increases the firm's market value and decreases its probability of default. Appendix E.3 contains details of the empirical exercises, and of the model-data comparison. 


\section{Conclusion}

We developed the unemployment accelerator, a new mechanism in which workers affects directly firms' financial conditions. We provided persuasive micro-evidence of the unemployment accelerator, and a model that can account for the empirical findings. We showed that a search friction in the labor market is eesential for this. We conclude that labor acts as an assets for firms, determining its value and default riskiness. 


\section{References}

Abel, A. (2015). Optimal Debt and Profitability in the Tradeoff Theory. Working paper, Wharton School of the University of Pennsylvania.

Andreasen, M., Fernandez-Villaverde, J. and Rubio-Ramirez, J. (2016). The Pruned State-Space System for Non-Linear DSGE Models: Theory and Empirical Applications. Working paper.

Arellano, C., Bai, Y. and Kehoe, P. (2011). Financial Markets and Fluctuations in Uncertainty. Federal reserve bank of minneapolis, research department staff report, Federal Reserve Bank of Minneapolis and Arizona State University.

- and Ramanarayanan, A. (2012). Default and the maturity structure in sovereign bonds. Journal of Political Economy, 120 (2), 187-232.

Bazdresch, S., Belo, F. and Lin, X. (2014). Labor hiring, investment, and stock return predictability in the cross section. Journal of Political Economy, 122 (1), 129-177.

Bharath, S. T. and Shumway, T. (2008). Forecasting default with the merton distance to default model. Review of Financial Studies, 21 (3), 1339-69.

Buera, F. J., Fattal-Jaef, R. and Shin, Y. (2013). Anatomy of a Credit Crunch: from Capital to Labor Markets. Working paper.

Chernozhukov, V. and Hong, H. (2003). An \{MCMC $\}$ approach to classical estimation. Journal of Econometrics, 115 (2), 293 - 346.

Chodorow-Reich, G. (2014). The employment effects of credit market disruptions: Firm-level evidence from the 2008-09 financial crisis. Quarterly Journal of Economics, 129, 1-59.

- and Karabarbounis, L. (2013). The cyclicality of the opportunity cost of employment. Tech. rep., National Bureau of Economic Research.

Davis, S. J., Haltiwanger, J., Jarmin, R. and Miranda, J. (2006). Volatility and Dispersion in Business Growth Rates: Publicly Traded versus Privately Held Firms. Nber working paper.

Duffie, D. (2011). Measuring Corporate Default Risk (Clarendon Lectures in Finance). Oxford University Press, 1st edn.

Favilukis, J., Lin, X. and Zhao, X. (2015). The Elephant in the Room: the Impact of Labor Obligations on Credit Risk. Working paper.

Garin, J. (2011). Borrowing Constraints, Collateral Fluctuations, and the Labor Market. Working paper, University of Notre Dame.

Gertler, M. and Kiyotaki, N. (2009). Financial intermediation and credit policy in business cycle analysis. Handbook of Monetary Economics.

Gilchrist, S. and Zakrajsek, E. (2012). Credit spreads and business cycle fluctuations. American Economic Review.

Giroud, X. and Mueller, H. M. (2014). Firm Leverage and Unemployment during the Great Recession. Working paper.

Gomes, J. F., Jermann, U. J. and Schmid, L. (2013). Sticky Leverage. Working paper. 
Graham, J. R. and Leary, M. T. (2011). A review of empirical capital structure research and directions for the future. Annual Review of Financial Economics, 3 (1), 309-345.

Hatchondo, J. C. and Martinez, L. (2009). Long-duration bonds and sovereign defaults. Journal of International Economics, 79 (1), 117 - 125.

Hennessy, C. A. and Whited, T. M. (2007). How costly is external financing? evidence from a structural estimation. Journal of Finance, 62 (4), 1705-1745.

Jarosch, G. (2015). Searching for Job Security and the Consequences of Job Loss. Working paper.

KaAs, L. and Kircher, P. (2015). Efficient firm dynamics in a frictional labor market. American Economic Review, 105 (10), 3030-60.

Lamadon, T. (2014). Productivity shocks, Optimal Contracts and Income Dynamics. Tech. rep.

Lise, J. (2012). On-the-job search and precautionary savings. The Review of Economic Studies, 80.

-, Meghir, C. and Robin, J.-M. (2016). Matching, sorting and wages. Review of Economic Dynamics, 19, 63 - 87, special Issue in Honor of Dale Mortensen.

— and Robin, J.-M. (2016). The Macro-dynamics of Sorting between Workers and Firms. Tech. rep.

Merton, R. C. (1974). On the pricing of corporate debt: The risk structure of interest rates. The Journal of Finance, 29 (2), 449-470.

Miao, J. and Wang, P. (2010). Credit Risk and Business Cycles. Working paper.

Monacelli, T., Quadrini, V. and Trigari, A. (2011). Financial Markets and Unemployment. Working paper.

Mortensen, D. T. and Pissarides, C. A. (1994). Job creation and job destruction in the theory of unemployment. Review of Economic Studies, pp. 397-415.

NaVArro, G. (2015). Financial Crises and Endogenous Volatility. Working paper.

Petrosky-Nadeau, N. (2011). Credit, Vacancies and Unemployment Fluctuations. Working paper, Carnegie Mellon University.

Pissarides, C. A. (1985). Short-run equilibrium dynamics of unemployment, vacancies, and real wages. American Economic Review, 74 (4), 676-690.

SchaAl, E. (2015). Uncertainty and Unemployment. Tech. rep.

Shimer, R. (2005). The cyclical behavior of equilibrium unemployment and vacancies. American Economic Review, 95, 25-49.

Strebulaev, I. A. and YAng, B. (2013). The mystery of zero-leverage firms. Journal of Financial Economics, 109 (1), 1-23. 


\section{A Model: Additional Details}

This section describes the investor problem in the models with search frictions - see A.1 - and the model with Walrasian labor markets-see A.2.

\section{A.1 Investor's Problem}

There is a continuum of investors with linear preferences over consumption with a discount factor given by $\beta$. Let $V(\Lambda, \omega)$ be the value of an investor with wealth $\omega$ and aggregate state $\Lambda$. Then

$$
\mathcal{I}(\Lambda, \omega)=\max _{\left\{C, b^{\prime}(h, z)\right\}}\left\{C+\beta \mathbb{E}_{\Lambda^{\prime}, F^{\prime}}\left[\mathcal{I}\left(\Lambda^{\prime}, \omega^{\prime}\right) \mid \Lambda\right]\right\}
$$

subject to

$$
\begin{aligned}
\omega & \geq C+\frac{1}{\psi(X)} \int_{\tilde{s}} Q\left(h^{\prime}, \Lambda, z\right) b^{\prime}(\tilde{s}) d \tilde{s}-\int d(s) d \mu(s) \\
\omega^{\prime} & =\int_{\tilde{s}, s^{\prime}}\left(1-\chi\left(\Lambda^{\prime}, s^{\prime}, F^{\prime}\right)\right)\left(c+\lambda+(1-\lambda) Q\left(h^{\prime}\left(h^{\prime}, z^{\prime}\right), \Lambda^{\prime}, z^{\prime}\right)\right) b^{\prime}(\tilde{s}) d \mu\left(s^{\prime} \mid \tilde{s}\right) d \tilde{s} \\
& +\int_{\tilde{s}, s^{\prime}} \chi\left(\Lambda^{\prime}, s^{\prime}, F^{\prime}\right)\left(\theta k^{\prime} \frac{b^{\prime}(\tilde{s})}{b^{\prime}}\right) d \mu\left(s^{\prime} \mid \tilde{s}\right) d \tilde{s}
\end{aligned}
$$

where $h^{\prime}=\left(B^{\prime}, K^{\prime}, N^{\prime}\right)$ is the period choice of debt, capital, and labor; $\tilde{s}=\left(h^{\prime}, z\right)$ is the period choice together with period productivity; $\mu\left(s^{\prime} \mid \tilde{s}\right)$ is the conditional distribution of the firm's state next period conditional on $\tilde{s}$. The first line is the investor budget constraint. The total income is given by firms' profit and initial wealth. The total expenditure is given by consumption plus the investment in the corporate bonds. Notice that the asset structure of this economy is extremely large. In particular, the investor is choosing to invest its wealth from a continuum of bonds indexed by $\left(h^{\prime}, z\right)$-firms' idiosyncratic state. The demand for bonds is denoted by $b^{\prime}\left(h^{\prime}, z\right)$. For no defaulting firms, each bond has a period payment equal to a coupon plus the maturity of the bond; plus the continuation value of the non-maturing bonds given by

the re-selling price. For the defaulting firms, each investor keep a fraction $\theta \frac{b^{\prime}\left(h^{\prime}, z\right)}{b^{\prime}}$ of the capital, where the former ratio represent the ratio debt hold by the investor with respect to the total.

\section{A.2 A Walrasian Labor Market Model}

In the models with walrasian market there are three agents: workers, investors and firms. Preferences, technology and debt contracts are the same as the model of search frictions, we only change the frictional labor market with walrasian labor where the firms take as given the wages. Given the preferences and technology, it is easy to see that the real wage in this economy is exogenous. I denote $w(X)$ the real wage 
of the economy. Next, we will describe each agent problem.

- Firms: let $\mathcal{F}(X, s, F)$ be the value of the firms with state $s=(B, K, N, z)$ when the aggregate state is $X$ and the fixed cost is $F$. Then

$$
\mathcal{F}(X, s, F)=\max _{d, I, H, b^{\prime}, \chi}\left\{d+\beta \mathbb{E}_{X^{\prime}}\left[\left\{\mathcal{F}\left(X^{\prime}, s^{\prime}, F^{\prime}\right)\right\}^{+} \mid X, z\right]\right\}
$$

subject to

$$
\begin{aligned}
\mathcal{P} & =\eta z K^{\alpha \nu} N^{(1-\alpha) \nu}-w(X) N-F_{K} K-F-[(1-\tau) c+\lambda] B \\
\pi & =-I+Q\left(B^{\prime}, K^{\prime}, N^{\prime}, z, \Lambda\right) b^{\prime}-\mathcal{C}^{K}(I, K)-\mathcal{C}^{N}\left(N^{\prime}, N\right)-\mathcal{C}^{B}\left(b^{\prime}, B\right) \\
d & \leq \mathcal{P}+\pi \\
K^{\prime} & =I+\left(1-\delta_{K}\right) K, \quad B^{\prime}=(1-\lambda) B+b^{\prime}
\end{aligned}
$$

where $\mathcal{C}^{N}\left(N^{\prime}, N\right)$ is the adjustment cost on labor and $w(X) N$ is the total labor cost.

- Investors: let $\mathcal{I}(X, s, F)$ be the value of an investor with wealth $\omega$ and aggregate state $\Lambda$. Then

$$
\mathcal{I}(X, \omega)=\max _{\left\{C, b^{\prime}(h, z)\right\}}\left\{C+\beta \mathbb{E}_{X^{\prime}, F^{\prime}}\left[\mathcal{I}\left(X^{\prime}, \omega^{\prime}\right) \mid X\right]\right\}
$$

subject to

$$
\begin{aligned}
\omega & \geq C+\frac{1}{\psi(X)} \int_{\tilde{s}} Q\left(h^{\prime}, X, z\right) b^{\prime}(\tilde{s}) d \tilde{s}-\int d(s) d \mu(s) \\
\omega^{\prime} & =\int_{\tilde{s}, s^{\prime}}\left(1-\chi\left(X^{\prime}, s^{\prime}, F^{\prime}\right)\right)\left(c+\lambda+(1-\lambda) Q\left(h^{\prime}\left(h^{\prime}, z^{\prime}\right), X^{\prime}, z^{\prime}\right)\right) b^{\prime}(\tilde{s}) d \mu\left(s^{\prime} \mid \tilde{s}\right) d \tilde{s} \\
& +\int_{\tilde{s}, s^{\prime}} \chi\left(X^{\prime}, s^{\prime}, F^{\prime}\right)\left(\theta k^{\prime} \frac{b^{\prime}(\tilde{s})}{b^{\prime}}\right) d \mu\left(s^{\prime} \mid \tilde{s}\right) d \tilde{s}
\end{aligned}
$$

See subsection A.1 for a description of this problem

- Workers: there are a continuum of workers with complete markets within them. They are hand-tomouth consumer. Let $\mathcal{W}(X)$ be the value functions of a worker with an aggregate state $\mathrm{X}$, then

$$
\mathcal{W}(X)=\max _{\left.C, b^{\prime}(h, z)\right\}}\left\{C-\Theta(X) N+\beta \mathbb{E}_{X^{\prime}, F^{\prime}}\left[\mathcal{W}\left(X^{\prime}, \omega^{\prime}\right) \mid X\right]\right\}
$$

subject to

$$
w(X) N \geq C
$$

Since in equilibrium $w(X)=\Theta(X)$, we have the equilibrium conditions described in subsection 3.3. 


\section{B Model: Computation Details}

This section describes the equilibrium equations for the model together with its derivation - see subsection B.1; the equilibrium equations with the calibrated adjustment cost together with the steady state the steady state - see section B.2; and the full description of the numerical algorithm to solve the firms policy functionsee section B.3.

\section{B.1 Model Equilibrium Equations Derivation}

The firm original problem is given by

$$
\begin{aligned}
\mathcal{S}(X, s, F) & =\max _{d, I, H, b^{\prime}, \chi}\left\{d+\beta \mathbb{E}_{X^{\prime}}\left[\left\{\mathcal{S}\left(X^{\prime}, s^{\prime}, F^{\prime}\right)\right\}^{+} \mid X, z\right]\right\} \\
\text { subject to } \mathcal{P} & =\eta z K^{\alpha \nu} N^{(1-\alpha) \nu}-\bar{u}(X) N-F_{K} K-F-[(1-\tau) c+\lambda] B \\
\pi & =-I+Q\left(B^{\prime}, K^{\prime}, N^{\prime}, z, \Lambda\right) b^{\prime}-\mathcal{C}^{K}(I, K)-\mathcal{C}^{N}(H, N)-\mathcal{C}^{B}\left(b^{\prime}, B\right) \\
d & \leq \mathcal{P}+\pi \\
N^{\prime} & =\left(1-\delta_{N}\right) N+H \\
K^{\prime} & =I+\left(1-\delta_{K}\right) K, \quad B^{\prime}=(1-\lambda) B+b^{\prime}
\end{aligned}
$$

From proposition 3 we have that

$$
\begin{aligned}
v(s, X) & =\max _{K^{\prime}, N^{\prime}, B^{\prime}}\left\{-\left[K^{\prime}-\left(1-\delta_{K}\right) K\right]-\mathcal{C}_{K}\left(K^{\prime}-\left(1-\delta_{K}\right) K, K\right)-\mathcal{C}_{N}\left(N^{\prime}-\left(1-\delta_{N}\right) N, N\right)\right. \\
& +Q\left(B^{\prime}, K^{\prime}, N^{\prime}, z, X\right)\left[B^{\prime}-(1-\lambda) B\right]-\mathcal{C}_{B}\left(B^{\prime}-(1-\lambda) B, B\right) \\
& \left.+\beta \mathbb{E}_{z^{\prime}, X^{\prime}}\left[\int_{-\infty}^{\underline{F}\left(s^{\prime}, X^{\prime}\right)} x^{\prime} \eta^{\prime} K^{\prime \alpha \nu} N^{\prime(1-\alpha) \nu}-\bar{u} N^{\prime}-F_{K} K^{\prime}-F-\tilde{\lambda} B^{\prime}+v\left(s^{\prime}, z^{\prime}, X^{\prime}\right) \mid z, X\right]\right\}
\end{aligned}
$$


The firm optimality conditions for capital, labor and debt are given by

$$
\begin{aligned}
& 1+\mathcal{C}_{K, 1}\left(K^{\prime}-\left(1-\delta_{K}\right) K, K\right)=Q_{K}\left(B^{\prime}, K^{\prime}, N^{\prime}, z, X\right)\left[B^{\prime}-(1-\lambda) B\right] \\
& +\beta \mathbb{E}_{z^{\prime}, X^{\prime}}\left[G\left(\underline{F}\left(B^{\prime}, K^{\prime}, N^{\prime}, z^{\prime}, X^{\prime}\right)\right)\left\{\alpha \nu z^{\prime} \eta^{\prime} K^{\prime \alpha \nu-1} N^{\prime(1-\alpha) \nu}-F_{K}+v_{K}\left(s^{\prime}, z^{\prime}, X^{\prime}\right)\right\} \mid z, X\right] \\
& \mathcal{C}_{N, 1}\left(N^{\prime}-\left(1-\delta_{n}\right) N, H\right)=Q_{N}\left(B^{\prime}, K^{\prime}, N^{\prime}, z, X\right)\left[B^{\prime}-(1-\lambda) B\right] \\
& +\beta \mathbb{E}_{z^{\prime}, X^{\prime}}\left[G\left(\underline{F}\left(B^{\prime}, K^{\prime}, N^{\prime}, z^{\prime}, X^{\prime}\right)\right)\left\{(1-\alpha) \nu z^{\prime} \eta^{\prime} K^{\prime \alpha \nu} N^{\prime(1-\alpha) \nu-1}-\bar{u}+v_{N}\left(s^{\prime}, z^{\prime}, X^{\prime}\right)\right\} \mid z, X\right] \\
& Q\left(B^{\prime}, K^{\prime}, N^{\prime}, z, X\right)+Q_{B}\left(B^{\prime}, K^{\prime}, N^{\prime}, z, X\right)\left[B^{\prime}-(1-\lambda) B\right]-\phi_{B}\left(B^{\prime}, B\right) \\
& =\beta \mathbb{E}_{z^{\prime}, X^{\prime}}\left[G\left(\underline{F}\left(B^{\prime}, K^{\prime}, N^{\prime}, z^{\prime}, X^{\prime}\right)\right)\left\{\tilde{\lambda}+v_{B}\left(s^{\prime}, z^{\prime}, X^{\prime}\right)\right\} \mid z, X\right]
\end{aligned}
$$

where $\tilde{\lambda}=(1-\tau) c+\lambda$. Using Benveniste and Scheinkman

$$
\begin{aligned}
v_{B}(s, z, X) & =-(1-\lambda) Q\left(B^{\prime}, K^{\prime}, N^{\prime}, x\right)+(1-\lambda) \mathcal{C}_{B, 1}\left(B^{\prime}-\left(1-\delta_{b}\right) B, B\right)-\mathcal{C}_{B, 2}\left(B^{\prime}-\left(1-\delta_{b}\right) B, B(47)\right. \\
v_{K}(s, z, X) & =\left(1-\delta_{K}\right)+\left(1-\delta_{k}\right) \mathcal{C}_{K, 1}\left(K^{\prime}-\left(1-\delta_{k}\right) K, K\right)-\mathcal{C}_{K, 2}\left(K^{\prime}-\left(1-\delta_{K}\right) K, K\right) \\
v_{N}(s, z, X) & =\left(1-\delta_{n}\right) \mathcal{C}_{N, 1}\left(N^{\prime}-\left(1-\delta_{n}\right) N, N\right)-\mathcal{C}_{n, 2}\left(K^{\prime}-\left(1-\delta_{n}\right) N, N\right)
\end{aligned}
$$

Given a price function for debt

$$
\begin{aligned}
Q\left(B^{\prime}, K^{\prime}, N^{\prime}, X, z\right) & =\xi \beta \mathbb{E}_{X^{\prime}, z^{\prime}}\left[G\left(\underline{\boldsymbol{F}}\left(X^{\prime}, s^{\prime}\right)\right)\left[c+\lambda+(1-\lambda) Q\left(\boldsymbol{B}^{\prime}\left(X^{\prime}, s^{\prime}\right), \boldsymbol{K}^{\prime}\left(X^{\prime}, s^{\prime}\right), \boldsymbol{N}^{\prime}\left(X^{\prime}, s^{\prime}\right), X^{\prime}, z^{\prime}\right)\right]\right. \\
& \left.+\left[1-G\left(\underline{\boldsymbol{F}}\left(X^{\prime}, s^{\prime}\right)\right)\right] \theta \frac{K^{\prime}}{B^{\prime}} \mid X, z\right]
\end{aligned}
$$


The bond price function derivatives are given by

$$
\begin{aligned}
Q_{B}(\cdot) & =\beta \xi \mathbb{E}_{z^{\prime}, X^{\prime}}\left[g(\underline{\boldsymbol{F}}(\cdot)) \underline{\boldsymbol{F}}_{B}(\cdot)\{[c+(1-\lambda) Q(\cdot)]\} \mid z, X\right] \\
& +\beta \xi \mathbb{E}_{z^{\prime}, X^{\prime}}\left[G(\underline{\boldsymbol{F}}(\cdot))(1-\lambda)\left\{Q_{B}(\cdot) \frac{B^{\prime}}{B} \boldsymbol{E}_{B B}(\cdot)+Q_{K}(\cdot) \frac{K^{\prime}}{B} \boldsymbol{E}_{K B}(\cdot)+Q_{N}(\cdot) \frac{N^{\prime}}{B} \boldsymbol{E}_{N B}(\cdot)\right\} \mid z, X\right] \\
& +\beta \xi \mathbb{E}_{z^{\prime}, X^{\prime}}\left[g(\underline{\boldsymbol{F}}(\cdot)) \underline{\boldsymbol{F}}_{B}(\cdot) \theta \frac{K^{\prime}}{\left(B^{\prime}\right)^{2}} \mid z, X\right] \\
Q_{K}(\cdot) & =\beta \psi \mathbb{E}_{z^{\prime}, X^{\prime}}\left[g(\underline{\boldsymbol{F}}(\cdot)) \underline{\boldsymbol{F}}_{K}(\cdot)\{[c+(1-\lambda) Q(\cdot)]\} \mid z, X\right] \\
& +\beta \xi \mathbb{E}_{z^{\prime}, X^{\prime}}\left[G(\underline{\boldsymbol{F}}(\cdot))(1-\lambda)\left\{Q_{B}(\cdot) \frac{B^{\prime}}{K} \boldsymbol{E}_{B K}(\cdot)+Q_{K}(\cdot) \frac{K^{\prime}}{K} \boldsymbol{E}_{K K}(\cdot)+Q_{N}(\cdot) \frac{N^{\prime}}{K} \boldsymbol{E}_{N K}(\cdot)\right\} \mid x, Z\right] \\
& -\beta \xi \mathbb{E}_{z^{\prime}, X^{\prime}}\left[g(\underline{\boldsymbol{F}}(\cdot)) \underline{\boldsymbol{F}}_{K}(\cdot) \theta \frac{1}{B^{\prime}} \mid z, X\right] \\
Q_{N}(\cdot) & =\beta \psi \mathbb{E}_{z^{\prime}, X^{\prime}}\left[g(\underline{\boldsymbol{F}}(\cdot)) \underline{\boldsymbol{F}}_{N}(\cdot)\{[c+(1-\lambda) Q(\cdot)]\} \mid x\right] \\
& +\beta \xi \mathbb{E}_{x^{\prime}}\left[G(\underline{\boldsymbol{F}}(\cdot))(1-\lambda)\left\{Q_{B}(\cdot) \frac{B^{\prime}}{N} \boldsymbol{E}_{B N}(\cdot)+Q_{K}(\cdot) \frac{K^{\prime}}{N} \boldsymbol{E}_{K N}(\cdot)+Q_{N}(\cdot) \frac{N^{\prime}}{N} \boldsymbol{E}_{N N}(\cdot)\right\} \mid z, X\right]
\end{aligned}
$$

where $\boldsymbol{E}_{\boldsymbol{X}^{\prime} Y}(\cdot)=\frac{\partial \boldsymbol{X}^{\prime}(\cdot)}{\partial Y} \frac{Y}{\boldsymbol{X}^{\prime}(\cdot)}$ is the elasticity of policy $\boldsymbol{X}^{\prime}(\cdot)$ with respect to $Y$.

\section{B.2 Model Equilibrium Equations and Steady State}

This section shows the equilibrium equations in the calibrated version of our model. We used the functional equations for the adjustment cost:

$$
\begin{aligned}
\mathcal{C}_{K}\left(K^{\prime}-\left(1-\delta_{K}\right) K, K\right) & =\frac{\phi_{K}}{2}\left(\frac{K^{\prime}-K}{K}\right)^{2} \\
\mathcal{C}_{N}\left(N^{\prime}-\left(1-\delta_{n}\right) N, N\right) & =\kappa\left(N^{\prime}-\left(1-\delta_{n}\right) N\right)+\frac{\phi_{n}}{2}\left(\frac{N^{\prime}-N}{N}\right)^{2} \\
\mathcal{C}_{B}\left(B^{\prime}-(1-\lambda) B, B\right) & =\frac{\phi_{B}}{2}\left(\frac{B^{\prime}-B}{B}\right)^{2}
\end{aligned}
$$


Since we are using a second order approximation of the equilibrium conditions we have that

$$
\begin{aligned}
g(F) & \approx g\left(F_{s s}\right)+g^{\prime}\left(F_{s s}\right)\left(F-F_{s s}\right)+\frac{g^{\prime \prime}\left(F_{s s}\right)}{2}\left(F-F_{s s}\right)^{2} \\
& =g_{s s}+g_{s s 1}\left(F-F_{s s}\right)+\frac{\left.g_{s s 2}\right)}{2}\left(F-F_{s s}\right)^{2} \\
G(F) & =\int_{-\infty}^{F} g(x) d x \\
& \approx G\left(F_{s s}\right)+g\left(F_{s s}\right)\left(F-F_{s s}\right)+\frac{g^{\prime}\left(F_{s s}\right)}{2}\left(F-F_{s s}\right)^{2} \\
& =G_{s s}+g_{s s}\left(F-F_{s s}\right)+\frac{g_{s s 1}}{2}\left(F-F_{s s}\right)^{2} \\
F^{e}(F) & =\int_{-\infty}^{F} x g(x) d x \\
& \approx F^{e}\left(F_{s s}\right)+F_{s s} g\left(F_{s s}\right)\left(F-F_{s s}\right)+\frac{g\left(F_{s s}\right)+F_{s s} g^{\prime}\left(F_{s s}\right)}{2}\left(F-F_{s s}\right)^{2} \\
& =F_{s s}^{e}+F_{s s} g_{s s}\left(F-F_{s s}\right)+\frac{g_{s s}+F_{s s} g_{s s 1}}{2}\left(F-F_{s s}\right)^{2}
\end{aligned}
$$

Each aggregate and idiosyncratic exogenous shocks follow

$$
\begin{aligned}
& \ln z_{t}=\rho_{z} \ln z_{t-1}+\sigma_{z} \epsilon_{z, t} \\
& \ln \eta_{t}=\rho_{\eta} \ln \eta_{t-1}+\sigma_{\eta} \epsilon_{x, t} \\
& \ln \xi_{t}=\rho_{\psi} \ln \xi_{t-1}+\sigma_{\xi} \epsilon_{\xi, t}
\end{aligned}
$$

To solve the firms' policy function we solve the following system of stochastic equations

\section{- Firms optimality Conditions}

$$
\begin{aligned}
1 & +\phi_{K}\left(\frac{K_{t, t+1}}{K_{t-1, t}}-1\right)=Q_{K t}\left[B_{t, t+1}-(1-\lambda) B_{t-1, t}\right] \\
& +\beta \mathbb{E}_{t}\left[G_{t+1}\left\{\alpha \nu z_{t+1} \eta_{t+1} K_{t, t+1}^{\alpha \nu-1} N_{t, t+1}^{(1-\alpha) \nu}-F_{0}+v_{K, t+1}\right\}\right] \\
\kappa & +\phi_{N}\left(\frac{N_{t, t+1}}{N_{t-1, t}}-1\right)=Q_{N, t}\left[B_{t, t+1}-(1-\lambda) B_{t-1, t}\right] \\
& +\beta \mathbb{E}_{t}\left[G_{t+1}\left\{(1-\alpha) \nu K_{t, t+1}^{\alpha \nu} N_{t, t+1}^{(1-\alpha) \nu-1}-\bar{u}+v_{N, t+1}\right\}\right] \\
Q_{t} & +Q_{B, t}\left[B_{t, t+1}-(1-\lambda) B_{t-1, t}\right]=\phi_{B}\left(\frac{B_{t, t+1}}{B_{t-1, t}}-1\right) \\
& +\beta \mathbb{E}_{t}\left[G_{t+1}\left[\tilde{\lambda}-v_{B, t+1}\right]\right]
\end{aligned}
$$


- Firms' value and marginal value

$$
\begin{aligned}
v_{t} & =-\left[K_{t, t+1}-\left(1-\delta_{K}\right) K_{t-1, t}\right]-\frac{\phi_{k}}{2}\left(\frac{K_{t, t+1}}{K_{t-1, t}}-1\right)^{2} K_{t-1, t} \\
& -\kappa\left[N_{t, t+1}-\left(1-\delta_{N}\right) N_{t-1, t}\right]-\frac{\phi_{N}}{2}\left(\frac{N_{t, t+1}}{N_{t-1, t}}-1\right)^{2} N_{t-1, t} \\
& +Q_{t}\left[B_{t, t+1}-(1-\lambda) B_{t-1, t}\right]-\frac{\phi_{B}}{2}\left(\frac{B_{t, t+1}}{B_{t-1, t}}-1\right)^{2} B_{t-1, t} \\
& +\beta \mathbb{E}_{t}\left[G_{t+1}\left\{z_{t+1} \eta_{t+1} K_{t, t+1}^{\alpha \nu} N_{t, t+1}^{(1-\alpha) \nu}-\bar{u} N_{t, t+1}-F_{0} K_{t, t+1}-\tilde{\lambda} B_{t, t+1}+v_{t+1}\right\}-F_{t+1}^{e}\right] \\
v_{B, t} & =-(1-\lambda) Q_{t}-\frac{\phi_{B}}{2}\left(\frac{B_{t, t+1}}{B_{t-1, t}}-1\right)^{2}+\phi_{B}\left(\frac{B_{t, t+1}}{B_{t-1, t}}-1\right) \frac{B_{t, t+1}}{B_{t-1, t}} \\
v_{K, t} & =\left(1-\delta_{K}\right)-\frac{\phi_{K}}{2}\left(\frac{K_{t, t+1}}{K_{t-1, t}}-1\right)^{2}+\phi_{K}\left(\frac{K_{t, t+1}}{K_{t-1, t}}-1\right) \frac{K_{t, t+1}}{K_{t-1, t}} \\
v_{N, t} & =\kappa\left(1-\delta_{N}\right)-\frac{\phi_{N}}{2}\left(\frac{N_{t, t+1}}{N_{t-1, t}}-1\right)^{2}+\phi_{N}\left(\frac{N_{t, t+1}}{N_{t-1, t}}-1\right) \frac{N_{t, t+1}}{N_{t-1, t}}
\end{aligned}
$$

- Firms default threshold and marginal threshold

$$
\begin{aligned}
\underline{F}_{t} & =z_{t} \eta_{t} K_{t-1, t}^{\alpha \nu} N_{t-1, t}^{(1-\alpha) \nu}-\bar{u} N_{t-1, t}-F_{K} K_{t-1, t}-\tilde{\lambda} B_{t-1, t}+v_{t} \\
\underline{F}_{B t} & =-\tilde{\lambda}+v_{B t} \\
\underline{F}_{K t} & =\alpha \nu z_{t} \eta_{t} K_{t-1, t}^{\alpha \nu-1} N_{t-1, t}^{(1-\alpha) \nu}-F_{K}+v_{K, t} \\
\underline{F}_{N t} & =(1-\alpha) \nu z_{t} \eta_{t} K_{t-1, t}^{\alpha \nu} N_{t-1, t}^{(1-\alpha) \nu-1}-\bar{u}+v_{N, t}
\end{aligned}
$$

- Idiosyncratic and aggregate shocks

$$
\begin{aligned}
G_{t} & =G_{s s}+g_{s s}\left(\underline{F}_{t}-\underline{F}_{s s}\right)+0.5 g_{1}\left(\underline{F}_{t}-\underline{F}_{s s}\right)^{2} \\
g_{t} & =g_{s s}+g_{1}\left(\underline{F}_{t}-\underline{F}_{s s}\right)+0.5 * g_{2}\left(\underline{F}_{t}-\underline{F}_{s s}\right)^{2} \\
F_{t}^{e} & =F_{s s}^{e}+F_{s s} g_{s s}\left(\underline{F}_{t}-\underline{F}_{s s}\right)+\frac{g_{s s}+F_{s s} g_{s s 1}}{2}\left(\underline{F}_{t}-\underline{F}_{s s}\right)^{2} \\
\ln z_{t} & =\rho_{z} \ln z_{t-1}+\sigma_{z} \epsilon_{z, t} \\
\ln \eta_{t} & =\rho_{\eta} \ln \eta_{t-1}+\sigma_{\eta} \epsilon_{x, t} \\
\ln \xi_{t} & =\rho_{\psi} \ln \xi_{t-1}+\sigma_{\xi} \epsilon_{\xi, t}
\end{aligned}
$$


- Pricing equations

$$
\begin{aligned}
Q_{t} & =\beta \xi_{t} \mathbb{E}_{t}\left[G_{t+1}\left[(c+\lambda)+(1-\lambda) Q_{t+1}\right]+\left(1-G_{t+1}\right) \theta \frac{K_{t, t+1}}{B_{t, t+1}}\right] \\
Q_{B, t} & =\beta \xi_{t} \mathbb{E}_{t}\left[g_{t+1} \underline{F}_{B, t+1}\left[(c+\lambda)+(1-\lambda) Q_{t+1}\right]\right] \\
& +\xi_{t} \beta \mathbb{E}_{t}\left[G_{t+1}(1-\lambda)\left\{Q_{B, t+1} \frac{B_{t+1, t+2}}{B_{t, t+1}} \boldsymbol{E}_{t+1}^{B B}+Q_{K, t+1} \frac{K_{t+1, t+2}}{B_{t, t+1}} \boldsymbol{E}_{t+1}^{K B}+Q_{N, t+1} \frac{N_{t+1, t+2}}{B_{t, t+1}} \boldsymbol{E}_{t+1}^{N B}\right\}\right] \\
& +\beta \xi_{t} \mathbb{E}_{t}\left[g_{t+1} \underline{F}_{B, t+1} \theta \frac{K_{t, t+1}}{B_{t, t+1}^{2}}\right] \\
Q_{K, t} & =\xi_{t} \beta \mathbb{E}_{t}\left[g_{t+1} \underline{F}_{K, t+1}\left[(c+\lambda)+(1-\lambda) Q_{t+1}\right]\right] \\
& +\xi_{t} \beta \mathbb{E}_{t}\left[G_{t+1}(1-\lambda)\left\{Q_{B, t+1} \frac{B_{t+1, t+2}}{K_{t, t+1}} \boldsymbol{E}_{t+1}^{B K}+Q_{K, t+1} \frac{K_{t+1, t+2}}{K_{t, t+1}} \boldsymbol{E}_{t+1}^{K K}+Q_{N, t+1} \frac{N_{t+1, t+2}}{K_{t, t+1}} \boldsymbol{E}_{t+1}^{N K}\right\}\right] \\
& -\beta \xi_{t} \mathbb{E}_{t}\left[g_{t+1} \underline{F}_{K, t+1} \theta \frac{1}{B_{t, t+1}}\right] \\
Q_{N, t} & =\xi_{t} \beta \mathbb{E}_{t}\left[g_{t+1} \underline{F}_{N, t+1}\left[(c+\lambda)+(1-\lambda) Q_{t+1}\right]\right] \\
& +\xi_{t} \beta \mathbb{E}_{t}\left[G_{t+1}(1-\lambda)\left\{Q_{B, t+1} \frac{B_{t+1, t+2}}{N_{t, t+1}} \boldsymbol{E}_{t+1}^{B N}+Q_{K, t+1} \frac{K_{t+1, t+2}}{N_{t, t+1}} \boldsymbol{E}_{t+1}^{K N}+Q_{N, t+1} \frac{N_{t+1, t+2}}{N_{t, t+1}} \boldsymbol{E}_{t+1}^{N N}\right\}\right]
\end{aligned}
$$

- Firm's policy elasticity for $X, Y \in\{B, K, N\}$

$$
\boldsymbol{E}_{t}^{X Y}=\beta_{0}^{X Y}+\beta_{B}^{X Y} B_{t-1, t}+\beta_{K}^{X Y} K_{t-1, t}+\beta_{N}^{X Y} N_{t-1, t}+\beta_{z}^{X Y} z_{t}+\beta_{\eta}^{X Y} \eta_{t}+\beta_{\xi}^{X Y} \xi_{t}
$$

Now we describe the steady state computation. Remember that include in the estimation the sufficient statistics from the distribution of the idiosyncratic i.i.d. shocks to firms' policies. Thus, at the time of solving for firm's policies, $G_{s s}, g_{s s}$ and $F_{s s}^{e}$ are parameters. We define a function $R\left(K_{s s}, N_{s s}, B_{s s}\right)$ in the following 
way:

$$
\begin{aligned}
Q_{s s} & =\frac{\beta G_{s s}(c+\lambda)}{1-\beta G_{s s}(1-\lambda)} \\
v_{s s} & =\frac{-\delta_{K} K_{s s}-\kappa \delta_{N} N_{s s}+Q_{s s} \lambda B_{s s}+\beta\left[G_{s s}\left\{K_{s s}^{\alpha \nu} N_{s s}^{(1-\alpha) \nu}-\bar{u} N_{s s}-F_{K} K_{s s}-\tilde{\lambda} B_{s s}\right\}-F_{s s}^{e}\right]}{1-\beta G_{s s}} \\
v_{B, s s} & =-(1-\lambda) Q_{s s} \\
v_{K, s s} & =\left(1-\delta_{K}\right) \\
v_{N, s s} & =\kappa\left(1-\delta_{N}\right) \\
\underline{F}_{s s} & =K_{s s}^{\alpha \nu} N_{s s}^{(1 \alpha) \nu}-\bar{u} N_{s s}-F_{K} K_{s s}-\tilde{\lambda} B_{s s}+v_{s s} \\
\underline{F}_{B, s s} & =-\tilde{\lambda}+v_{B, s s} \\
\underline{F}_{K, s s} & =\alpha \nu K_{s s}^{\alpha \nu-1} N_{s s}^{(1-\alpha) \nu}-F_{K}+v_{K, s s} \\
\underline{F}_{N, s s} & =(1-\alpha) \nu K_{s s}^{\alpha \nu} N_{s s}^{(1-\alpha) \nu-1}-\bar{u}+v_{N, s s}
\end{aligned}
$$

Then we solve for $\partial \vec{Q}_{s s}=\left[\begin{array}{lll}Q_{B, s s} & Q_{K, s s} & Q_{N, s s}\end{array}\right]^{\prime}$ as $\partial \vec{Q}_{s s}=M_{0}+M_{1} \partial \vec{Q}_{s s}$

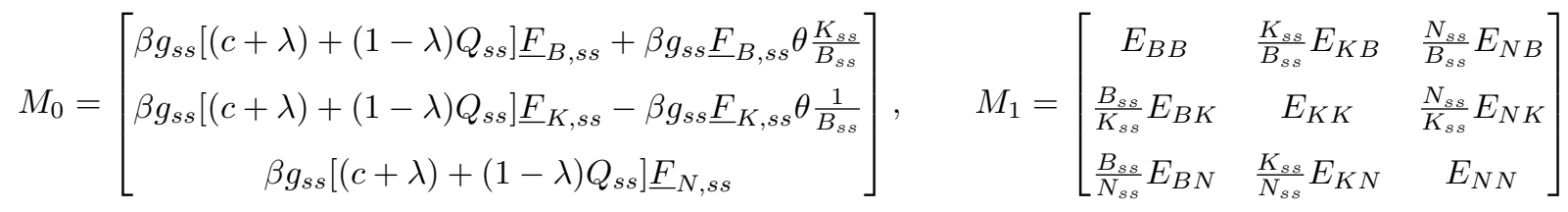

Then $R\left(K_{s s}, N_{s s}, B_{s s}\right)$

$$
\begin{gathered}
R_{1}\left(K_{s s}, N_{s s}, B_{s s}\right)=-1+Q_{K, s s} \lambda B_{s s}+\beta G_{s s}\left[\alpha \nu K_{s s}^{\alpha \nu-1} N_{s s}^{(1-\alpha) \nu}-F_{K}+v_{K, s s}\right] \\
R_{2}\left(K_{s s}, N_{s s}, B_{s s}\right)=-\kappa+Q_{N, s s} \lambda B_{s s}+\beta G_{s s}\left[(1-\alpha) \nu K_{s s}^{\alpha \nu} N_{s s}^{(1-\alpha) \nu-1}-\bar{u}+v_{N, s s}\right] \\
R_{3}\left(K_{s s}, N_{s s}, B_{s s}\right)=-Q_{s s}+Q_{B, s s} \lambda B_{s s}=\beta G_{s s}\left[\tilde{\lambda}-v_{B, s s}\right]
\end{gathered}
$$

We apply the Newton algorithm to solve $R\left(K_{s s}, N_{s s}, B_{s s}\right)=0$ and find the steady state.

\section{B.3 Model Solution: Iterative Procedure}

In this section we describe the iterative method to compute the second order approximation of the firms policy function. Let $h, h_{Y} \in R^{6 \times 6}$ for $Y \in\{K, N, B\}$ and let

$$
x_{t}=\left[K_{t-1, t}, N_{t-1, t}, B_{t-1, t}, z_{t}, \eta_{t}, \xi_{t}\right] \in R^{6 \times 1}
$$


When we apply perturbation methods we log-linearize the state variables and linearize the control variables

- Step 1: Guess $h_{0} \in R^{6 \times 6}$ in the set of diagonal matrices with positive diagonal.

- Step 2: Given $h_{k}$, compute the policy using first order perturbation methods on the equilibrium conditions (55)-(72). In this step $\beta_{0}^{X Y}$ is obtain from $h_{k}$ and $\beta_{B}^{X Y}=\beta_{K}^{X Y}=\beta_{N}^{X Y}=\beta_{z}^{X Y}=\beta_{\eta}^{X Y}=$ $\beta_{\xi}^{X Y}=0$. Denote $h_{k+1}$ the solution of the equilibrium equations that satisfies

$$
x_{t}=h_{k+1} x_{t-1}+\Sigma \epsilon_{t}
$$

- Step 3: if $\frac{n o r m\left(h_{k+1}-h_{k}\right)}{1+\text { norm }\left(h_{k}\right)}<\epsilon$, then go to step 4- where norm denotes the euclidian norm of the vectorize matrix. If not, go to step 2 .

- Step 4: given $h_{k}$, compute the equilibrium solution using second order perturbation methods. Let $h_{Y k}$ be the quadratic form for the quadratic term in the policy of $Y \in\{K, N, B\}$.

- Step 5: given $h_{k}, h_{K k}, h_{N k}, h_{B k}$, compute the policy using second order perturbation methods on the equilibrium conditions (55)-(72). In this step $\beta_{0}^{X Y}$ is obtain from $h_{k}$ and $\beta_{B}^{X Y}, \beta_{K}^{X Y}, \beta_{N}^{X Y}, \beta_{z}^{X Y}, \beta_{\eta}^{X Y}, \beta_{\xi}^{X Y}$ are obtain from $h_{K k}, h_{N k}, h_{B k}$. Denote $h_{k+1}, h_{Y k+1}$ the solution of the equilibrium equations that satisfies

$$
Y_{t}=h_{k+1}^{Y} Y_{t-1}+x_{t-1}^{T} h_{Y k+1}^{i} x_{t-1}+\Sigma \epsilon_{t}
$$

where $Y \in\{K, N, B\}$ and $h_{k+1}^{Y}$ is the row of the matrix corresponding to $\mathrm{Y}$.

- Step 6: if $\frac{\operatorname{norm}\left(h_{k+1}-h_{k}\right)+\sum_{Y} \text { norm }\left(h_{Y k+1}-h_{Y k}\right)}{1+n o r m\left(h_{k}\right)} \geq \epsilon$, go to step 5. If not, you find the equilibrium policy using second order perturbation methods.

\section{B.4 Equilibrium Conditions for the Walrasian Market model}

The model with walrasian market is identical to search frictions when $\kappa=0, \delta_{n}=1$ and we replace $b(X)=w(X)$. 


\section{Data Appendix}

This section describes the micro-data and the macro-data that we used in this papers. Table 4 describe the variables that we used from COMPUSTAT and CRSP. For some variables we use the quarterly frequency, for example to compute the expected default probability in date, and also the annual frequency for computing the micro-price statistics in the GMM estimation.

\section{C.1 GMM Micro-Moments Computation From COMPUSTAT}

Table 4 describes the mnemonic for capital, output, debt and employment in COMPUSTAT. We computed a employment, capita, output and debt:

- Employment (n): $n_{t i}=e m p_{t i}$ and we define employment growth as

$$
\Delta n_{t i}=\frac{e m p_{t i}-e m p_{t-1 i}}{0.5 *\left(e m p_{t i}+e m p_{t-1 i}\right)}
$$

- Capital (k): $k_{t i}=$ ppent $_{t i}$ and we define capital growth as

$$
\Delta k_{t i}=\frac{(\text { capx }- \text { sppe })_{t i}}{0.5 *\left(\text { ppent }_{t i}+\text { ppent }_{t-1 i}\right)}
$$

- Output (y): $y_{t i}=$ sale $_{t i}$ and we define capital growth as

$$
\Delta y_{t i}=\frac{\text { sale }_{t i}-\text { sale }_{t-1 i}}{0.5 *\left(\text { sale }_{t i}+\text { sale }_{t-1 i}\right)}
$$

- Debt (b): $b_{t i}=\max \left\{d l c_{t i}+d l t t_{t i}-c h e_{t i}, 0\right\}$ and we define capital growth as

$$
\Delta b_{t i}=\frac{(d l t i s-d l t r+u s t d n c-c h e c h)_{t i}}{0.5 *\left(b_{t i}+b_{t-1 i}\right)}
$$

We apply the following filters to compute each moment:

- We drop observations with negative total assets, negative capital or negative sales.

- We drop firms with less than 5 years.

- For each $x \in\{b, n, k, y\}$, we construct a renormalize growth rate given by

$$
\Delta \tilde{x}_{t i}=\Delta x_{t i}-\sum_{i} \frac{\Delta x_{t i}}{I(t)}-\sum_{t} \frac{\Delta x_{t i}}{T(i)}
$$




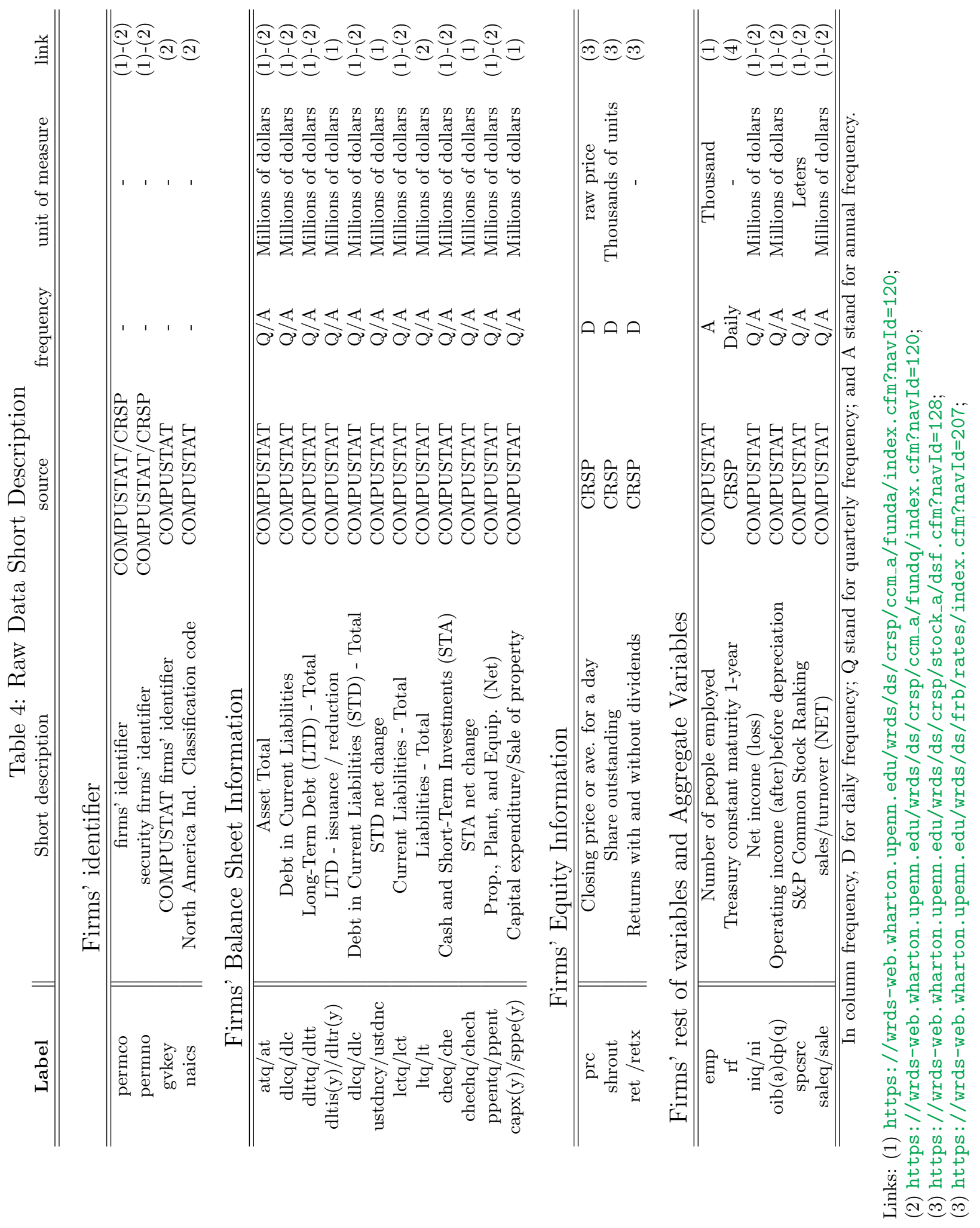


- We drop $\pm 1 \%$ outliers in employment, capital, debt and sales growth.

Mean, median, standard deviation, Skewness, kurtosis and correlation with debt are in growth rate and persistence is in log-levels.

\section{Table 5: Micro-Moments From COMPUSTAT-Annual Frequency \\ moment Debt Employment Sales Capital}

\begin{tabular}{ccccc} 
Micro-Moments & \multicolumn{5}{c}{} \\
\hline \hline mean & -0.001 & 0.000 & 0.001 & -0.001 \\
median & -0.026 & -0.004 & -0.004 & -0.018 \\
Standard Dev. & 0.450 & 0.231 & 0.294 & 0.197 \\
Skewness & 0.223 & 0.082 & 0.101 & 0.996 \\
Kurtosis & 4.954 & 6.331 & 7.400 & 6.159 \\
mean [w] & 0.015 & 0.003 & 0.005 & -0.001 \\
median [w] & 0.002 & -0.002 & -0.002 & -0.004 \\
Standard Dev. [w] & 0.365 & 0.151 & 0.181 & 0.099 \\
Skewness [w] & 0.259 & 0.561 & 0.475 & 0.765 \\
Kurtosis [w] & 6.975 & 11.287 & 11.102 & 11.220 \\
Corr. with Debt & 1.000 & 0.167 & 0.105 & 0.200 \\
Corr. with Debt [w] & 1.000 & 0.188 & 0.069 & 0.173 \\
Persistence & -0.108 & -0.003 & 0.046 & 0.549 \\
Persistence [w] & -0.062 & 0.042 & 0.120 & 0.432 \\
& & & & \\
Macro-Moments & & & & \\
\hline \hline & & & & \\
Standard Dev. & 0.056 & 0.016 & 0.039 & 0.075 \\
Correlation with debt & 1.000 & 0.236 & 0.438 & 0.684 \\
Persistence & 0.185 & 0.190 & 0.077 & 0.204 \\
& & & & \\
\hline \hline
\end{tabular}

This table describes firm level moments and aggregate moments computed from COMPUSTAT at annual frequency.

For aggregate business cycle moments we use HP filter with smooth parameter 6.25 of the sum across firms. The weighted moments are with share of total assets (at in COMPUSTAT) and [w] denotes the weighted moment.

\section{C.2 Merging CRSP with COMPUSTAT}

- For annual data and daily data we generate a variable of date referring to the quarterly time. With this variable and permco we did the merge. For some firms, one permco is associated to several gvkeys 
of repeted data. We dropped duplicated observations whenever one permco is associated with several gvkeys.

- We clean the data base from financial firms $(\operatorname{sic} \in[6000,6999])$, regulated firms $(\operatorname{sic} \in[4900,4999])$ and public service firms $($ sic $\in[9000, \infty])$ for annual and quarterly data.

- For treasury rate drop date before 1965 and and write the rate of return on a daily bases.

- Merge annual COMPUSTAT with quarterly COMPUSTAT using date (quarterly) and permco.

- Use linear interpolation for going from annual to quarterly data. Use backward interpolation but never forward interpolation. Use these for two variables: employment and labor cost (emp and xstf).

- Scale balance sheet data by 1000000 and emp by 1000 .

- Generate a balance panel for daily market value using linear interpolation for missing values.

- For the CRSP daily generates market value (watch out with negative values of prices), complete the missing values of market value using linear interpolation and collapse using sum by permco market value.

- Merge daily CRSP market value with compustat using permco and quarterly date. Then merge with daily treasury.

\section{C.3 Estimation of the Merton Model}

- Generate liaval using dsttq+0.5 dlttq

- Define $L$ as liabilities; $E$ as market value; $r_{t}$ daily risk free rate.

- Use an iteration method to compute the value of the firm and distance to default.

1. Guess and initial value for $\mathrm{V}:=$ assets values.

2. Compute the mean and variance of the rate of return using $V$ over a rolling window $T$. 
3. Compute the following objects:

$$
\begin{aligned}
\delta_{1 t} & =\frac{1}{\sigma_{V t} \sqrt{d T}}\left(\log \left(V_{t} / L_{t}\right)+\left(r_{t} * d T+\sigma_{V}^{2} * d T * 0.5\right)\right) \\
\delta_{2 t} & =\delta_{1 t}-\sigma_{V} \sqrt{d T} \\
N_{1 t} & =\Phi\left(\delta_{1 t}\right) \\
N_{2 t} & =\Phi\left(\delta_{2 t}\right) \\
V_{t}^{\prime} & =\frac{E_{t}+L_{t} * \exp \left(r_{t} * d T * N_{2 t}\right)}{\sigma_{V t} \sqrt{d T}}
\end{aligned}
$$

4. Check if $V^{\prime}-V$ is small. If it is small go to step 2 and there is only one iteration of step 4 , stop. If it is small and there is more than one iteration of step 4 go to 2 . If it is big, go to step 4 .

- Compute distance to default using the following:

$$
\begin{aligned}
D D_{t} & \left.=\frac{1}{\sigma_{V t} \sqrt{d T}}\left(\log \left(\frac{V_{t}}{L_{t}}\right)+\mu_{V} d T-0.5 * \sigma_{V t} d T\right)\right) \\
P r_{t} & =\Phi\left(-D D_{t}\right)
\end{aligned}
$$

\section{C.4 Sources and Data Description of Aggregate Macroeconomic Variables}

Table 6 describes the data sources for US macroeconomic time series together with the mnemonic for each variable. We follow Shimer (2005) to construct separation and finding probabilities; and Gilchrist and Zakrajsek (2012) credit spread time series. Monthly variables are transformed to quarterly frequency using averages. We construct additional variables using the following formulas:

- Real Interest Rate: $\left(1+\left(1+D F F_{t} / 100\right)-\left(\frac{G D P D E F_{t}}{G D P D E F_{t-1}}\right)^{4}\right)^{0.25}$

- Labor Supply: $\frac{E_{t} H_{t}}{N_{t}}$

- Real wage: $\frac{W_{t}}{G D P E F_{t}}$

- Finding Rate: $f_{t}=1-\frac{U_{t+1}-U r_{t}}{U_{t}}$

- Separation Rate: $s_{t}=U r_{t+1} /\left(E_{t}\left(1-f_{t} / 2\right)\right)$

- Rate of Return-Credit Spread I-: $c s_{t}^{I}=\left(1+\left(B a a_{t}-A a a_{t}\right) / 100\right)^{0.25}$

- Rate of Return-Credit Spread II-: $c s_{t}^{I I}=\left(1+\left(B a a_{t}-T B 3_{t} / 100\right)^{0.25}\right.$

- Rate of Return-Credit Spread III-: $c s_{t}^{I I I}=\left(1+g z-\text { spread }_{t} / 100\right)^{0.25}$ 
Business cycle components are obtained from a HP filter with smooth parameter 1600. TFP is constructed with the Solow residuals using business cycle fluctuation of TFP, output, labor and investment with the following formulas

$$
T \hat{F} P_{t}=G \hat{D} P_{t}-0.66 * \hat{L}_{t}-0.33 * \hat{K_{t-1}} \quad ; \quad \hat{K}_{t}=(1-0.0025) \hat{K}_{t-1}+0.0025 \hat{I}_{t} \quad ; \quad \hat{K}_{-1}=0
$$

Leverage is computed from COMPUSTAT using the following formula (see table 4 for the definition of each variable)

$$
l e v_{t}=\frac{\max \left\{D L C Q_{t i}+D L T T Q_{t i}-C H E Q_{t i}, 0\right\}}{P P E N T Q_{t i}}
$$

where $D L C Q$ and $D L T T Q$ denotes short and long term debt respectively, CEHQ denotes liquid assets and PPENTQ denotes capital. $i$ denotes the ith-firm and time denotes time.

Aggregate debt is from Flow of Funds, Table Z1 "Financial Accounts of the United States". In particular, we use Table L.103 (Non-Financial Corporate Business, Quarterly) and constructed aggregate private debt as the sum of Commercial Paper, Corporate Bonds, Loans from Depositary Institutions, Other Loans and Advances and Total Mortgages. 


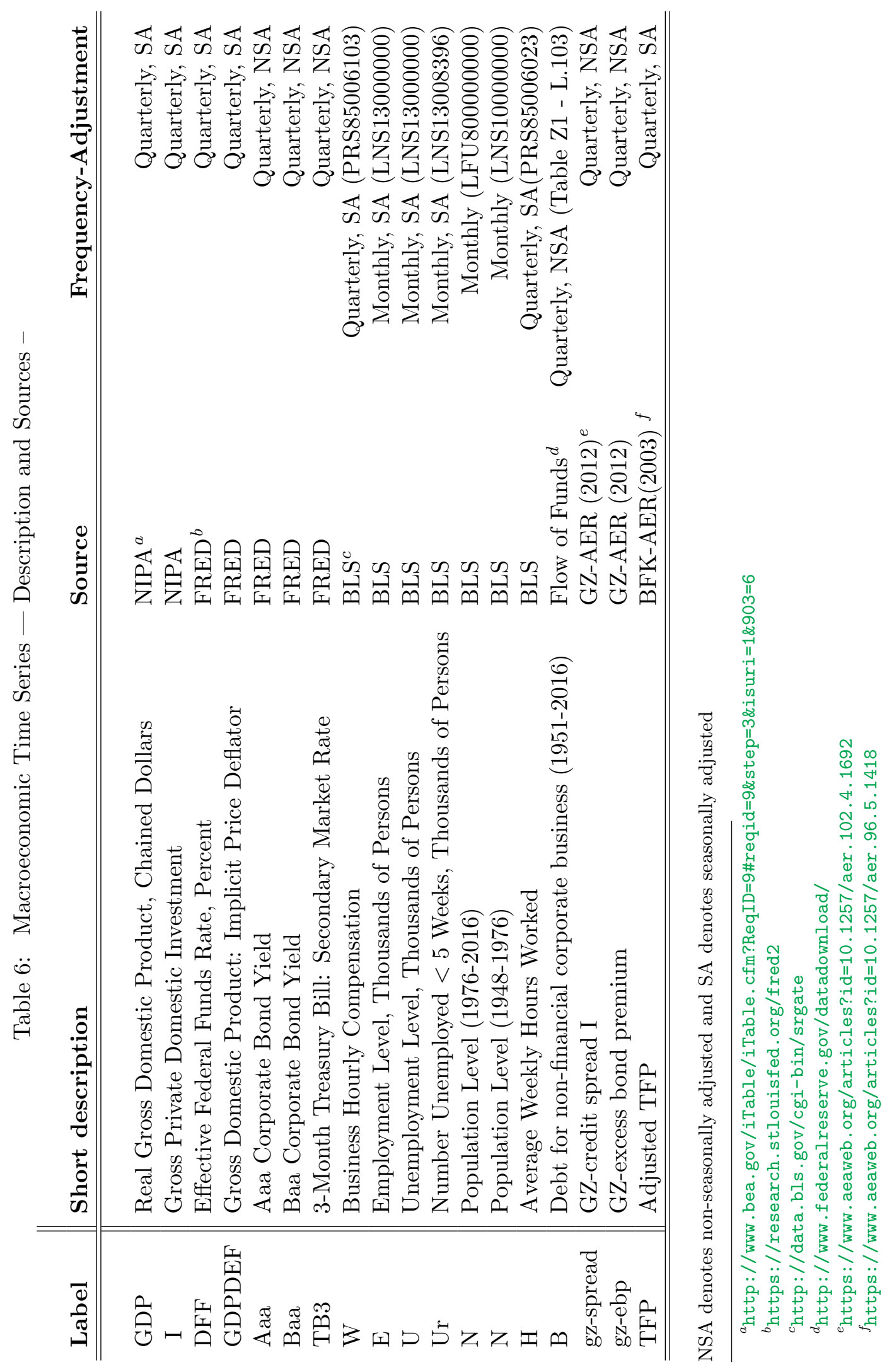




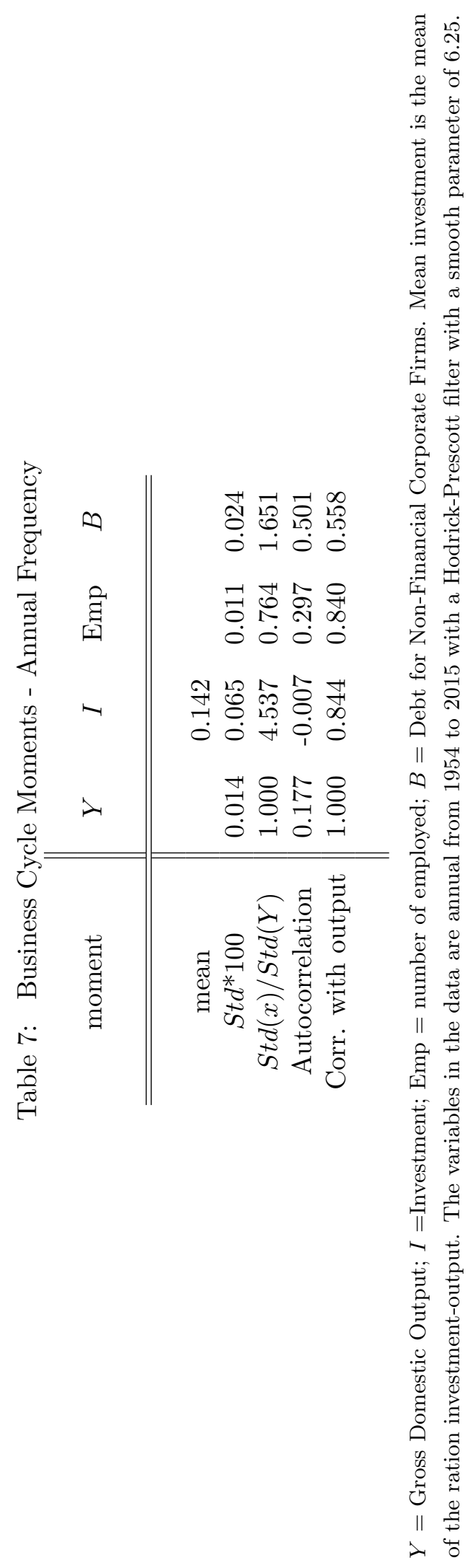




\section{Estimation Details}

This sections describes the calibrated and estimated parameters in the model with walrasian market together with the model with search frictions and plots the kernel estimate of the posterior in the Walrasian market and in the search frictions model.

Table 8: Calibrated Parameters

\begin{tabular}{c|ccl} 
Parameter & Value SF & Value WM & Target/Source \\
\hline \hline$\beta$ & 0.98 & 0.98 & Standard \\
$\nu$ & 0.85 & 0.85 & Standard \\
$\alpha$ & 0.4 & 0.4 & Standard \\
$\delta_{K}$ & 0.025 & 0.025 & Standard \\
$\delta_{N}$ & 0.033 & - & Shimer (2005) \\
$\lambda$ & 0.0417 & 0.0417 & Gomez, Jermann and Schmid (2016) \\
$c$ & 0.0101 & 0.0101 & Normalization \\
$\kappa$ & 40 & - & normalization \\
$\rho_{\eta}$ & 0.85 & 0.85 & Solow residual persistence \\
$\sigma_{\eta}$ & 0.008 & 0.008 & Solow residual variance \\
$\rho_{\psi}$ & 0.52 & 0.52 & one-period risk-free persistence \\
$\sigma_{\psi}$ & 0.003 & 0.003 & one-period risk-free variance \\
$\varphi_{w}$ & - & 1 & volatility of wages \\
& & & \\
\hline \hline
\end{tabular}

\section{D.1 Impulse Response Functions to Aggregate Shocks}




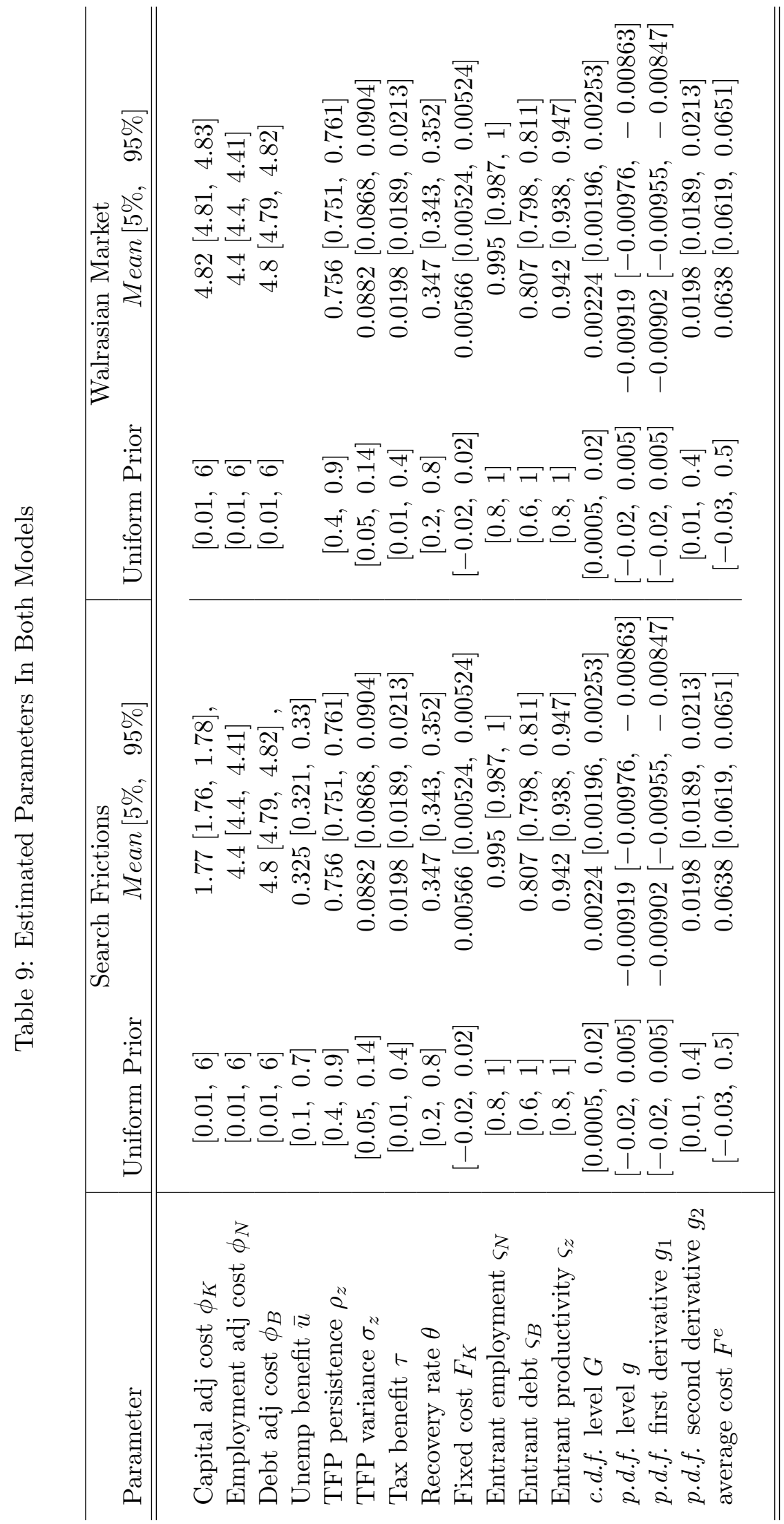




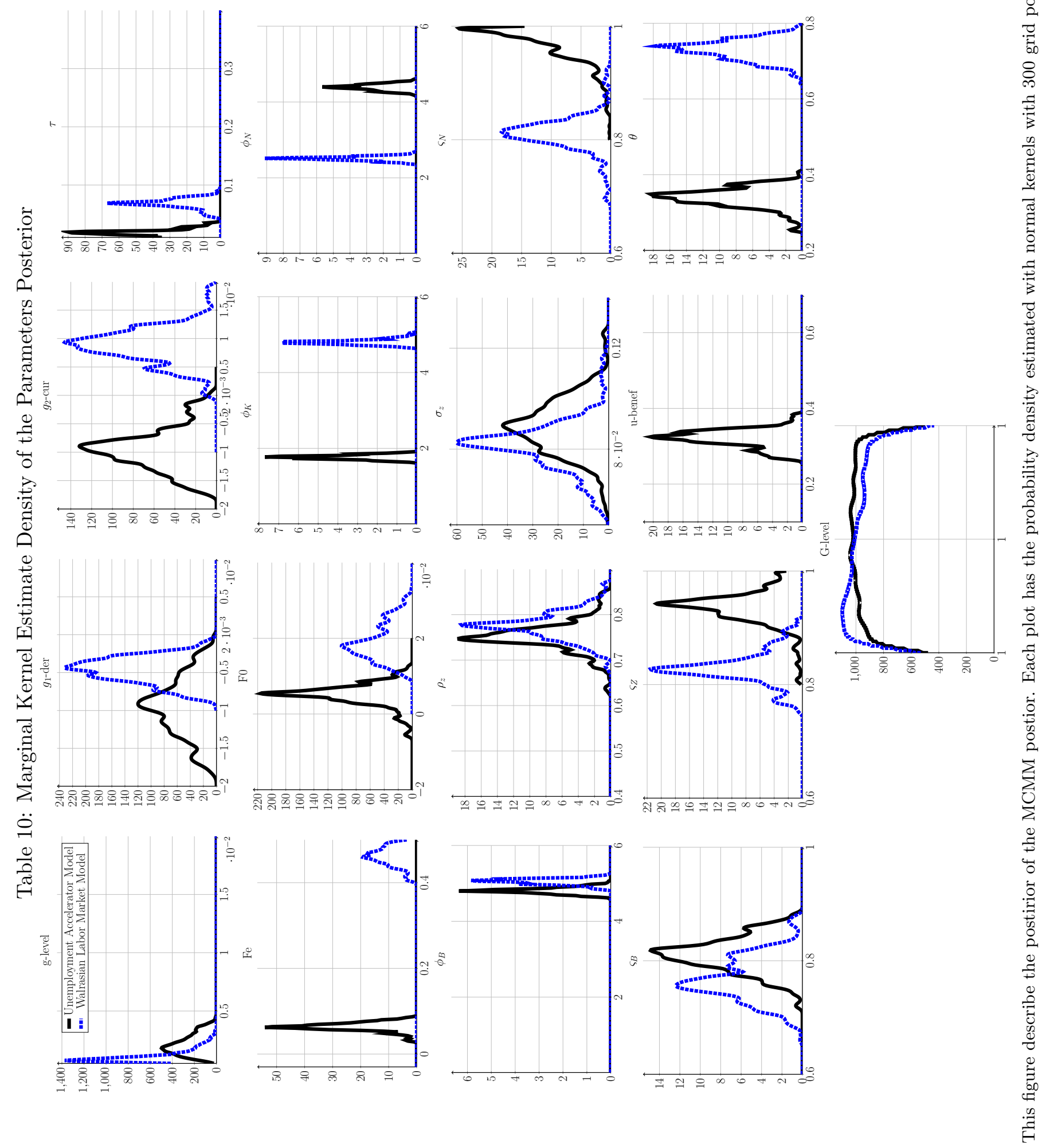


Figure 5: Firm's Impulse Response to Aggregate TFP shock $\eta$
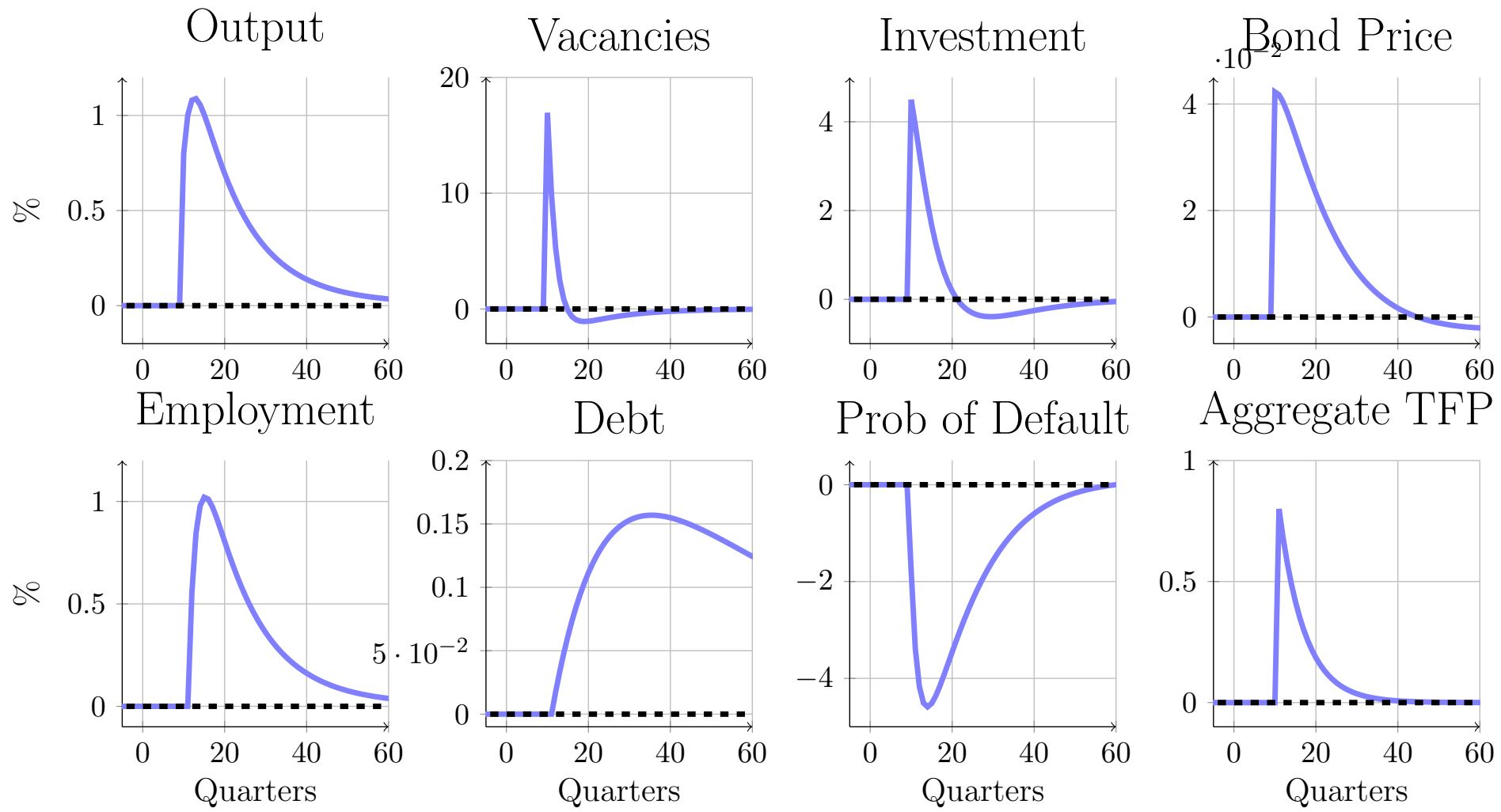
Figure 6: Firm's Impulse Response to Financial shock $\psi$
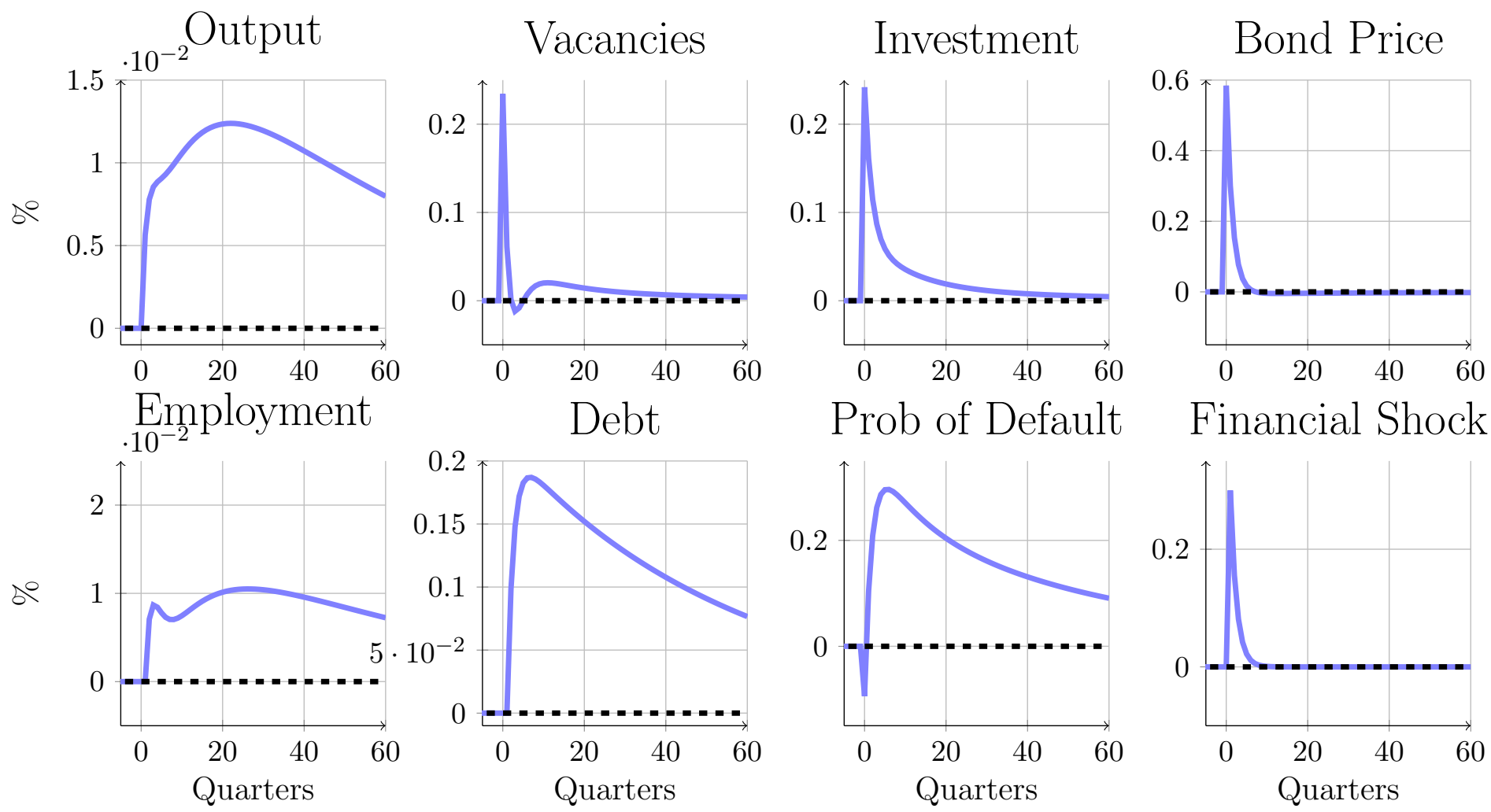


\section{E The Financial Value of Capital and a Worker}

This section reports the additional exercises that we did with respect to the main results in the section 5 . Subsection E.1 shows the dynamic correlation between the innovation in a set of financial variables and the number of workers. Subsection E.2 shows show the linear projections of financial variables with respect to the number of workers and a large set of control variables. In subsections Subsection E.3 and E.3 we repeat the same exercises with capital.

\section{E.1 The Financial Value of a Worker: Robustness Exercise I}

The model in section 2 abstracts from several frictions than could generate a bias in the evidence of the financial value of a worker - section 5.3. In this appendix, we do a set of robustness checks. First, I will define the variable we used in the regressions and then we describe each of the 28 specifications we study.

The variable definitions for this sections are - see table 4:

- Total Assets: This variable defined as the log of total assets (atq) in COMPUSTAT.

- Total Debt: This variable defined as the log of debt in current liabilities, plus long-term debt minus liquid assets $(d l c q+d l t t q-c h e q)$ in COMPUSTAT. If this variable is negative, we replace it with a missing value.

- Total normalized profits: This variable defined as the the ratio between operating income before depression and total asset (oibdpq/atq) in COMPUSTAT.

- Investment rate: This variable is defined as capital expenditure minus sales of property, divide the mean capital in the last two periods $\left(\frac{c a p x y_{t}-s p p e y}{0.5 *\left(\text { ppent } q_{t}+p p e n t q_{t-1}\right)}\right)$ in COMPUSTAT.

- Capital: This variable defined as the log of total physical assets (ppentq) in COMPUSTAT.

- Normalized Sales: This variable defined as the log of the ratio between total sales and total cpaital (saleq/ppentq) in COMPUSTAT.

- Liquid assets: This variable defined as the log of liquid assets (cheq) in COMPUSTAT.

We make robustness checks for different sets of independent and dependent variables. If we define the model

$$
\begin{aligned}
& y_{i t}=\gamma_{t}^{y}+\alpha_{i}^{y}+\beta_{X}^{y} X_{i t}+\epsilon_{i t}^{y, X} \\
& n_{i t}=\gamma_{t}^{n}+\alpha_{i}^{n}+\beta_{X}^{n} X_{i t}+\epsilon_{i t}^{n, X}
\end{aligned}
$$


We test the autocorrelation of $\epsilon_{i t}^{y, X}=\beta \epsilon_{i t}^{n, X}+\eta_{t i}^{y, X}$ for 28 specifications. In the case of $y_{i t}$ we have 4 specifications of dependent variables: $\log$ of probability of default $(\log (\operatorname{prdf}))$, logic of probability of default

$(\log (\operatorname{prdf} /(1-\operatorname{prdf})))$, distance to default $(d s d f)$ and the log of market value $(\log ($ mktval $))$. In the case of the control variable we have 6 specifications:

I- Benchmark Specification: $X$ is composed by capital, total debt, total normalized profits and investment rates.

II- Imperfect Controls over Permanent and Transitory Shocks: $X$ is composed bycapital, total debt, total normalized profits, investment rates, and 1, 2 and 3 quarter lags of total normalized profits.

III- Imperfect Controls over Future News: $X$ is composed by capital, total debt, total normalized profits, investment rates, and 1, 2 and 3 quarter forwards of total normalized profits.

IV- Imperfect Controls over Capital Compositions: $X$ is composed by total assets, capital and liquid assets, total debt, total normalized profits and investment rates.

V- Benchmark Specification with sales: $X$ is composed by capital, total debt, total normalized profits, normalized sales and investment rates.

Figure 11 describes the results under the 6 specifications for the log probability of default; figure 12 describes the results under the 6 specifications for the logic of the probability of default; figure 13 describes the results under the 6 specifications for the distance of default; and figure 14 describes the results under the 6 specifications for the market value of the firm.

\section{E.2 The Financial Value of a Worker: Robustness Exercise II}

In this section of the appendix we regress the log of probability of default $(\log (\operatorname{prdf}))$, the logic of probability of default $(\log (\operatorname{prdf} /(1-\operatorname{prdf})))$, the distance to default $(d s d f)$ and the log of market value $(\log ($ mktval $))$ to a set of control variables and the log of unemployment. We choose the same specifications as in section E.1. 


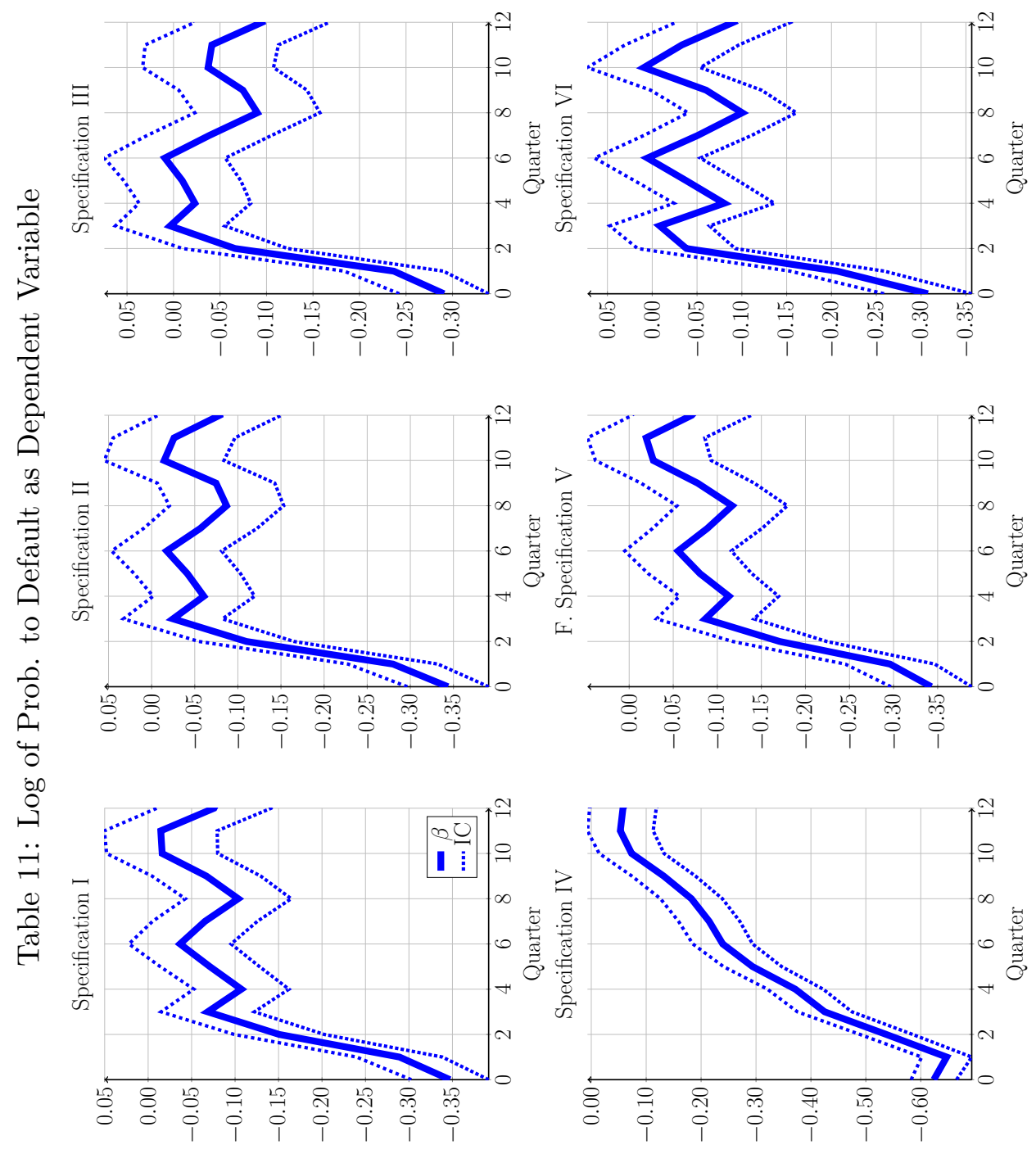




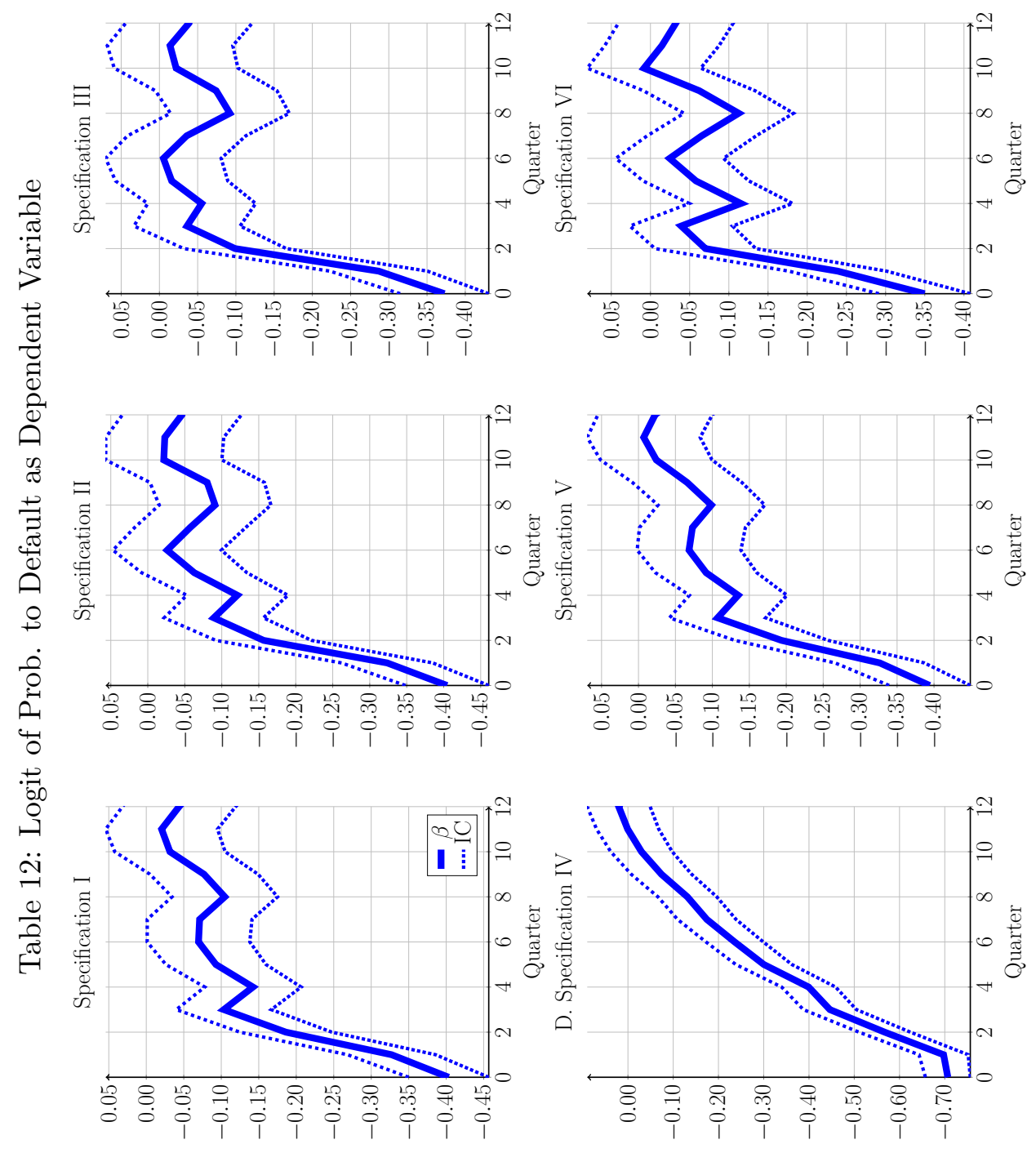




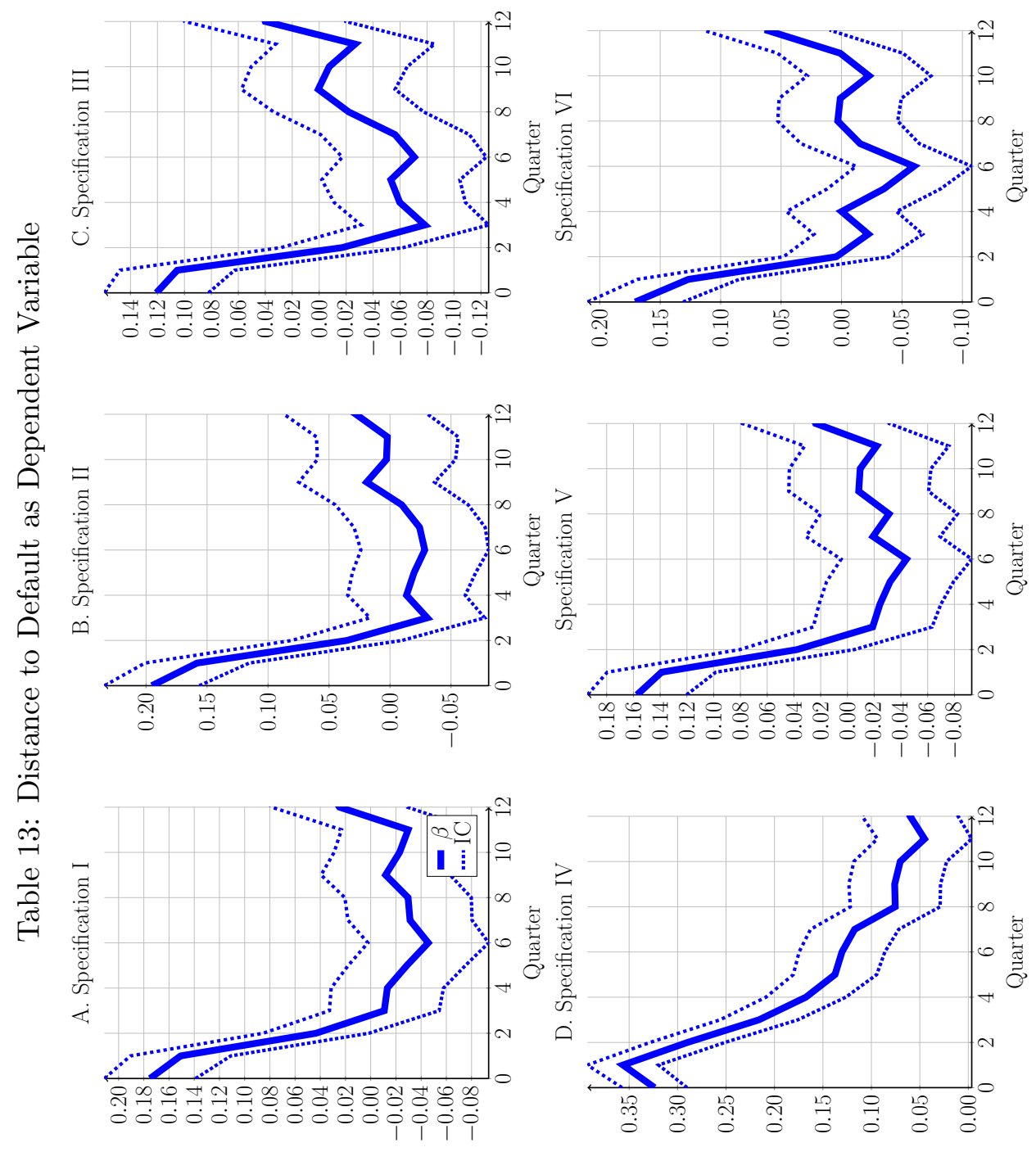




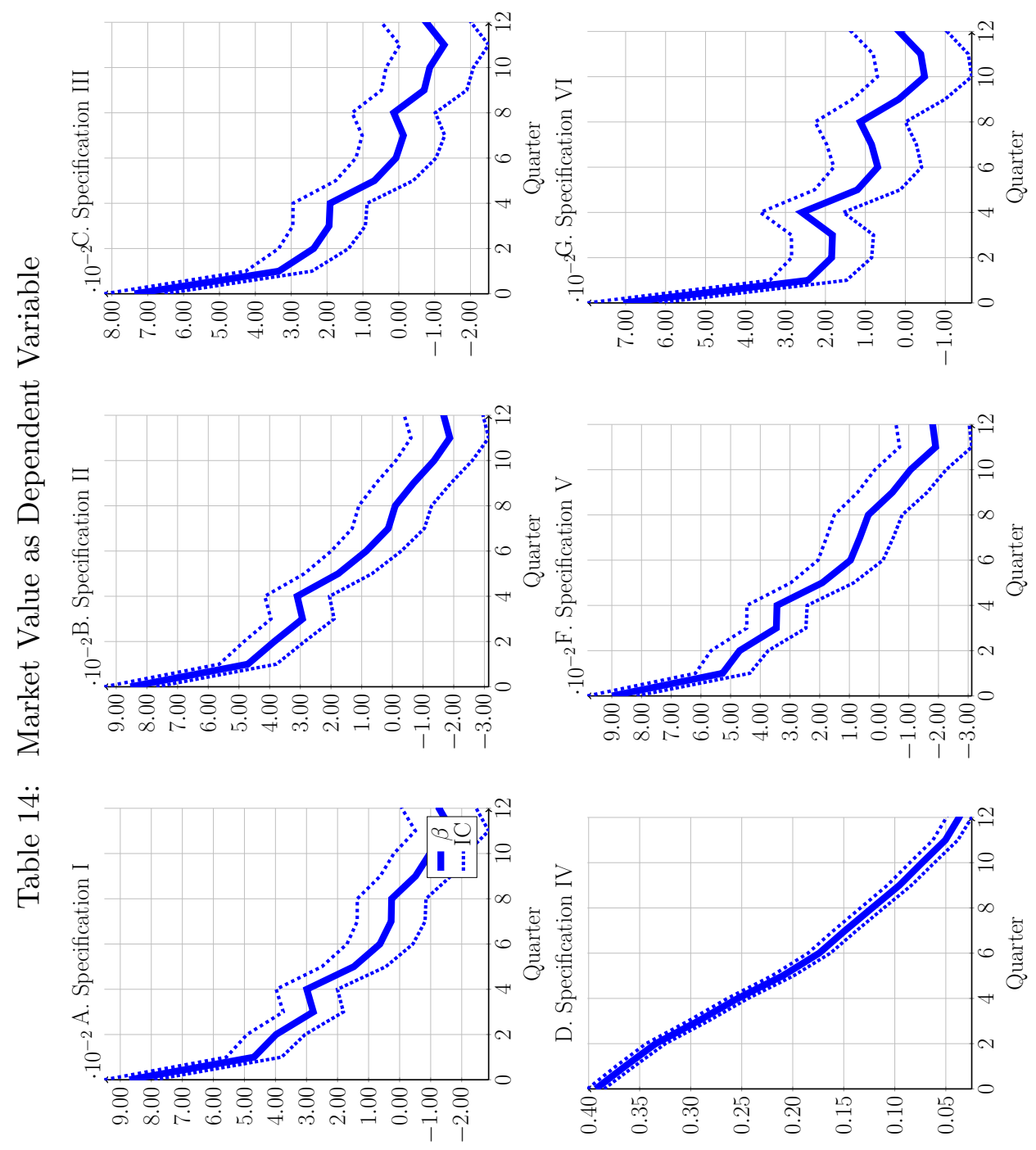


Table 15: Dependent Variable: Log of Probability of Default

\begin{tabular}{l||ccccccc} 
Variable & UA & WM & I & II & III & Reg. IV & Reg. V \\
\hline \hline & & & & & & & \\
Workers & $-0.88^{* * *}$ & $0.48^{* * *}$ & $-0.63^{* * *}$ & $-0.56^{* * *}$ & $-0.55^{* * *}$ & $-0.37^{* * *}$ & $-0.32^{* * *}$ \\
Capital & $-3.39^{* * *}$ & $-6.54^{* * *}$ & $-0.35^{* * *}$ & $-0.34^{* * *}$ & $-0.40^{* * *}$ & $-0.22^{* * *}$ & $-0.78^{* * *}$ \\
Assets & - & - & - & - & - & $-0.58^{* * *}$ & - \\
Debt & $1.29^{* * *}$ & $4.91^{* * *}$ & $0.71^{* * *}$ & $0.65^{* * *}$ & $0.69^{* * *}$ & $0.77^{* * *}$ & $0.73^{* * *}$ \\
Profits & $12.44^{* * *}$ & $9.23^{* * *}$ & $-1.52^{* * *}$ & $-1.43^{* * *}$ & $-1.79^{* * *}$ & $-1.37^{* * *}$ & $-1.37^{* * *}$ \\
Profits $L$ & - & - & - & $-3.38^{* * *}$ & - & - & - \\
Profits $L^{2}$ & - & - & - & $-3.43^{* * *}$ & - & - & - \\
Profits $L^{3}$ & - & - & - & $-4.68^{* * *}$ & - & - & - \\
Profits $F$ & - & - & - & - & $-1.83^{* * *}$ & - & - \\
Profits $F^{2}$ & - & - & - & - & $-1.66^{* * *}$ & - & - \\
Profits $F^{3}$ & - & - & - & - & $-0.81^{* * *}$ & - & - \\
Invest. rate & $-27.95^{* * *}$ & $-59.82^{* * *}$ & $-0.06^{* * *}$ & $-0.04^{* * *}$ & $-0.15^{* * *}$ & $-0.06^{* * *}$ & $-0.25^{* * *}$ \\
Liquid assets & - & - & - & - & - & $0.04^{* * *}$ & - \\
Sales & - & - & - & - & - & - & $-0.51^{* * *}$ \\
& & - & -15072 & 139199 & 138740 & 151358 & 153031 \\
\hline N obs & 154600 & 152913 & 154072 & 0.217 & 0.239 & 0.237 \\
$R^{2}$ & 0.688 & 0.680 & 0.204 & 0.234 & 0.217 \\
\hline \hline
\end{tabular}

Table 16: Dependent Variable: Logic of Probability of Default

\begin{tabular}{|c|c|c|c|c|c|}
\hline Variable & I & II & III & IV & $\mathrm{V}$ \\
\hline Workers & $-0.71^{* * *}$ & $-0.65^{* * *}$ & $-0.65^{* * *}$ & $-0.42^{* * *}$ & $-0.34^{* * *}$ \\
\hline Capital & $-0.41^{* * *}$ & $-0.38^{* * *}$ & $-0.48^{* * *}$ & $-0.28^{* * *}$ & $-0.91^{* * *}$ \\
\hline Assets & - & - & - & $-0.63^{* * *}$ & - \\
\hline Debt & $0.70^{* * *}$ & $0.66^{* * *}$ & $0.69^{* * *}$ & $0.77^{* * *}$ & $0.73^{* * *}$ \\
\hline Profits & $-0.94^{* * *}$ & $-0.97^{* * *}$ & $-1.45^{* * *}$ & $-0.82^{* * *}$ & $-0.68^{* * *}$ \\
\hline Profits $L$ & - & $-1.86^{* * *}$ & - & - & - \\
\hline Profits $L^{2}$ & - & $-3.20^{* * *}$ & - & - & - \\
\hline Profits $L^{3}$ & - & $-4.82^{* * *}$ & - & - & - \\
\hline Profits $F$ & - & - & $-1.55^{* * *}$ & - & - \\
\hline Profits $F^{2}$ & - & - & $-0.87^{* * *}$ & - & - \\
\hline Profits $F^{3}$ & - & - & $-0.79^{* * *}$ & - & - \\
\hline Invest. rate & $-0.04^{* * *}$ & -0.01 & $-0.10^{* * *}$ & $-0.04^{* * *}$ & $-0.17^{* * *}$ \\
\hline Liquid assets & - & - & - & $0.05^{* * *}$ & - \\
\hline Sales & - & - & - & - & $-0.61^{* * *}$ \\
\hline N obs & 160761 & 145249 & 142585 & 157896 & 159615 \\
\hline$R^{2}$ & 0.355 & 0.388 & 0.251 & 0.376 & 0.371 \\
\hline
\end{tabular}


Table 17: Dependent Variable: Logic of Probability of Default

\begin{tabular}{|c|c|c|c|c|c|}
\hline Variable & I & II & III & IV & $\mathrm{V}$ \\
\hline Workers & $0.33^{* * *}$ & $0.30^{* * *}$ & $0.28^{* * *}$ & $0.19^{* * *}$ & $0.17^{* * *}$ \\
\hline Capital & $0.27^{* * *}$ & $0.27^{* * *}$ & $0.33^{* * *}$ & $0.21^{* * *}$ & $0.49^{* * *}$ \\
\hline Assets & - & - & - & $0.31^{* * *}$ & - \\
\hline Debt & $-0.50^{* * *}$ & $-0.48^{* * *}$ & $-0.50^{* * *}$ & $-0.54^{* * *}$ & $-0.52^{* * *}$ \\
\hline Profits & $0.64^{* * *}$ & $0.68^{* * *}$ & $0.92^{* * *}$ & $0.54^{* * *}$ & $0.55^{* * *}$ \\
\hline Profits $L$ & - & $2.12^{* * *}$ & - & - & - \\
\hline Profits $L^{2}$ & - & $1.95^{* * *}$ & - & - & - \\
\hline Profits $L^{3}$ & - & $2.38^{* * *}$ & - & - & - \\
\hline Profits $F$ & - & - & $1.16^{* * *}$ & - & - \\
\hline Profits $F^{2}$ & - & - & $1.52^{* * *}$ & - & - \\
\hline Profits $F^{3}$ & - & - & $0.84^{* * *}$ & - & - \\
\hline Invest. rate & $0.08^{* * *}$ & $0.06^{* * *}$ & $0.07^{* * *}$ & $0.08^{* * *}$ & $0.11^{* * *}$ \\
\hline Liquid assets & - & - & - & $-0.02^{* * *}$ & - \\
\hline Sales & - & - & - & - & $0.26^{* * *}$ \\
\hline N obs & 152883 & 138151 & 137673 & 150209 & 151876 \\
\hline$R^{2}$ & 0.158 & 0.184 & 0.183 & 0.188 & 0.183 \\
\hline
\end{tabular}

\section{E.3 The Financial Value of Capital: Robustness Exercise I}

This section repeat the same exercise that we did with the stock of workers with the stock of capital. The model in section 2 abstracts from several frictions than could generate a bias in the evidence of the financial value of a capital-section 5.3. In this appendix, we do a set of robustness checks. First, I will define the variable we used in the regressions and then we describe each of the 28 specifications we study.

The variable definitions for this sections are - see table 4:

- Total Assets: This variable defined as the log of the maximum between the difference of total assets and capital $(\max \{a t q-p p e n t q, 0\})$ in COMPUSTAT.

- Total Debt: This variable defined as the log of debt in current liabilities, plus long-term debt minus liquid assets $(d l c q+d l t t q-c h e q)$ in COMPUSTAT. If this variable is negative, we replace it with a missing value.

- Total normalized profits: This variable defined as the the ratio between operating income before depression and total asset (oibdpq/atq) in COMPUSTAT.

- Investment rate: This variable is defined as capital expenditure minus sales of property, divide the mean capital in the last two periods $\left(\frac{c a p x y_{t}-\text { sppey }}{0.5 *\left(\text { ppent } q_{t}+\text { ppent } q_{t-1}\right)}\right)$ in COMPUSTAT.

- Capital: This variable defined as the log of total physical assets (ppentq) in COMPUSTAT. 
- Normalized Sales: This variable defined as the log of the ratio between total sales and total capital (saleq/ppentq) in COMPUSTAT.

- Liquid assets: This variable defined as the log of liquid assets (cheq) in COMPUSTAT.

We make robustness checks for different sets of independent and dependent variables. If we define the model

$$
\begin{aligned}
& y_{i t}=\gamma_{t}^{y}+\alpha_{i}^{y}+\beta_{X}^{y} X_{i t}+\epsilon_{i t}^{y, X} \\
& n_{i t}=\gamma_{t}^{n}+\alpha_{i}^{n}+\beta_{X}^{n} X_{i t}+\epsilon_{i t}^{n, X}
\end{aligned}
$$

We test the autocorrelation of $\epsilon_{i t}^{y, X}=\beta \epsilon_{i t}^{n, X}+\eta_{t i}^{y, X}$ for 28 specifications. In the case of $y_{i t}$ we have 4 specifications of dependent variables: $\log$ of probability of default $(\log (\operatorname{prdf}))$, logic of probability of default

$(\log (\operatorname{prdf} /(1-\operatorname{prdf})))$, distance to default $(d s d f)$ and the log of market value $(\log ($ mktval $))$. In the case of the control variable we have 6 specifications:

I- Benchmark Specification: $X$ is composed by total assets, total debt, total normalized profits and investment rates.

II- Imperfect Controls over Permanent and Transitory Shocks: $X$ is composed by total assets, total debt, total normalized profits, investment rates, and 1, 2 and 3 quarter lags of total normalized profits.

III- Imperfect Controls over Future News: $X$ is composed by total assets, total debt, total normalized profits, investment rates, and 1, 2 and 3 quarter forwards of total normalized profits.

IV- Benchmark Specification with Physical Capital: $X_{i t}: X$ is composed by labor, total debt, total normalized profits and investment rates.

V- Imperfect Controls over Capital Compositions: $X$ is composed by total assets, labor and liquid assets, total debt, total normalized profits and investment rates.

VI- Benchmark Specification with sales: $X$ is composed by total assets, total debt, total normalized profits, normalized sales and investment rates.

Figure 18 describes the results under the 6 specifications for the log probability of default; figure 19 describes the results under the 6 specifications for the logic of the probability of default; figure 20 describes the results under the 6 specifications for the distance of default; and figure 21 describes the results under the 6 specifications for the market value of the firm. 


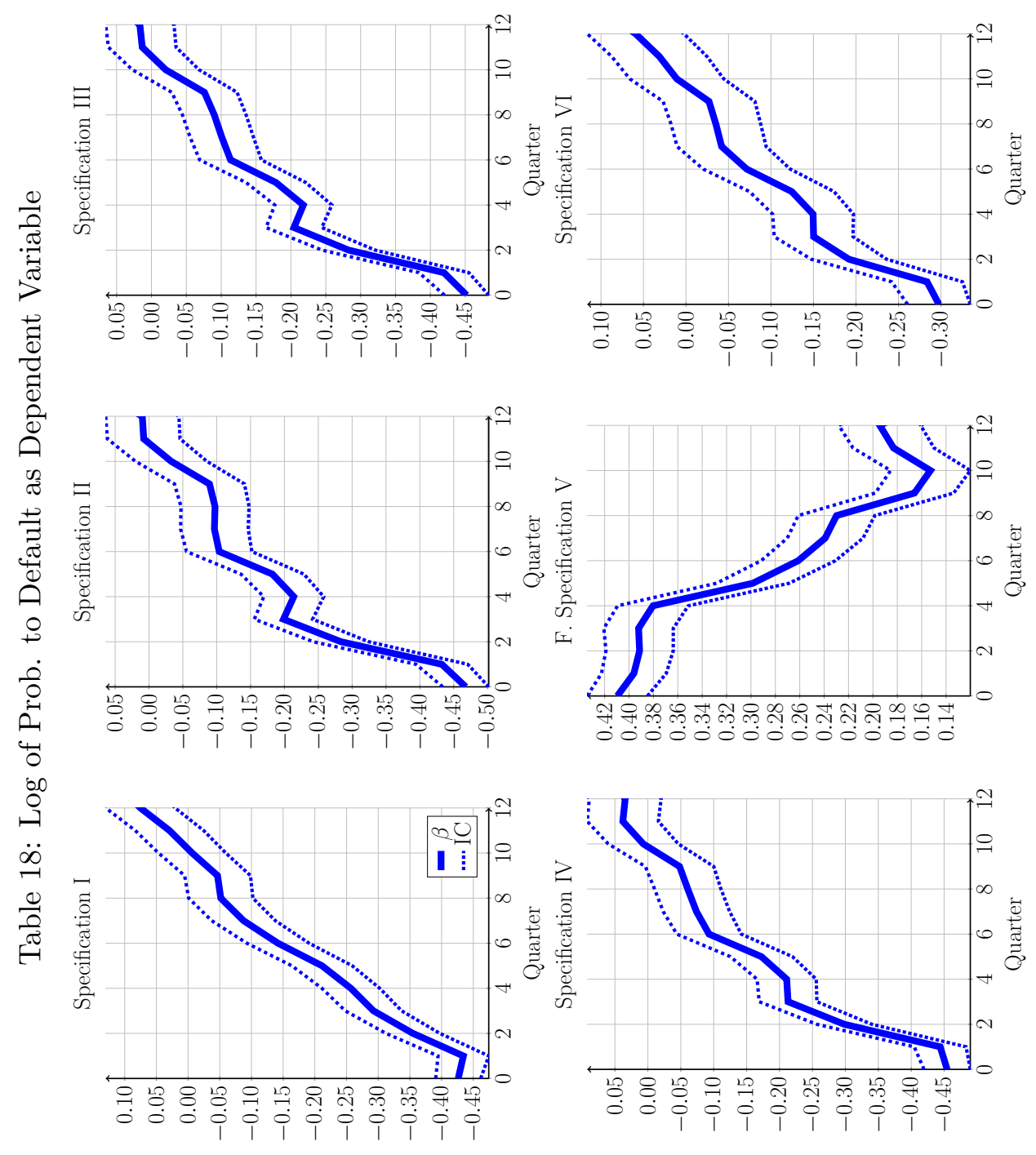




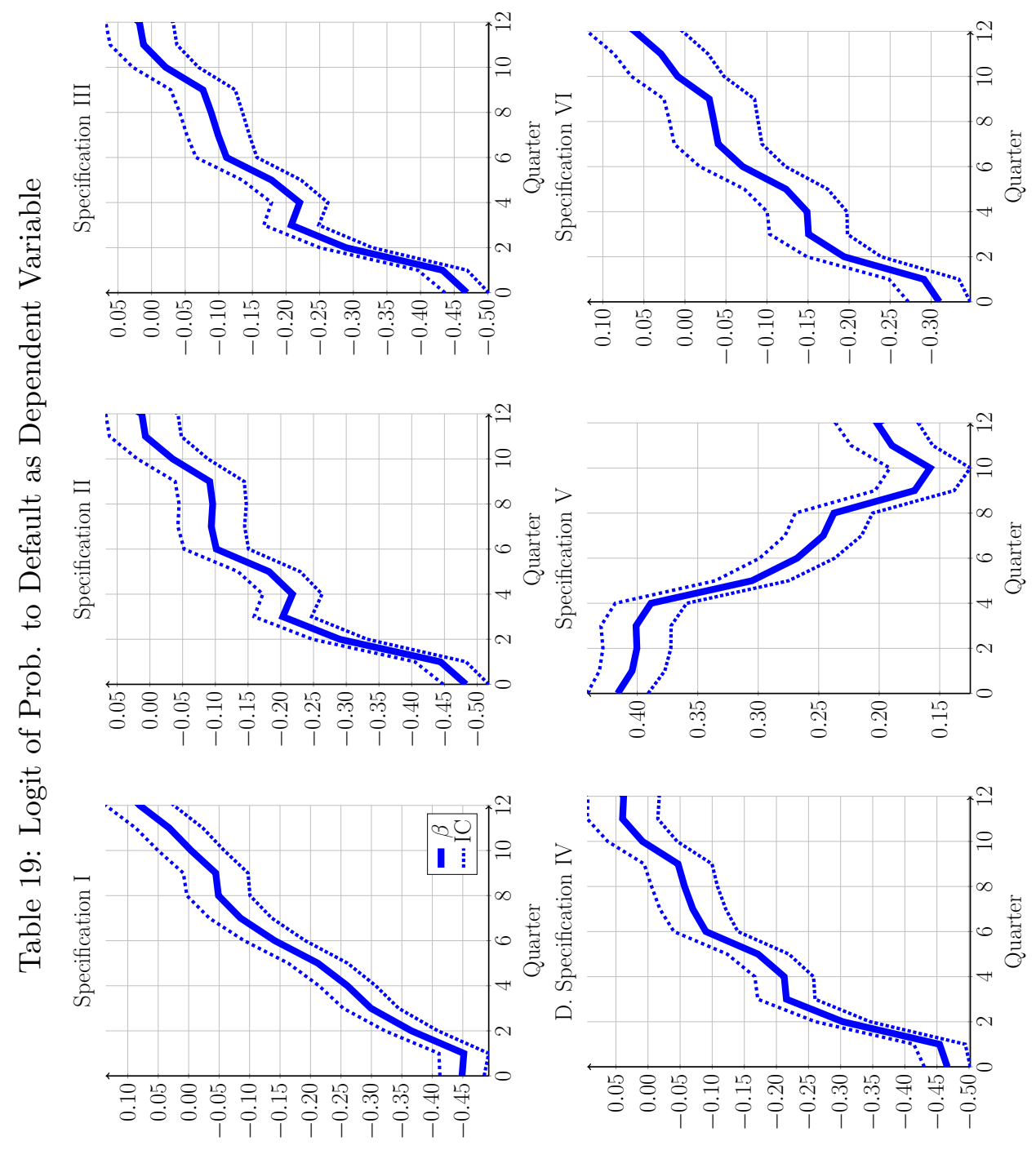




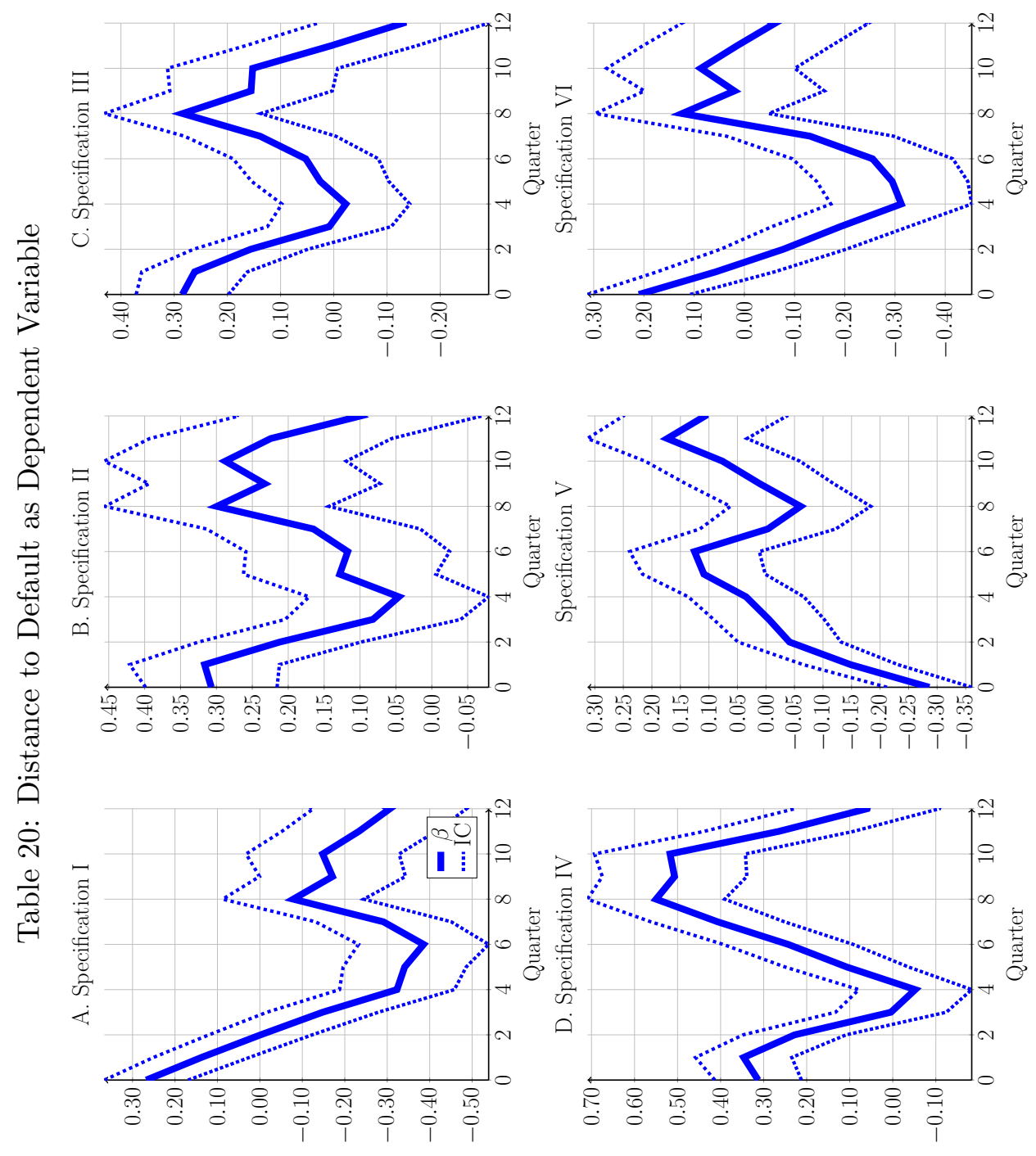




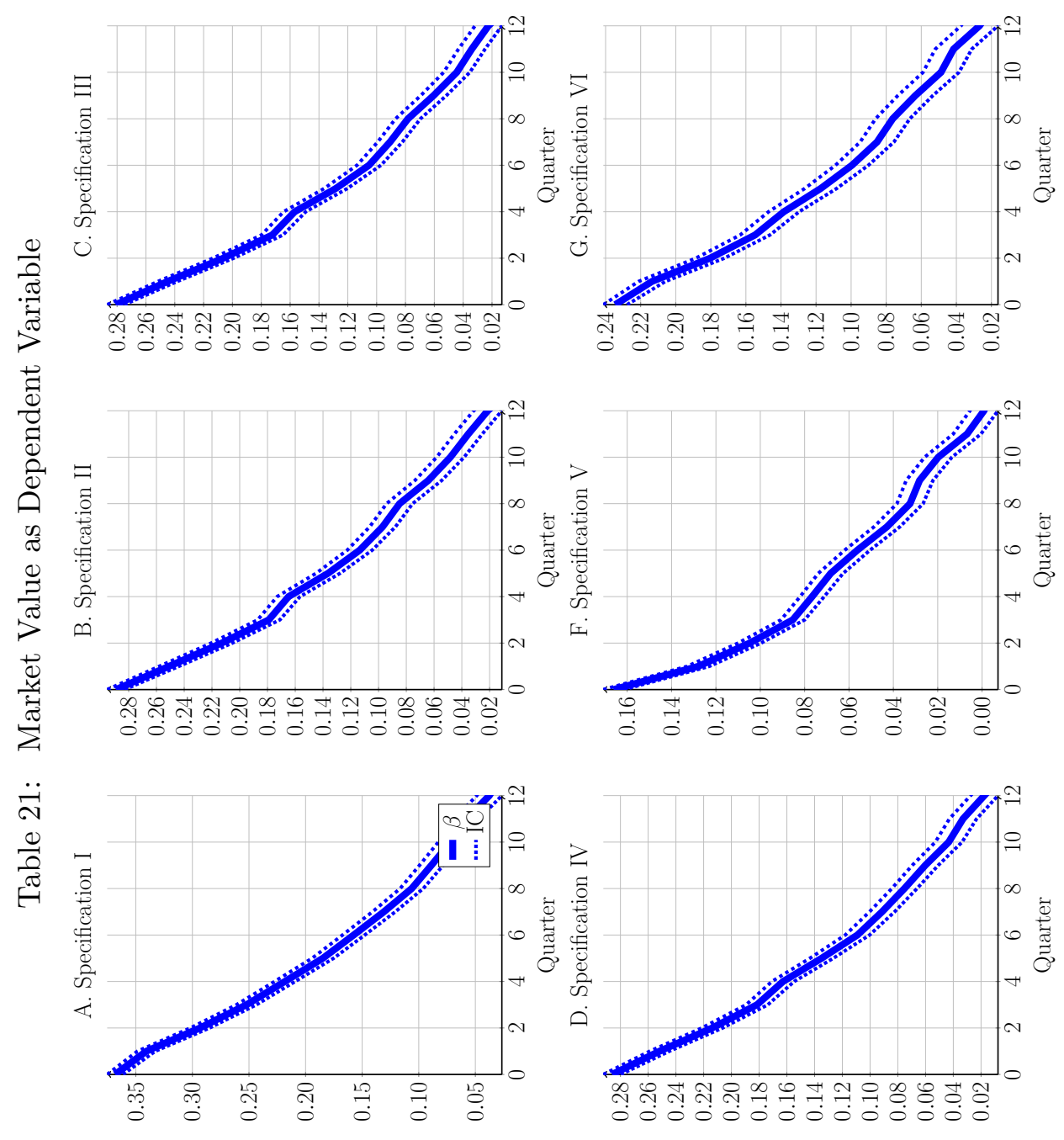




\section{E.4 The Financial Value of Capital: Robustness Exercise II}

In this section of the appendix we regress the log of probability of default $(\log (\operatorname{prdf}))$, the logic of probability of default $(\log (\operatorname{prdf} /(1-\operatorname{prdf})))$, the distance to default $(d s d f)$ and the $\log$ of market value $(\log ($ mktval $))$ to a set of control variables and the log of capital. We choose the same specifications as in section E.1.

Table 22: Dependent Variable: Log of Probability of Default

\begin{tabular}{l||cccccc} 
Variable & Reg. I & Reg. II & Reg. III & Reg. IV & Reg. V & Reg. VI \\
\hline \hline & & & & & & \\
capital & $-0.39^{* * *}$ & $-0.40^{* * *}$ & $-0.40^{* * *}$ & $-0.35^{* * *}$ & $-0.24^{* * *}$ & $-0.70^{* * *}$ \\
workers & - & - & - & $-0.63^{* * *}$ & $-0.37^{* * *}$ & - \\
assets & $-0.72^{* * *}$ & $-0.70^{* * *}$ & $-0.62^{* * *}$ & - & $-0.58^{* * *}$ & $-0.51^{* * *}$ \\
debt & $0.78^{* * *}$ & $0.75^{* * *}$ & $0.74^{* * *}$ & $0.71^{* * *}$ & $0.77^{* * *}$ & $0.79^{* * *}$ \\
profits & $-1.23^{* * *}$ & $-1.36^{* * *}$ & $-1.63^{* * *}$ & $-1.52^{* * *}$ & $-1.37^{* * *}$ & $-1.30^{* * *}$ \\
lag(1) profits & - & $-0.98^{* * *}$ & - & - & - & - \\
lag(2) profits & - & $-0.66^{* * *}$ & - & - & - & - \\
lag(3) profits & - & $-1.11^{* * *}$ & - & - & - & - \\
forward(1) profits & - & - & $-1.57^{* * *}$ & - & - & - \\
forward(2) profits & - & - & $-1.40^{* * *}$ & - & - & - \\
forward(3) profits & - & - & $-0.81^{* * *}$ & - & - & - \\
invest. rate & $-0.06^{* * *}$ & $-0.05^{* * *}$ & $-0.13^{* * *}$ & $-0.06^{* * *}$ & $-0.06^{* * *}$ & $-0.20^{* * *}$ \\
liquid assets & - & - & - & - & $0.04^{* * *}$ & - \\
sales & - & - & - & - & - & $-0.41^{* * *}$ \\
& & - & & & & \\
\hline \hline $\mathrm{N}$ & 163914 & 147789 & 141925 & 154072 & 151358 & 162526 \\
R-sq & 0.250 & 0.275 & 0.247 & 0.204 & 0.239 & 0.263 \\
\hline \hline
\end{tabular}

\section{E.5 The Financial Value of Capital and Workers: Quantile Regressions I}

This section studies if our result is driven by size distribution of firms. We regress the log of probability of default and the log of market value with respect to a set of control variables and capital and labor for different quantiles distribution of firms. The model we are estimating is given by

$$
y_{i t}=\gamma_{t}^{y}+\alpha_{i}^{y}+\beta_{K} \log \left(K_{i t}\right)+\beta_{N} \log \left(N_{i t}\right)+\beta_{X}^{y} X_{i t}+\epsilon_{i t}^{y, X}
$$

where $X_{i t}$ includes total assets minus capital, debt, profits, investment rates and liquid assets defined in section E.3. $y_{i t}$ denotes the $\log$ of the probability to default or the log of market value. Table XX and YY describes the results 
Table 23: Dependent Variable: Logic of Probability of Default

\begin{tabular}{l||cccccc} 
Variable & Reg. I & Reg. II & Reg. III & Reg. IV & Reg. V & Reg. VI \\
\hline \hline & & & & & & \\
capital & $-0.44^{* * *}$ & $-0.42^{* * *}$ & $-0.49^{* * *}$ & $-0.41^{* * *}$ & $-0.28^{* * *}$ & $-0.82^{* * *}$ \\
workers & - & - & - & $-0.71^{* * *}$ & $-0.42^{* * *}$ & - \\
assets & $-0.79^{* * *}$ & $-0.78^{* * *}$ & $-0.69^{* * *}$ & - & $-0.63^{* * *}$ & $-0.52^{* * *}$ \\
debt & $0.78^{* * *}$ & $0.74^{* * *}$ & $0.74^{* * *}$ & $0.70^{* * *}$ & $0.77^{* * *}$ & $0.78^{* * *}$ \\
profits & $-0.73^{* * *}$ & $-0.89^{* * *}$ & $-1.28^{* * *}$ & $-0.94^{* * *}$ & $-0.82^{* * *}$ & $-0.66^{* * *}$ \\
lag(1) profits & - & $-0.82^{* * *}$ & - & - & - & - \\
lag(2) profits & - & $-0.70^{* * *}$ & - & - & - & - \\
lag(3) profits & - & $-1.20^{* * *}$ & - & - & - & - \\
forward(1) profits & - & - & $-1.32^{* * *}$ & - & - & - \\
forward(2) profits & - & - & $-0.84^{* * *}$ & - & - & - \\
forward(3) profits & - & - & $-0.73^{* * *}$ & - & - & - \\
invest. rate & $-0.04^{* * *}$ & $-0.03^{* * *}$ & $-0.09^{* * *}$ & $-0.04^{* * *}$ & $-0.04^{* * *}$ & $-0.14^{* * *}$ \\
liquid assets & - & - & - & - & $0.05^{* * *}$ & - \\
sales & - & - & - & - & - & $-0.52^{* * * *}$ \\
& & - & & & & \\
\hline \hline $\mathrm{N}$ & 171730 & 154867 & 146113 & 160761 & 157896 & 170198 \\
R-sq & 0.389 & 0.419 & 0.266 & 0.355 & 0.376 & 0.396 \\
\hline \hline
\end{tabular}

Table 24: Dependent Variable: Logic of Probability of Default

\begin{tabular}{l||cccccc} 
Variable & Reg. I & Reg. II & Reg. III & Reg. IV & Reg. V & Reg. VI \\
\hline \hline & & & & & & \\
capital & $0.28^{* * *}$ & $0.31^{* * *}$ & $0.31^{* * *}$ & $0.27^{* * *}$ & $0.21^{* * *}$ & $0.45^{* * *}$ \\
workers & - & - & - & $0.33^{* * *}$ & $0.19^{* * *}$ & - \\
assets & $-.39^{* * *}$ & $0.37^{* * *}$ & $0.35^{* * *}$ & - & $0.31^{* * *}$ & $0.29^{* * *}$ \\
debt & $-0.54^{* * *}$ & $-0.53^{* * *}$ & $-0.54^{* * *}$ & $-0.50^{* * *}$ & $-0.54^{* * *}$ & $-0.55^{* * *}$ \\
profits & $0.48^{* * *}$ & $0.64^{* * *}$ & $0.83^{* * *}$ & $0.64^{* * *}$ & $0.54^{* * *}$ & $0.51^{* * *}$ \\
lag(1) profits & - & $0.26^{* * *}$ & - & - & - & - \\
lag(2) profits & - & $0.32^{* * *}$ & - & - & - & - \\
lag(3) profits & - & $0.57^{* * *}$ & - & - & - & - \\
forward(1) profits & - & - & $0.97^{* * *}$ & - & - & - \\
forward(2) profits & - & - & $1.13^{* * *}$ & - & - & - \\
forward(3) profits & - & - & $0.76^{* * *}$ & - & - & - \\
invest. rate & $0.07^{* * *}$ & $0.05^{* * *}$ & $0.06^{* * *}$ & $0.08^{* * *}$ & $0.08^{* * *}$ & $0.08^{* * *}$ \\
liquid assets & - & - & - & - & $-0.02^{* * *}$ & - \\
sales & - & - & - & - & - & $0.20^{* * *}$ \\
& & - & & & & \\
\hline \hline N & 162692 & 146717 & 140834 & 152883 & 150209 & 161338 \\
R-sq & 0.193 & 0.209 & 0.205 & 0.158 & 0.188 & 0.207 \\
\hline \hline
\end{tabular}


Table 25: Dependent Variable: Log of Market Value

\begin{tabular}{l||cccccc} 
Variable & Reg. I & Reg. II & Reg. III & Reg. IV & Reg. V & Reg. VI \\
\hline \hline & & & & & & \\
capital & $0.27^{* * *}$ & $0.27^{* * *}$ & $0.28^{* * *}$ & $0.35^{* * *}$ & $0.22^{* * *}$ & $0.38^{* * *}$ \\
workers & - & - & - & $0.40^{* * *}$ & $0.10^{* * *}$ & - \\
assets & $0.65^{* * *}$ & $0.65^{* * *}$ & $0.62^{* * *}$ & - & $0.60^{* * *}$ & $0.58^{* * *}$ \\
debt & $-0.13^{* * *}$ & $-0.13^{* * *}$ & $-0.12^{* * *}$ & $-0.06^{* * *}$ & $-0.12^{* * *}$ & $-0.14^{* * *}$ \\
profits & $0.04^{* * *}$ & $0.07^{* * *}$ & $0.19^{* * *}$ & $0.22^{* * *}$ & $0.07^{* * *}$ & $0.03^{* *}$ \\
lag(1) profits & - & $0.12^{* * *}$ & - & - & - & - \\
lag(2) profits & - & $0.17^{* * *}$ & - & - & - & - \\
lag(3) profits & - & $0.20^{* * *}$ & - & - & - & - \\
forward(1) profits & - & - & $0.31^{* * *}$ & - & - & - \\
forward(2) profits & - & - & $0.15^{* * *}$ & - & - & - \\
forward(3) profits & - & - & $0.08^{* * *}$ & - & - & - \\
invest. rate & $0.01^{* * *}$ & $0.01^{* * *}$ & $0.03^{* * *}$ & $0.01^{* * *}$ & $0.01^{* * *}$ & $0.05^{* * *}$ \\
liquid assets & - & - & - & - & $0.01^{* * *}$ & - \\
sales & - & - & - & - & - & $0.15^{* * *}$ \\
& & - & & & & \\
\hline \hline $\mathrm{N}$ & 171730 & 154867 & 146113 & 160761 & 157896 & 170198 \\
R-sq & 0.813 & 0.817 & 0.820 & 0.726 & 0.811 & 0.810 \\
\hline \hline
\end{tabular}

Table 26: Dependent Variable: Log of Probability of Default (Quantile Regression in Assets)

\begin{tabular}{l||ccccc} 
Variable & QI & QII & QIII & QIV & QV \\
\hline \hline & & & & & \\
Workers & $-0.61^{* * *}$ & $-0.33^{* * *}$ & $-0.72^{* * *}$ & $-0.47^{* * *}$ & $-0.44^{* * *}$ \\
Capital & 0.03 & $-0.34^{* * *}$ & $-0.31^{* * *}$ & $-0.28^{* * *}$ & $-0.12^{* * *}$ \\
Assets & $-0.42^{* * *}$ & $-0.59^{* * *}$ & $-0.56^{* * *}$ & $-0.62^{* * *}$ & $-0.29^{* * *}$ \\
Debt & $0.65^{* * *}$ & $0.82^{* * *}$ & $0.82^{* * *}$ & $0.78^{* * *}$ & $0.63^{* * *}$ \\
Profits & -0.02 & $-7.43^{* * *}$ & $-10.24^{* * *}$ & $-16.26^{* * *}$ & $-19.07^{* * *}$ \\
Invest. rate & -0.01 & $-0.08^{* * *}$ & $-0.17^{* * *}$ & $-0.54^{* * *}$ & $-1.43^{* * *}$ \\
Liquid assets & $-0.13^{* * *}$ & $0.04^{* *}$ & 0.01 & $0.13^{* * *}$ & $0.21^{* * *}$ \\
& & & & & \\
\hline \hline $\mathrm{N}$ & 23393 & 25001 & 27992 & 36610 & 38362 \\
$\mathrm{R}-\mathrm{sq}$ & 0.141 & 0.208 & 0.246 & 0.234 & 0.201 \\
\hline \hline
\end{tabular}


Table 27: Dependent Variable: Log of Market Value (Quantile Regression in Assets)

\begin{tabular}{l||ccccc} 
Variable & QI & QII & QIII & QIV & QV \\
\hline \hline & & & & & \\
Workers & $0.15^{* * *}$ & $0.16^{* * *}$ & $0.19^{* * *}$ & $0.09^{* * *}$ & $0.09^{* * *}$ \\
Capital & $0.13^{* * *}$ & $0.17^{* * *}$ & $0.20^{* * *}$ & $0.31^{* * *}$ & $0.26^{* * *}$ \\
Assets & $0.33^{* * *}$ & $0.59^{* * *}$ & $0.60^{* * *}$ & $0.61^{* * *}$ & $0.64^{* * *}$ \\
Debt & $-0.07^{* * *}$ & $-0.12^{* * *}$ & $-0.15^{* * *}$ & $-0.15^{* * *}$ & $-0.13^{* * *}$ \\
Profits & $-0.09^{* * *}$ & $1.33^{* * *}$ & $1.84^{* * *}$ & $4.27^{* * *}$ & $6.37^{* * *}$ \\
Invest. rate & 0.00 & $0.01^{*}$ & $0.04^{* * *}$ & $0.18^{* * *}$ & $0.75^{* * *}$ \\
Liquid assets & $0.04^{* * *}$ & $0.01^{* * *}$ & $0.01^{* * *}$ & $-0.01^{* *}$ & $-0.03^{* * *}$ \\
& & & & & \\
\hline \hline $\mathrm{N}$ & 24505 & 26216 & 29284 & 38034 & 39857 \\
$\mathrm{R}-\mathrm{Nq}$ & 0.269 & 0.412 & 0.521 & 0.587 & 0.611 \\
\hline \hline
\end{tabular}

Table 28: Dependent Variable: Log of Probability of Default (Quantile Regression in Employment)

\begin{tabular}{l||ccccc} 
Variable & QI & QII & QIII & QIV & QV \\
\hline \hline & & & & & \\
Workers & $-0.49^{* * *}$ & $-0.62^{* * *}$ & $-1.88^{* * *}$ & $-0.99^{* * *}$ & $-0.28^{* * *}$ \\
Capital & $-0.13^{* * *}$ & $-0.07^{*}$ & $-0.08^{*}$ & $-0.34^{* * *}$ & $-0.57^{* * *}$ \\
Assets & $-0.26^{* * *}$ & $-0.46^{* * *}$ & $-0.35^{* * *}$ & $-0.21^{* * *}$ & $-0.34^{* * *}$ \\
Debt & $0.65^{* * *}$ & $0.79^{* * *}$ & $0.82^{* * *}$ & $0.74^{* * *}$ & $0.65^{* * *}$ \\
Profits & -0.07 & $-4.64^{* * *}$ & $-12.73^{* * *}$ & $-19.54^{* * *}$ & $-18.77^{* * *}$ \\
Invest. rate & -0.00 & $-0.61^{* * *}$ & $-1.62^{* * *}$ & $-1.89^{* * *}$ & $-1.28^{* * *}$ \\
Liquid assets & $-0.15^{* * *}$ & $-0.04^{* *}$ & $0.07^{* * *}$ & $0.06^{* * *}$ & $0.22^{* * *}$ \\
& & & & & \\
\hline \hline $\mathrm{N}$ & 20358 & 24828 & 31061 & 37444 & 37667 \\
R-sq & 0.091 & 0.144 & 0.208 & 0.221 & 0.225 \\
\hline \hline
\end{tabular}

Table 29: Dependent Variable: Log of Market Value (Quantile Regression in Employment)

\begin{tabular}{l||ccccc} 
Variable & QI & QII & QIII & QIV & QV \\
\hline \hline & & & & & \\
Workers & $0.18^{* * *}$ & $0.20^{* * *}$ & $0.33^{* * *}$ & $0.20^{* * *}$ & $0.05^{* * *}$ \\
Capital & $0.18^{* * *}$ & $0.17^{* * *}$ & $0.17^{* * *}$ & $0.26^{* * *}$ & $0.35^{* * *}$ \\
Assets & $0.34^{* * *}$ & $0.56^{* * *}$ & $0.61^{* * *}$ & $0.65^{* * *}$ & $0.63^{* * *}$ \\
Debt & $-0.05^{* * *}$ & $-0.12^{* * *}$ & $-0.13^{* * *}$ & $-0.16^{* * *}$ & $-0.13^{* * *}$ \\
Profits & $-0.09^{* * *}$ & $0.70^{* * *}$ & $2.49^{* * *}$ & $5.38^{* * *}$ & $6.79^{* * *}$ \\
Invest. rate & $-0.00^{* * *}$ & $0.14^{* * *}$ & $0.48^{* * *}$ & $0.72^{* * *}$ & $0.65^{* * *}$ \\
Liquid assets & $0.04^{* * *}$ & $0.02^{* * *}$ & $0.01^{* *}$ & $-0.01^{* *}$ & $-0.03^{* * *}$ \\
& & & & & \\
\hline \hline $\mathrm{N}$ & 21457 & 25951 & 32422 & 38878 & 39188 \\
R-sq & 0.522 & 0.645 & 0.724 & 0.758 & 0.698 \\
\hline \hline
\end{tabular}




\section{F Proofs}

Proposition 1 (Equivalence Result) The firm's problem in (11) and the surplus maximization problem in (14) are equivalent in the following sense

(i) The surplus and the firm's value satisfy

$$
\mathcal{S}(\Lambda, s, F)=\mathcal{J}\left(\Lambda, s, F,\left\{W_{j}\right\}_{j \in[0, N]}\right)+\int_{0}^{N}\left(W_{j}-\mathcal{U}(X)\right) d j
$$

(ii) If a policy $\left\{I, H, b^{\prime}, \chi\right\}$ maximizes the surplus, then there exist wages $\left\{w_{j}\right\}$ and continuation values $\left\{W_{j}\right\}$ such that a contract $\omega_{j}=\left\{w_{j}, \varphi_{j}, \chi, W_{j}\right\}$ is consistent with the promise keeping constraint (8), and $\left\{I, H, b^{\prime},\left\{\omega_{j}\right\}\right\}$ solves the firm's problem and achieves value $\mathcal{J}\left(\Lambda, s, F,\left\{W_{j}\right\}_{j \in[0, N]}\right)$.

(iii) Conversely, if a policy $\left\{I, H, b^{\prime},\left\{\omega_{j}\right\}\right\}$ maximizes the firm's problem; then $\left\{I, H, b^{\prime}, \chi\right\}$ solves the surplus' problem and achieve $\mathcal{S}(\Lambda, s, F)$.

We will show this results with three lemmas than shows parts i-ii of the proposition. First we will show the part (i) of the theorem.

Lemma 2 Let $\mathcal{S}(\Lambda, s, F)$ be the solution of 14 and $\mathcal{J}\left(\Lambda, s, F,\left\{W_{j}\right\}_{j \in[0, N]}\right)$ the solution of 11 , then

$$
\mathcal{J}\left(\Lambda, s, F,\left\{W_{j}\right\}_{j \in[0, N]}\right)=-\int_{0}^{N} W_{j} d j+\mathcal{U}(X) N+S(\Lambda, s, F)
$$

Proof. Let guess and verify that $\mathcal{J}\left(\Lambda, s, F,\left\{W_{j}\right\}_{j \in[0, N]}\right)=-\int_{0}^{N} W_{j} d j+\mathcal{U}(X) N+S(\Lambda, s, F)$. Assume that $\mathcal{J}\left(\Lambda, s, F,\left\{W_{j}\right\}_{j \in[0, N]}\right)=-\int_{0}^{N} W_{j} d j+\mathcal{U}(X) N+S(\Lambda, s, F)$.

Step 1-Promise keeping constraint is binding: First, we show that the promise keeping bind for all $j$. Because the firm's profits decline with wages, it is never optimal for the firm to have the incentive constraint not binding. In particular, if exists a worker $j$ with wage $w_{j}$ such that $\mathcal{W}\left(X, s, \omega_{j}\right)>W_{j}$, then $\exists \epsilon>0$ such that a wage $w_{j}-\epsilon$ and the same continuation value $W_{j}$ still satisfy the promise keeping constraint, but the firm strictly more profits.

Then, an optimal firm policy must always satisfy

$$
\begin{aligned}
w_{j} & =W_{j}-\beta \mathbb{E}_{\Lambda^{\prime}, z^{\prime}}\left[\left\{\varphi_{j}+\left(1-\varphi_{j}\right) \chi\left(\Lambda^{\prime}, s^{\prime}, F^{\prime}\right)\right\} \mathcal{U}\left(X^{\prime}\right)\right. \\
& \left.+\left(1-\varphi_{j}\right)\left(1-\chi\left(\Lambda^{\prime}, s^{\prime}, F^{\prime}\right)\right) W\left(\Lambda^{\prime}, s^{\prime}, F^{\prime}\right) \mid X, z\right]
\end{aligned}
$$


Step 2-mean wages as a function of value function of worker: Now we will show that the following condition holds for any solution of the firm problems

$$
\begin{aligned}
\int_{0}^{N} w_{j} d j & =\int_{0}^{N} W_{j} d j-\mathcal{U}(X) N+b(X) N \\
& -\beta \mathbb{E}_{\Lambda^{\prime}, z^{\prime}}\left[\left(1-\chi\left(\Lambda^{\prime}, s^{\prime}, F^{\prime}\right)\right)\left(N^{\prime}-\{H\}^{+}\right) \int_{0}^{N}\left(W_{j}\left(\Lambda^{\prime}, s^{\prime}, F^{\prime}\right)-\mathcal{U}\left(X^{\prime}\right)\right) d j \mid X, z\right]
\end{aligned}
$$

From step 1 we have that

$$
\begin{aligned}
w_{j} & =W_{j}-\beta \mathbb{E}_{\Lambda^{\prime}, z^{\prime}}\left[\left\{\varphi_{j}+\left(1-\varphi_{j}\right) \chi\left(\Lambda^{\prime}, s^{\prime}, F^{\prime}\right)\right\} \mathcal{U}\left(X^{\prime}\right)\right. \\
& \left.+\left(1-\varphi_{j}\right)\left(1-\chi\left(\Lambda^{\prime}, s^{\prime}, F^{\prime}\right)\right) W\left(\Lambda^{\prime}, s^{\prime}, F^{\prime}\right) \mid \Lambda, z\right]
\end{aligned}
$$

Integrating for all $j$

$$
\begin{aligned}
\int_{0}^{N} w_{j} d j & =\int_{0}^{N} W_{j} d j-\beta \int_{0}^{N} \mathbb{E}_{\Lambda^{\prime}, z^{\prime}}\left[\left\{\varphi_{j}+\left(1-\varphi_{j}\right) \chi\left(\Lambda^{\prime}, s^{\prime}, F^{\prime}\right)\right\} \mathcal{U}\left(X^{\prime}\right)\right. \\
& \left.+\left(1-\varphi_{j}\right)\left(1-\chi\left(\Lambda^{\prime}, s^{\prime}, F^{\prime}\right)\right) W\left(\Lambda^{\prime}, s^{\prime}, F^{\prime}\right) \mid \Lambda, z\right] d j
\end{aligned}
$$

We can rewrite previous equation as

$$
\int_{0}^{N} w_{j} d j=\int_{0}^{N} W_{j} d j-\beta \int_{0}^{N} \mathbb{E}_{\Lambda^{\prime}, z^{\prime}}\left[\mathcal{U}\left(X^{\prime}\right)+\left(1-\varphi_{j}\right)\left(1-\chi\left(\Lambda^{\prime}, s^{\prime}, F^{\prime}\right)\right)\left(W\left(\Lambda^{\prime}, s^{\prime}, F^{\prime}\right)-\mathcal{U}\left(X^{\prime}\right)\right) \mid \Lambda, z\right] d j
$$

Using the assumption of no risky behavior and the value function of the worker

$$
\begin{aligned}
\int_{0}^{N} w_{j} d j & =\int_{0}^{N} W_{j} d j-\beta N \mathbb{E}_{X^{\prime}, z^{\prime}}\left[\mathcal{U}\left(X^{\prime}\right) \mid X, z\right] \\
& -\beta \mathbb{E}_{\Lambda^{\prime}, z^{\prime}}\left[\left(1-\chi\left(\Lambda^{\prime}, s^{\prime}, F^{\prime}\right)\right) \int_{0}^{N}\left(1-\varphi_{j}\right) d j \int_{0}^{N}\left(W_{j}\left(\Lambda^{\prime}, s^{\prime}, F^{\prime}\right)-\mathcal{U}\left(X^{\prime}\right)\right) d j \mid \Lambda, z\right] \\
& =\int_{0}^{N} W_{j} d j-\mathcal{U}(X) N+b(X) N \\
& -\beta \mathbb{E}_{\Lambda^{\prime}, z^{\prime}}\left[\left(1-\chi\left(\Lambda^{\prime}, s^{\prime}, F^{\prime}\right)\right)\left(N^{\prime}-\{H\}^{+}\right) \int_{0}^{N}\left(W_{j}\left(\Lambda^{\prime}, s^{\prime}, F^{\prime}\right)-\mathcal{U}\left(X^{\prime}\right)\right) d j \mid X, z\right]
\end{aligned}
$$

Step 3-Equivalent problem with a changing control variable for dividends: Using as control 
$\chi$ and using the guess we have that

$$
\begin{aligned}
& =\mathcal{J}\left(\Lambda, s, F,\left\{W_{j}\right\}_{j \in[0, N]}\right) \\
& =\max _{d, I, H, b^{\prime},\left\{\omega_{j}\right\}, \chi}\left\{d+\beta \mathbb{E}\left[\left(1-\chi\left(\Lambda^{\prime}, s^{\prime}, F^{\prime}\right)\right)\left(-\int_{0}^{N} W_{j}^{\prime} d j+\mathcal{U}\left(X^{\prime}\right) N^{\prime}+S\left(\Lambda^{\prime}, s^{\prime}, F^{\prime}\right)\right)\right]\right\}
\end{aligned}
$$

Changing the control variable to $d^{*}=d+\int_{0}^{N} W_{j} d j-\mathcal{U}(X) N$

$$
\mathcal{J}\left(\Lambda, s, F,\left\{W_{j}\right\}_{j \in[0, N]}\right)=-\int_{0}^{N} W_{j} d j+\mathcal{U}(X) N+\tilde{S}(\Lambda, s, F)
$$

where $\tilde{S}(\Lambda, s, F)$ satisfies

$$
\begin{aligned}
\tilde{S}(\Lambda, s, F) & =\max _{d^{*}, I, H, b^{\prime}, \chi, \hat{W}\left(X^{\prime}, s^{\prime}, F^{\prime}\right)}\left\{d^{*}+\right. \\
& \left.+\beta \mathbb{E}\left[\left(1-\chi\left(\Lambda^{\prime}, s^{\prime}, F^{\prime}\right)\right)\left(-\int_{0}^{N} W_{j}^{\prime} d j+\mathcal{U}\left(X^{\prime}\right) N^{\prime}+S\left(\Lambda^{\prime}, s^{\prime}, F^{\prime}\right)\right)\right]\right\} \\
\text { s. to } \mathcal{P} & =\eta z K^{\alpha \nu} N^{(1-\alpha) \nu}-b(X) N-F_{K} K-F-[(1-\tau) c+\lambda] B \\
\pi & =-I-\kappa H+Q\left(B^{\prime}, K^{\prime}, N^{\prime}, z, \Lambda\right) b^{\prime}-\mathcal{C}^{K}(I, K)-\mathcal{C}^{N}(H, N)-\mathcal{C}^{B}\left(b^{\prime}, B\right) \\
d^{*} & \leq \mathcal{P}+\pi \\
& +\beta \mathbb{E}_{\Lambda^{\prime}, z^{\prime}}\left[\left(1-\chi\left(X^{\prime}, s^{\prime}, F^{\prime}\right)\right)\left(N^{\prime}-\{H\}^{+}\right) \int_{0}^{N}\left(W_{j}\left(\Lambda^{\prime}, s^{\prime}, F^{\prime}\right)-\mathcal{U}\left(X^{\prime}\right)\right) d j \mid X, z\right] \\
K^{\prime} & =I+\left(1-\delta_{K}\right) K, \quad B^{\prime}=(1-\lambda) B+b^{\prime} \\
N^{\prime} & =\int_{0}^{N}\left(1-\varphi_{j}\right) d j+\{H\}^{+} \\
\int_{0}^{N} \varphi_{j} d j & =\delta_{N} N-\{H\}-
\end{aligned}
$$

By assumption of Bertrand competition for wages and using the law of motion of worker

$$
\begin{aligned}
& =\mathbb{E}_{\Lambda^{\prime}, z^{\prime}}\left[\left(1-\chi\left(\Lambda^{\prime}, s^{\prime}, F^{\prime}\right)\right)\left(N^{\prime}-\{H\}^{+}\right) \int_{0}^{N}\left(W_{j}\left(\Lambda^{\prime}, s^{\prime}, F^{\prime}\right)-\mathcal{U}\left(X^{\prime}\right)\right) d j \mid \Lambda, z\right] \\
& =\mathbb{E}_{\Lambda^{\prime}, z^{\prime}}\left[\left(1-\chi\left(\Lambda^{\prime}, s^{\prime}, F^{\prime}\right)\right) \int_{0}^{N^{\prime}}\left(W_{j}\left(\Lambda^{\prime}, s^{\prime}, F^{\prime}\right) d j-\mathcal{U}\left(X^{\prime}\right) N^{\prime} \mid \Lambda, z\right]\right.
\end{aligned}
$$

Doing a second substitution of dividends

$$
d^{* *}=d^{*}-\mathbb{E}_{\Lambda^{\prime}, z^{\prime}}\left[\left(1-\chi\left(X^{\prime}, s^{\prime}, F^{\prime}\right)\right) \int_{0}^{N^{\prime}}\left(W_{j}\left(\Lambda^{\prime}, s^{\prime}, F^{\prime}\right) d j-\mathcal{U}\left(X^{\prime}\right) N^{\prime} \mid \Lambda, z\right]\right.
$$


and since equations (103) and (104) can be collapse into

$$
N^{\prime}=\left(1-\delta_{n}\right) N+H
$$

we have that

$$
\begin{aligned}
\tilde{S}(\Lambda, s, F) & =\max _{d^{* *}, I, H, b^{\prime}, \chi, \hat{W}\left(X^{\prime}, s^{\prime}, F^{\prime}\right)}\left\{d^{* *}+\beta \mathbb{E}\left[(1-\chi)\left\{\mathcal{S}\left(\Lambda^{\prime}, s^{\prime}, F^{\prime},\left\{W_{j^{\prime}}^{\prime}\right\}_{j^{\prime} \in\left[0, N^{\prime}\right]}\right)\right\}\right]\right\} \\
\text { s. to } \mathcal{P} & =\eta z K^{\alpha \nu} N^{(1-\alpha) \nu}-b(X) N-F_{K} K-F-[(1-\tau) c+\lambda] B \\
\pi & =-I-\kappa H+Q\left(B^{\prime}, K^{\prime}, N^{\prime}, z, \Lambda\right) b^{\prime}-\mathcal{C}^{K}(I, K)-\mathcal{C}^{N}(H, N)-\mathcal{C}^{B}\left(b^{\prime}, B\right) \\
d^{* *} & \leq \mathcal{P}+\pi \\
N^{\prime} & =\left(1-\delta_{N}\right) N+H \\
K^{\prime} & =I+\left(1-\delta_{K}\right) K, \quad B^{\prime}=(1-\lambda) B+b^{\prime}
\end{aligned}
$$

therefore $\tilde{S}(\Lambda, s, F)=S(\Lambda, s, F)$ and we have the result.

Given that we have the part (i) of the proposition, now we show part (ii) and (iii).

Lemma 3 If a policy $\left\{d, I, H, b^{\prime}, \chi\right\}$ maximizes the surplus; then it exists wages $\left\{w_{j}\right\}$ and continuation values $\left\{W_{j}\right\}$ such that a contract $\omega_{j}=\left\{w_{j}, \varphi_{j}, \chi, W_{j}\right\}$ is consistent with the promise keeping constraint (8), and $\left\{I, H, b^{\prime},\left\{\omega_{j}\right\}\right\}$ solves the firm's problem and achieves value $\mathcal{J}\left(\Lambda, s, F,\left\{W_{j}\right\}_{j \in[0, N]}\right)$.

Proof. Define the contract

$$
\begin{aligned}
\varphi_{j} & =\frac{\delta_{N} N-\{H\}^{-}}{N} \\
W_{j} & =U\left(X^{\prime}\right) \\
w_{j} & =W_{j}-\mathcal{U}(X) N+b(X) N
\end{aligned}
$$

and dividends given by this policy. It is easy to see that this policy satisfies all the constraint; thus, it is feasible. To show that it is optimal, assume not. Then there is another optimal plant s.t. the value is higher. Let $\mathcal{J}^{*}\left(\Lambda, s, F,\left\{W_{j}\right\}_{j \in[0, N]}\right)$ be this value and $\mathcal{J}\left(\Lambda, s, F,\left\{W_{j}\right\}_{j \in[0, N]}\right)$ the value of the original plan, then 
using lemma 1

$$
\begin{aligned}
\mathcal{S}(\Lambda, s, F) & =\mathcal{J}\left(\Lambda, s, F,\left\{W_{j}\right\}_{j \in[0, N]}\right)+\int_{0}^{N} W_{j} d j-\mathcal{U}(X) N \\
& =\mathcal{J}^{*}\left(\Lambda, s, F,\left\{W_{j}\right\}_{j \in[0, N]}\right)+\int_{0}^{N} W_{j} d j-\mathcal{U}(X) N \\
& <\mathcal{S}^{*}(\Lambda, s, F)
\end{aligned}
$$

Thus, $\mathcal{S}(\Lambda, s, F)$ is not the optimal value and we have the contradiction.

Lemma 4 If a policy $\left\{d, I, H, b^{\prime},\left\{\omega_{j}\right\}\right\}$ maximizes the firm's problem; then $\left\{I, H, b^{\prime}, \chi\right\}$ solves the surplus' problem and achieve $\mathcal{S}(\Lambda, s, F)$.

Proof. We show the result by contradiction. Assume that there exist another policy $\left\{I^{*}, H^{*}, b^{*}, \chi^{*}\right\}$ that achieves higher value that $\mathcal{S}(\Lambda, s, F)$. Let $\mathcal{S}^{*}(\Lambda, s, F)$ be this value. Then using lemma 1

$$
\begin{aligned}
\mathcal{J}\left(X, s, F,\left\{W_{j}\right\}_{j \in[0, N]}\right) & =\mathcal{S}(\Lambda, s, F)-\int_{0}^{N} W_{j} d j+\mathcal{U}(X) N \\
& <\mathcal{S}^{*}(\Lambda, s, F)-\int_{0}^{N} W_{j} d j+\mathcal{U}(X) N \\
& =\mathcal{J}^{*}\left(\Lambda, s, F,\left\{W_{j}\right\}_{j \in[0, N]}\right)
\end{aligned}
$$

Thus, $\mathcal{J}\left(\Lambda, s, F,\left\{W_{j}\right\}_{j \in[0, N]}\right)$ is not the optimal value and we have the contradiction.

Lemma 1 (Partial Independence) Assume the bond price is independent of $\mu$ - given as $Q\left(B^{\prime}, K^{\prime}, N^{\prime}, X, z\right)$; then, the surplus problem (14) is independent of $\mu$, which yields policies as $(\chi(X, s, F), \boldsymbol{h}(X, s, F))$ independent of $\mu$ as well, and equation 12 defining $Q(\cdot)$ is independent of $\mu$. Alternatively, if firm's policies are independent of $\mu$, so is the bond price and thus the surplus problem.

Proof. Assuming the price is independent of $\mu(s)$, we can see in the surplus recursive problem (14) that it is independent of the distribution. In the same way, if the firms policies are independent of the distribution $\mu(s)$, then (12) is independent of the distribution.

Proposition 2 (Independence) Assume that there exist an unique fixed point in $T_{X}$. Then $T_{\Lambda}$ has an unique fixed point that depends only on $X$.

Proof. Assume that $T_{\Lambda}$ has more than one solution, $(v, Q, h, \chi)(\mu, X, s)$. Then we can construct $\left(v_{1}, Q_{1}, h_{1}, \chi_{1}\right)\left(\bar{\mu}_{1}, \cdot\right)$ and $\left(v_{2}, Q_{2}, h_{2}, \chi_{2}\right)\left(\bar{\mu}_{2}, \cdot\right)$ and $T_{X}$ has two solution; thus, a contradiction. In the case the unique solution 
depends on $\mu$, then we can construct $\left(v_{1}, Q_{1}, h_{1}, \chi_{1}\right)\left(\bar{\mu}_{1}, \cdot\right)$ and $\left(v_{2}, Q_{2}, h_{2}, \chi_{2}\right)\left(\bar{\mu}_{2}, \cdot\right)$ and $T_{X}$ has two solution; thus, a contradiction. Therefore, we have the results.

Proposition 3 (Firm's policies) A firm finds it optimal to default if and only if its cost shock is above a threshold $\underline{\boldsymbol{F}}(X, s)$ given as

$$
\underline{\boldsymbol{F}}(X, s)=\eta z K^{\alpha \nu} N^{(1-\alpha) \nu}-\bar{u}(X) N-F_{K} K-[(1-\tau) c+\lambda] B+v(X, s)
$$

where $v(X, s)=\mathcal{S}(X, s, F)-\mathcal{P}$. Then, a firm with state $(X, s)$ defaults with probability $1-G(\underline{\boldsymbol{F}}(X, s))$.

If a firm does not default, its policies for investment, vacancy posting and debt issuance are independent of the cost shock. Denote $\boldsymbol{K}^{\prime}(X, s), \boldsymbol{N}^{\prime}(X, s)$ and $\boldsymbol{B}^{\prime}(X, s)$ the resulting states for capital, workers and debt next period, respectively.

Proof. We guess and verify that the value function satisfies $\mathcal{S}(X, s, F)=\mathcal{P}+v(X, s)$. Because, under the guess, the firm defaults if $\mathcal{P}+v(X, s)<0$, we have that the a default threshold $\underline{F}(s, X)$ is given as $(15)$. Using our guess and introducing (15) in (14), we obtain

$$
\begin{aligned}
v(s, X) & =\max _{K^{\prime}, N^{\prime}, B^{\prime}}\left\{-\left[K^{\prime}-\left(1-\delta_{K}\right) K\right]-\mathcal{C}_{K}\left(K^{\prime}-\left(1-\delta_{K}\right) K, K\right)-\mathcal{C}_{N}\left(N^{\prime}-\left(1-\delta_{N}\right) N, N\right)(115\right. \\
& +Q\left(B^{\prime}, K^{\prime}, N^{\prime}, z, X\right)\left[B^{\prime}-(1-\lambda) B\right]-\mathcal{C}_{B}\left(B^{\prime}-(1-\lambda) B, B\right) \\
& \left.+\beta \mathbb{E}_{z^{\prime}, X^{\prime}}\left[\int_{-\infty}^{\underline{F}\left(s^{\prime}, X^{\prime}\right)} x^{\prime} \eta^{\prime} K^{\prime \alpha \nu} N^{\prime(1-\alpha) \nu}-\bar{u} N^{\prime}-F_{K} K^{\prime}-F-\tilde{\lambda} B^{\prime}+v\left(s^{\prime}, z^{\prime}, X^{\prime}\right) \mid z, X\right]\right\}
\end{aligned}
$$

where $\tilde{\lambda}=(1-\tau) c+\lambda$,. Equation (115) recursively defines $v(s, X)$ and verifies our guess. The last result is immediately from (115).

Proposition 4 (The marginal value of a worker and capital) The marginal value of a worker and capital is given by

$$
\frac{\partial \mathcal{S}(X, s)}{\partial N}=\frac{1}{g(X, s)} \frac{\partial G(X, s)}{\partial N} \quad ; \quad \frac{\partial \mathcal{S}(X, s)}{\partial K}=\frac{1}{g(X, s)} \frac{\partial G(X, s)}{\partial K}
$$

Assume that $\mathcal{C}^{N}(H, N)=\tilde{\mathcal{C}}^{H}(H, N)+\frac{\phi_{N}}{2}\left(\frac{\left(1-\delta_{n}\right) N+H}{N}-1\right)^{2}$ and $\mathcal{C}^{K}(I, K)=\frac{\phi_{K}}{2}\left(\frac{\left(1-\delta_{k}\right) K+I}{K}-1\right)^{2}$, where 
$\tilde{\mathcal{C}}^{H}(H, N)$ is increasing in $H$. Then

$$
\begin{array}{r}
\tilde{\mathcal{C}}_{1}^{H}(X, s)+\phi_{N} g r^{N}(X, s)=Q_{N}(X, s) B\left[g r^{B}(X, s)+\lambda\right]+\beta \mathbb{E}_{X^{\prime}, s^{\prime}}\left[\frac{G\left(X^{\prime}, s^{\prime}\right)}{g\left(X^{\prime}, s^{\prime}\right)} \frac{\partial G\left(X^{\prime}, s^{\prime}\right)}{\partial N^{\prime}} \mid X, s\right] \\
1+\phi_{K} g r^{K}(X, s)=Q_{K}(X, s) B\left[g r^{B}(X, s)+\lambda\right]+\beta \mathbb{E}_{X^{\prime}, s^{\prime}}\left[\frac{G\left(X^{\prime}, s^{\prime}\right)}{g\left(X^{\prime}, s^{\prime}\right)} \frac{\partial G\left(X^{\prime}, s^{\prime}\right)}{\partial K^{\prime}} \mid X, s\right]
\end{array}
$$

If additionally $\lambda=1$ and $c=1$

$$
\begin{aligned}
\tilde{\mathcal{C}}_{1}^{H}(X, s)+\phi_{N} g r^{N}(X, s) & =\beta \mathbb{E}_{X^{\prime}, s^{\prime}}\left[\left(\frac{1+g r^{B}(X, s)}{\psi}+\frac{G\left(X^{\prime}, s^{\prime}\right)}{g\left(X^{\prime}, s^{\prime}\right)}\right) \frac{\partial G\left(X^{\prime}, s^{\prime}\right)}{\partial N^{\prime}} \mid X, s\right] \\
1+\phi_{K} g r^{K}(X, s) & =\beta \mathbb{E}_{X^{\prime}, s^{\prime}}\left[\left(\frac{1+g r^{B}(X, s)}{\psi}+\frac{G\left(X^{\prime}, s^{\prime}\right)}{g\left(X^{\prime}, s^{\prime}\right)}\right) \frac{\partial G\left(X^{\prime}, s^{\prime}\right)}{\partial K^{\prime}} \mid X, s\right] \\
Q_{K}(X, s) & =\beta \psi \mathbb{E}_{X^{\prime}, s^{\prime}}\left[\frac{\partial G\left(X^{\prime}, s^{\prime}\right)}{\partial K} \mid X, s\right] \quad ; \quad Q_{N}(X, s)=\beta \psi \mathbb{E}_{X^{\prime}, s^{\prime}}\left[\frac{\partial G\left(X^{\prime}, s^{\prime}\right)}{\partial N} \mid X, s\right]
\end{aligned}
$$

Proof. From proposition 3, we have that for each firm

$$
\begin{aligned}
& F_{N t}=(1-\alpha) \nu z_{t} \eta_{t} K_{t-1, t}^{\alpha \nu} N_{t-1}^{(1-\alpha) \nu-1}-\bar{u}\left(X_{t}\right)+v_{N t} \\
& F_{K t}=\alpha \nu z_{t} \eta_{t} K_{t-1, t}^{\alpha \nu-1} N_{t-1}^{(1-\alpha) \nu}-F_{K}+v_{K t}
\end{aligned}
$$

Using the chain rule derivative

$$
\frac{\partial G(F(X, s))}{\partial Y}=g(F(X, s)) F_{Y}(X, s)
$$

for $Y \in\{N, K\}$. Using the envelope theorem over $\mathcal{S}(s)$ and from 116 to 118 we have 17. From proposition 3

$$
\begin{aligned}
\tilde{\mathcal{C}}_{1}^{H}\left(H_{t}, N_{t}\right) & =Q_{N t}\left[B_{t, t+1}-(1-\lambda) B_{t-1, t}\right]-\phi_{N}\left(\frac{N_{t, t+1}}{N_{t-1, t}}-1\right) \\
& +\beta \mathbb{E}_{t}\left[G\left(\underline{F}_{t+1}\right)\left\{(1-\alpha) \nu z_{t+1} \eta_{t+1} K_{t, t+1}^{\prime \alpha \nu} N_{t, t+1}^{\prime(1-\alpha) \nu-1}-\bar{u}+v_{N}(t+1)\right\}\right] \\
1 & =-\phi_{K}\left(\frac{K_{t, t+1}}{K_{t-1, t}}-1\right)+Q_{K t}\left[B_{t, t+1}-(1-\lambda) B_{t-1, t}\right] \\
& +\beta \mathbb{E}_{t}\left[G\left(F_{t+1}\right)\left\{\alpha \nu z_{t+1} \eta_{t+1} K_{t, t+1}^{\alpha \nu-1} N_{t, t+1}^{(1-\alpha) \nu}-F_{0}+v_{K, t+1}\right\}\right]
\end{aligned}
$$

Define $g r_{t}^{Y}=\frac{Y_{t, t+1}}{Y_{t-1, t}}-1$ the growth rate for capital and labor $-Y \in\{K, N\}$. Combining equations 116 to 120 we have that

$$
\begin{aligned}
\tilde{\mathcal{C}}_{1}^{H}\left(H_{t}^{i}, N_{t}^{i}\right)+\phi_{N} g_{t}^{N i} & =Q_{N t} B_{t-1, t}^{i}\left[g_{t}^{B i}+\lambda\right]+\beta \mathbb{E}_{t}\left[G\left(\underline{F}_{t+1}^{i}\right) F_{N t+1}^{i}\right] \\
1+\phi_{K} g_{t}^{K i} & =Q_{K t}^{i} B_{t-1, t}^{i}\left[g_{t}^{B i}+\lambda\right]+\beta \mathbb{E}_{t}\left[G\left(\underline{F}_{t+1}^{i}\right) F_{K t+1}^{i}\right]
\end{aligned}
$$


Using 118 we have that

$$
\begin{aligned}
\tilde{\mathcal{C}}_{1}^{H}(X, s)+\phi_{N} g^{N}(X, s) & =Q_{N}(X, s) B\left[g^{B}(X, s)+\lambda\right]+\beta \mathbb{E}_{X^{\prime}, s^{\prime}}\left[\frac{G\left(X^{\prime}, s^{\prime}\right)}{g\left(X^{\prime}, s^{\prime}\right)} \frac{\partial G\left(X^{\prime}, s^{\prime}\right)}{\partial N} \mid X, s\right] \\
1+\phi_{K} g^{K}(X, s) & =Q_{K}(X, s) B\left[g^{B}(X, s)+\lambda\right]+\beta \mathbb{E}_{X^{\prime}, s^{\prime}}\left[\frac{G_{t+1}\left(s^{\prime}\right)}{g_{t+1}\left(s^{\prime}\right)} \frac{\partial G_{t+1}\left(s^{\prime}\right)}{\partial K} \mid X, s\right]
\end{aligned}
$$

To get the third part of the proposition note that when $\lambda=1$ and $c=0$

$$
\begin{aligned}
& Q_{K}(X, s)=\beta \psi \mathbb{E}_{X^{\prime}, s^{\prime}}\left[g\left(X^{\prime}, s^{\prime}\right) \underline{\boldsymbol{F}}_{K}\left(X^{\prime}, s^{\prime}\right) \mid X, s\right]=\beta \psi \mathbb{E}_{X^{\prime}, s^{\prime}}\left[\frac{\partial G\left(X^{\prime}, s^{\prime}\right)}{\partial K} \mid X, s\right] \\
& Q_{N}(X, s)=\beta \psi \mathbb{E}_{X^{\prime}, s^{\prime}}\left[g\left(X^{\prime}, s^{\prime}\right) \underline{\boldsymbol{F}}_{N}\left(X^{\prime}, s^{\prime}\right) \mid X, s\right]=\beta \psi \mathbb{E}_{X^{\prime}, s^{\prime}}\left[\frac{\partial G\left(X^{\prime}, s^{\prime}\right)}{\partial N} \mid X, s\right]
\end{aligned}
$$

Using 123 and 124 together with 125 and 126 we have 20 and 21. 


\section{Online Appendices-NOT FOR PUBLICATION}

THE UNEMPLOYMENT ACCELERATOR 